\title{
Functional and/or structural brain changes in response to resistance exercises and resistance training lead to cognitive improvements - a systematic review
}

Fabian Herold ${ }^{1 *}$ (D) Alexander Törpel ${ }^{4}$, Lutz Schega ${ }^{4}$ and Notger G. Müller ${ }^{1,2,3}$

\begin{abstract}
Background: During the aging process, physical capabilities (e.g., muscular strength) and cognitive functions (e.g., memory) gradually decrease. Regarding cognitive functions, substantial functional (e.g., compensatory brain activity) and structural changes (e.g., shrinking of the hippocampus) in the brain cause this decline. Notably, growing evidence points towards a relationship between cognition and measures of muscular strength and muscle mass. Based on this emerging evidence, resistance exercises and/or resistance training, which contributes to the preservation and augmentation of muscular strength and muscle mass, may trigger beneficial neurobiological processes and could be crucial for healthy aging that includes preservation of the brain and cognition. Compared with the multitude of studies that have investigated the influence of endurance exercises and/or endurance training on cognitive performance and brain structure, considerably less work has focused on the effects of resistance exercises and/or resistance training. While the available evidence regarding resistance exercise-induced changes in cognitive functions is pooled, the underlying neurobiological processes, such as functional and structural brain changes, have yet to be summarized. Hence, the purpose of this systematic review is to provide an overview of resistance exercise-induced functional and/or structural brain changes that are related to cognitive functions.
\end{abstract}

Methods and results: A systematic literature search was conducted by two independent researchers across six electronic databases; 5957 records were returned, of which 18 were considered relevant and were analyzed.

Short conclusion: Based on our analyses, resistance exercises and resistance training evoked substantial functional brain changes, especially in the frontal lobe, which were accompanied by improvements in executive functions. Furthermore, resistance training led to lower white matter atrophy and smaller white matter lesion volumes. However, based on the relatively small number of studies available, the findings should be interpreted cautiously. Hence, future studies are required to investigate the underlying neurobiological mechanisms and to verify whether the positive findings can be confirmed and transferred to other needy cohorts, such as older adults with dementia, sarcopenia and/or dynapenia.

Keywords: Cognition, Neuroplasticity, Strength exercises, Strength training, Physical activity

\footnotetext{
* Correspondence: fabian.herold@dzne.de

${ }^{1}$ Research Group Neuroprotection, German Center for Neurodegenerative

Diseases (DZNE), Leipziger Str. 44, 39120 Magdeburg, Germany

Full list of author information is available at the end of the article
}

(c) The Author(s). 2019 Open Access This article is distributed under the terms of the Creative Commons Attribution 4.0 International License (http://creativecommons.org/licenses/by/4.0/), which permits unrestricted use, distribution, and reproduction in any medium, provided you give appropriate credit to the original author(s) and the source, provide a link to the Creative Commons license, and indicate if changes were made. The Creative Commons Public Domain Dedication waiver (http://creativecommons.org/publicdomain/zero/1.0/) applies to the data made available in this article, unless otherwise stated. 


\section{Background}

\section{Aging, the brain, and cognition}

Throughout the lifespan, the human organism undergoes considerable changes. As a consequence of aging, the structure and function of organic systems (i.e., brain) can be negatively affected, which in turn can converge in a decline of individual capabilities (e.g., cognition). In this regard, in recent years, evidence has shown that the hippocampus [1-4] and the grey matter in the frontal lobe [1-3, 5-12] are affected by age-related shrinking. In contrast, the grey matter volume of other brain structures such as the parietal and occipital cortices have been reported to change slightly with increasing age [1, $5,8]$, whereas a severe decline in white matter volume of the prefrontal cortex (PFC) is most pronounced in the very oldest $[1,8,9,13,14]$. These age-related changes in brain structure $[15,16]$ are assumed to play major roles in the worsening of cognition functions, such as processing speed and memory [17-20]. In fact, in older adults, it was observed that a decrease in hippocampal volume is associated with worsening of memory performance [21-23]. Conversely, an increase in hippocampal volume after a yearlong aerobic training intervention was associated with memory improvements [24]. These findings suggest that the preservation of brain structures (e.g., hippocampus) is important to ensure the proper functioning of cognitive processes (e.g., memory). Similar to the relationship of brain structure and cognition, it is assumed that changes in brain function (e.g., brain activation during a cognitive task) contribute to changes in cognition [16, 25-27]. Such an intertwined relationship between brain activation and cognition is underpinned by the findings linking activation of the PFC to behavioral performance in executive function tasks [28-31], in visuomotor tasks [32], or in working memory tasks [3335]. Currently, several hypotheses exist that aim to explain age-related alterations in brain activation and cognition [16, 25-27]. For instance, the HAROLD model predicts that there is hemispheric asymmetry reduction in older adults in the PFC during the execution of memory tasks $[27,36]$. In the compensation-related utilization of the neural circuits hypothesis (CRUNCH), it is postulated that adults will recruit more brain regions (mainly the PFC) as the task load increases and that older adults need to recruit these brain regions at lower levels of cognitive load than younger adults (e.g., during working memory tasks) [26, 37-39]. In the Scaffolding Theory of Aging and Cognition (STAC), it is postulated that increased brain activity with age, especially in the PFC, is a compensatory mechanism caused by reorganization of the brain in response to the age-related decline in neural structures and neural functioning $[16,39,40]$. To date, none of these hypotheses satisfactorily explain the observed age-related changes in brain function [41], but all of these hypotheses emphasize the important role of the PFC in age-related functional brain changes. It is well recognized in the literature that physical exercises [28-30, 42, 43] and physical training [44-47] lead to positive changes in cognitive performance (e.g., executive functions) and brain activation patterns. Furthermore, the changes in brain activation patterns (i.e., shown by higher levels of oxygenated hemoglobin in brain regions) are associated with cognitive performance improvements [28-30,47], which illustrate the important role of physical interventions in preserving cognition and brain health.

In summary, distinct cognitive functions (e.g., memory) are negatively affected, and substantial changes in brain structure (e.g., shrinkage of hippocampus) and brain function (e.g., compensatory brain activation; i.e., of PFC) occur as consequences of "normal" aging. Notably, regular engagement in physical exercise is a valuable strategy to counteract age-related decline in brain and cognition [48-52].

\section{Aging, muscular system, and cognition}

There is solid evidence in the literature that muscle mass (sarcopenia) [53-57] and muscular strength (dynapenia) [53, 57-59], which constitute the ability to produce muscular force and power [60], decline gradually as a function of age. Notably, the age-related decrease in muscular strength was noticed to be more pronounced than the decrease in muscle mass [61-63]. Moreover, the decline in maximum muscular strength is more serious in the lower limbs than in upper limbs [62, 64-67]. In general, it was observed that the age-related loss in, for instance, maximum isokinetic hip/leg extensor strength is rather minimal until the fifth decade of life but accelerates considerably thereafter [58, 68-70]. Potential reasons for the pronounced decline in muscular strength are the reduction in cross-sectional area of the muscle fibers $[64,71]$ as well as the loss of muscle fibers and motor units $[55,56$, 58, 61, 72, 73]. However, appropriate levels of muscular strength are needed for independent and healthy living. For instance, an appropriate level of muscular strength in the muscles of the lower limbs (e.g., hip and leg extensors) is required to ensure proper function for engaging in activities of daily living (e.g., balance and gait) $[74,75]$. Hence, it is not surprising that a decline in isokinetic muscular strength in leg extensors is associated with reduced mobility [76-78] and increased risk of mortality [77, 79, 80].

However, there is growing evidence that an appropriate level of muscular strength is also linked to brain health and functioning (e.g., cognitive functions). In this regard, it has been reported in the literature that higher levels of isokinetic strength of the $M$. quadriceps femoris are linked to better performance in general cognitive abilities (operationalized by Mini-Mental State Examination [MMSE]) [81] and to better performance in 
executive functions [82, 83]. This link is further reinforced by the findings that higher leg power [84] and higher whole-body muscle strength [85] are associated with higher scores in standardized cognitive test batteries. Furthermore, higher handgrip strength is linked to higher scores in general cognitive abilities (e.g., operationalized by MMSE) [86, 87] and to higher scores in standardized cognitive test batteries [88-90]. Moreover, it was observed that gains in dynamic muscular strength (assessed by one repetition maximum in different resistance exercises) after 6 months of progressive resistance training mediate improvements in global cognitive performance (according to the Alzheimer's Disease Assessment Scale-cognitive subscale) [91]. Similar to the previously mentioned finding, it was reported that changes in isokinetic knee extension and knee flexion torques after 3 months of progressive resistance training mediate improvements in executive functions [92]. Notably, a meta-analysis did not observe a correlation between muscle size and cognition [93] but reported that both muscle function (e.g., muscular strength) and muscle structure (e.g., muscle size) were linked to brain structure [93].

Taken together, during aging processes, a substantial decline in muscular strength, especially in lower limb muscles, occurs, and accumulating evidence suggests that lower muscular strengths are linked to poorer cognitive performance. Hence, resistance (strength) exercises (a single bout of resistance exercise, also referred to as acute exercise) and resistance (strength) training (more than one resistance exercise session, also referred to as chronic exercise; see also section 'Data extraction') seem to be promising activities to ensure the preservation of physical functioning and cognitive functions with aging.

\section{Resistance exercises, resistance training, brain, and} cognition

One physical intervention strategy that is frequently recommended to counteract the age-related deterioration of both physical functioning and cognition is the continuous and regular execution of resistance exercises and/or resistance training [94-106]. There is solid evidence in the form of systematic reviews and meta-analyses indicating that resistance exercises and resistance training (for distinction, see section 'Data extraction') have substantial benefits for specific domains of cognitive functions (e.g., executive functions) [105, 107-111], but the underlying neurobiological mechanisms of resistance exercise-induced improvements in cognitive functions are not yet fully understood $[107,110]$.

As shown in Fig. 1, cognitive improvements in response to resistance exercises and/or resistance training are based on changes on multiple levels of analysis $[112,113]$. At the first level, molecular and cellular changes occur, which are summarized in the "neurotrophic hypothesis" [114-117]. The "neurotrophic hypothesis" claims that in response to physical exercises (e.g., resistance exercises), a pronounced release of distinct neurochemicals occurs (e.g., brainderived neurotrophic factor [BDNF]) [114-117]. The pronounced release of specific neurochemicals triggers complex neurobiological processes evoking functional and/or structural brain changes that facilitate, at best, improvements in cognitive functions [24, 50, 114, 118-120]. With regard to the molecular and cellular levels, a systematic review summarized the evidence of resistance exercise and resistance training-induced changes in the release of several myokines (e.g., BDNF) and highlighted their positive effects on cognitive functions [121]. However, with respect to functional and structural brain changes and socioemotional changes (see Level 2 and Level 3 in Fig. 1),

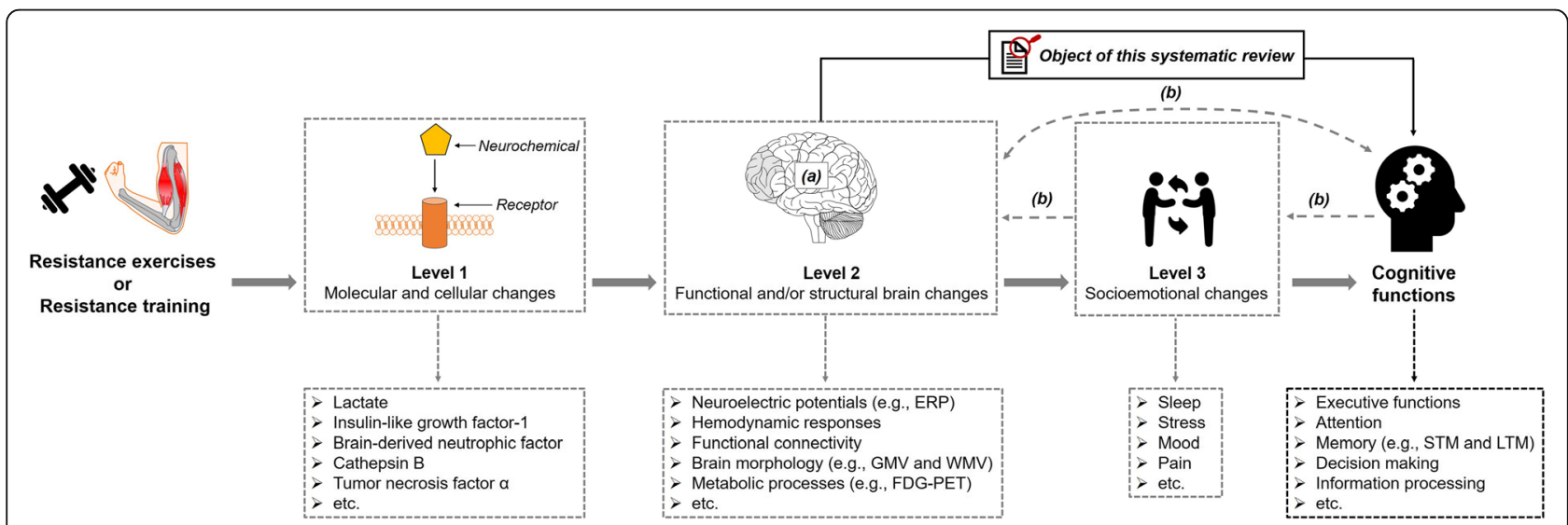

Fig. 1 Schematic illustration of the objective of the present systematic review and the levels of analysis. 'a' indicates that the brain could be regarded as an outcome, a mediator or a predictor [122]. 'b' indicates several possibilities for how structural and functional brain changes, socioemotional changes, and cognitive changes are intertwined [112]. ERP: event-related potentials; FDG-PET: F-2-deoxy-D-glucose (FDG) positron-emissions tomography (PET); GMV: grey matter volume; LTM: long-term memory; STM: short-term memory; WMV: white matter volume 
knowledge about resistance exercise and/or resistance training-induced changes is still relatively scarce, and the available literature has not yet been systematically pooled. In particular, the pooling of available evidence regarding functional and structural brain changes is needed because the brain may act as a mediator for the effect of resistance exercises and/or resistance training on cognition [112, 122]. Such a systematic pooling of available evidence is needed to provide evidence-based recommendations for individualized exercise prescriptions [123-125]. Because resistance exercises and/or resistance training is a promising strategy that could "hit many birds with one stone" (i.e., simultaneously counteracting different types of physical and brain-related health problems), the objective of this systematic review is to provide an overview of resistance exercise and/or resistance training-induced functional and/or structural brain changes that are related to changes in cognitive functions.

\section{Methods}

\section{Search strategy and process}

In accordance with the guidelines for systematic reviews [126], two independent researchers conducted a systematic literature search on the 25th of April 2019 across the following six electronic databases (applied specifications): PubMed (all fields), Scopus (title, abstract, keywords), Web of Science (title), PsycInfo (all text), SportDiscus (abstract), and the Cochrane Library (title, abstract, keywords; trials). The following terms were used as search strings:

- "strength exercise" OR "strength training" OR "resistance exercise" OR "resistance training" OR "weight exercise" OR "weight training" OR "weight lifting" OR "weight bearing" OR "elastic band" OR toning OR calisthenics OR "functional training"

\section{AND}

- mental OR neuropsychological OR brain OR cogniti* OR neurocogni* OR executive OR attention OR memory OR "response time" OR "reaction time" OR accuracy OR error OR inhibition OR visual OR spatial OR visuospatial OR processing OR recall OR learning OR language OR oddball OR "task switching" OR "problem solving" OR Flanker OR Stroop OR Sternberg OR “Trail Making” OR “Tower of London" OR "Tower of Hanoi" OR "Wisconsin Card Sorting" OR "Simon task"

\section{AND}

- cortex OR hemodynamic OR oxygenation OR "grey matter" OR "gray matter" OR "white matter" OR "brain volume" OR plasticity OR neuroelectric OR electrophysiological OR "P 300" OR "P 3" OR "eventrelated potentials" OR ERP OR Alpha OR Beta OR Gamma OR Theta OR NIR OR fNIRS OR "functional near-infrared spectroscopy" OR "near-infrared spectroscopy" OR "functional near-infrared spectroscopic" OR "optical imaging system" OR "optical topography" OR fMRI OR MRI OR "MR imaging" OR "magnetic resonance imaging" OR EEG OR electroencephalography OR electrocorticography OR MEG OR magnetoencephalography OR PET OR "positron emission tomography"

Afterwards, the results of the systematic search were loaded into a citation manager (Citavi 6.3), which was used for further analyses and for removing duplicates (see Fig. 2).

\section{Inclusion and exclusion criteria}

Screening for relevant studies was conducted using the established PICOS-principle [126, 127]. The acronym "PICOS" stands for participants (P), intervention (I), comparisons $(\mathrm{C})$, outcomes $(\mathrm{O})$, and study design $(\mathrm{S})[126$, 127]. The following inclusion and exclusion criteria were used: $(\mathrm{P})$ we applied no restrictions and included all age groups regardless of pathologies; (I) only studies involving resistance exercises and/or resistance training were included; $(C)$ in this systematic literature search, no specific restrictions were used; $(\mathrm{O})$ studies considered relevant assessed functional brain changes and/or structural brain changes related to cognitive changes; (S) interventional or cross-sectional studies.

As shown in Fig. 3, 46 studies were excluded after full text screening because they did not meet our inclusion criteria. Eight studies were excluded because they only assessed functional or structural brain changes but did not measure cognitive performance [128-135]. Vice versa, 38 studies were excluded because they solely measured changes in cognitive performance without quantifying functional or structural brain changes [81, 91, 136-171].

\section{Data extraction}

We extracted information about the first author, year of publication, population characteristics including age, gender, cognitive status, exercise characteristics (e.g., muscle action, loading and volume, rest period between sets/between exercises, repetition velocity, frequency, resistance exercise selection), cognitive testing (e.g., tested cognitive domain, administration after exercise cessation), and functional and structural brain data. The extraction of information followed the recommendations of Hecksteden et al. [173]. 


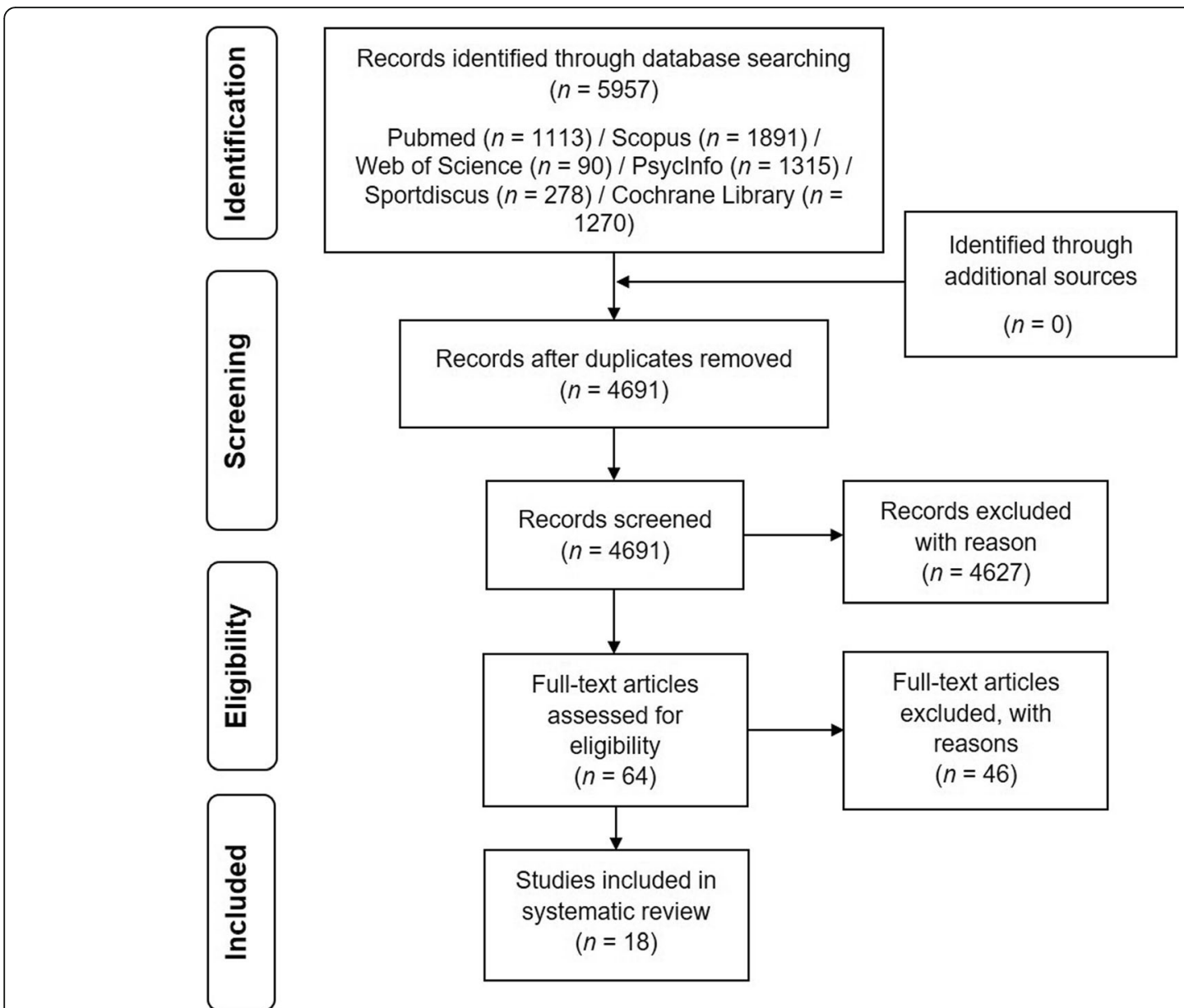

Fig. 2 Flow chart with information about the search, screening, and selection processes that led to the identification of relevant articles included in this systematic review

Prior to presentation of the findings, it is necessary to clarify the different terms used in the field of exercise cognition. 'Physical activity' is defined as any muscle-induced bodily movements that increase energy expenditure from 1.0 to 1.5 MET [174, 175]. Hence, physical activity covers a wide range of acute and chronic physical activities (e.g., from housework to resistance exercises/resistance training). Specific forms of structured, planned, and regularly (chronically) conducted physical activities aiming to increase individual capabilities in a certain fitness domain are referred to as 'training' or 'chronic (repetitive) exercises' [174, 176178]. Single sessions of physical activities (exercises) are referred to as 'an acute (single) bout of physical activities' or 'physical exercises' $[174,179,180]$. In this article, we use the term 'resistance training' when more than two exercise sessions were conducted. Consequently, a single session of resistance exercises is referred to as 'a single (acute) bout of resistance exercises' and/or 'resistance exercises'. Furthermore, we use 'exercise prescription' as an umbrella term to denote exercise (e.g., load for an exercise) and training variables (e.g., frequency).

\section{Risk of bias assessment}

Two evaluators independently performed the risk of bias assessment using the Cochrane Collaboration's Risk of Bias tool [181]. The Cochrane Collaboration's Risk of Bias tool evaluates the methodological quality of a study by rating the risk of bias in distinct criteria (see Figure 3 ) as being 'low', 'high', or 'unclear' [181]. Any discrepancies in the ratings of the risk of bias were resolved by a discussion among the two evaluators or/and the consultation of the third author of the review. The risk of bias assessment is summarized in Fig. 3.

\section{Results}

\section{Risk of bias}

As shown in Fig. 3, the results regarding the judgment of risk of bias are heterogeneous. In the domains of sequence generation, allocation concealment, blinding of participants and personnel, and blinding of outcome assessment, the majority of studies were rated as low risk of bias or unclear risk of bias. The reviewed studies were judged as having an unclear risk of bias in those domains because procedures 


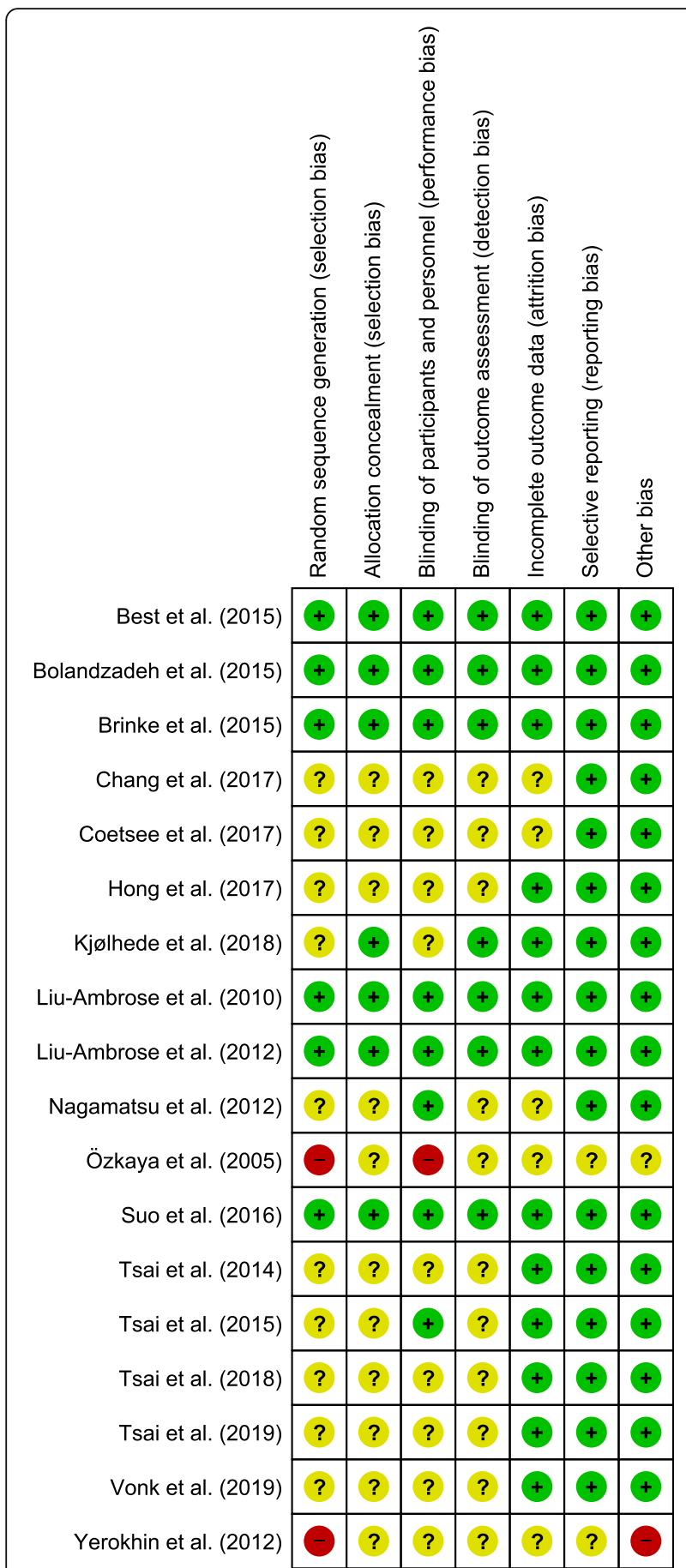

Fig. 3 Analysis of the risk of bias in the included studies in accordance with the Cochrane Collaboration guidelines. This figure was created using Review Manager [172]. A "green plus" indicates a low risk of bias, a "yellow question mark" indicates an unclear risk of bias, and a "red minus" denotes a high risk of bias

were not described in sufficient detail (e.g., method of random sequence generation). In the domains of incomplete outcome data, selective reporting, and other bias, most studies were judged as having a low risk of bias.

\section{Participants' characteristics and study design}

In the reviewed studies, the effect of resistance exercises and/or resistance training on cognition and the brain was investigated in different cohorts, including healthy young adults $[43,182,183]$, healthy older adults $[44,45$, 184-188], older adults with mild cognitive impairment [188-191], older adults in an early stage of dementia [192], and individuals with multiple sclerosis [193]. Detailed information about participant characteristics (e.g., age, height, body mass) is provided in Table 1 .

Regarding the study design, almost all studies could be classified as interventional and as randomized controlled trials [43-45, 183-186, 188-190, 195, 197].

Additionally, three resistance exercise studies [43, 182, $183,195]$ accounted for circadian variability as a possible moderating factor.

\section{Resistance exercise characteristics}

In four studies investigating the acute effects of single resistance exercise sessions on cognitive performance and on functional neuroelectric or hemodynamic brain processes, the exercise sessions lasted approximately 30 $\min [183]$ or $40 \min [43,182,195]$.

Studies on the effects of resistance training on cognition and functional and/or structural brain changes involved groups who trained 1 day [45, 184-186], 2 days [45, 184186, 188-190, 193, 197], or 3 days per week [44, 187, 191]. Exercise sessions in the resistance training studies lasted $30 \mathrm{~min}$ [44], $40 \mathrm{~min}$ [191], $60 \mathrm{~min}$ [45, 184-189, 197] or $90 \mathrm{~min}$ [190]. The regimes were conducted for 9 weeks [194], 10 weeks [192], 12 weeks [188], 16 weeks [44, 191], 24 weeks [193], 26 weeks [190, 197], 48 weeks [187], or 52 weeks [45, 184-186, 189]. In most of the resistance training studies reviewed, the exercise sessions were conducted in supervised classes [44, 45, 184-187, 189-191, 193, 197]. Furthermore, in most of the reviewed studies, participants were asked to perform two or three sets during the exercise sessions with a minimum of six and a maximum of ten repetitions of upper and lower body exercises at a load ranging from 50 to $92 \%$ of $1 \mathrm{RM}$ (one repetition maximum) using free weights and/or machines (for a detailed overview, see Table 1).

\section{Main findings}

Functional brain changes and cognition Hemodynamic functional brain changes and cognition

With regard to an acute bout of resistance exercises, in healthy young adults, a decrease in tissue oxygenation index in the left prefrontal cortex during the Stoop test and improved behavioral performance (i.e., faster reaction time and higher number of solved items in neutral condition) was observed after a single bout of highintensity resistance exercise [43]. 
Table 1 Overview of the population characteristics and resistance exercises and/or resistance training characteristics of the reviewed studies

\begin{tabular}{lll}
\hline First author [ref.] & Study design and sample characteristics & Resistance exercise characteristics \\
\hline & (1) Design / Comparison groups & (1) Muscle action \\
& (2) Participants characteristics & (2) Load, number of sets, and number of repetitions \\
(2.1) Number of participants (N) ( $\mathrm{N}$ female / $\mathrm{N}$ male), & (3) Inter-set rest periods and inter-exercise rest periods \\
[included in fMRl or EEG], gender / mean age & (4) Repetition velocity \\
in years $\pm \mathrm{SD}$ & (5) Resistance exercise selection \\
(2.2) Mean height in $\mathrm{cm} \pm \mathrm{SD} /$ mean body mass in & (6) Duration of an exercise session \\
$\mathrm{kg} \pm \mathrm{SD} / \mathrm{BMl} \pm \mathrm{SD}$ in $\mathrm{kg} / \mathrm{m}^{2}$ & (7) Training frequency \\
(3) Cognitive status / disability status & (8) Training density \\
& (9) Training duration \\
& (10) Training setting
\end{tabular}

Functional near-infrared spectroscopy

Chang et al. [43] (1) IS (RCT, between-group design) / CON (n), HIRE, MIC, HIA

(2) Healthy young adults

(2.1) - CON: $N=9(9 \mathrm{f} / 0 \mathrm{~m}) / 21.8 \pm 1.4$

- HIRE: $N=9(9 \mathrm{f} / 0 \mathrm{~m}) / 21.1 \pm 1.6$

- MIC: $N=9(9 \mathrm{f} / 0 \mathrm{~m}) / 20.4 \pm 1.5$

- HIA: $N=9(9 \mathrm{f} / 0 \mathrm{~m}) / 22.1 \pm 1.4$

(2.2) - CON: $160.8 \pm 4.1 / 52.2 \pm 6.2 / 20.3 \pm 3.1$

- HIRE: $162.1 \pm 5.0 / 56.3 \pm 5.0 / 21.4 \pm 1.8$

- MIC: $162.9 \pm 5.5 / 56.4 \pm 5.8 / 21.2 \pm 1.3$

- HIA: $166.0 \pm 5.3 / 59.6 \pm 5.7 / 21.6 \pm 2.1$

(3) N.A.

Coetsee et al. [44] (1) IS (RCT, between-group design) / CON (n), HIIT, MCT, RT

(2) Healthy older adults

(2.1) - CON: $N=19(11 \mathrm{f} / 8 \mathrm{~m}) / 62.5 \pm 5.6$

- HIIT: $N=13(10 \mathrm{f} / 3 \mathrm{~m}) / 64.5 \pm 6.3$

- MCT: $N=13(10 \mathrm{f} / 3 \mathrm{~m}) / 61.6 \pm 5.8$

- RT: $N=22(15 \mathrm{f} / 7 \mathrm{~m}) / 62.4 \pm 5.1$

(2.2) - CON: $168.7 \pm 7.9 / 76.8 \pm 13.7 / 26.9 \pm 3.7$

- HIIT: $166.0 \pm 8.9$ / $73.8 \pm 13.7 / 26.6 \pm 4.0$

- MCT: $163.5 \pm 8.6 / 71.0 \pm 14.4 / 26.5 \pm 4.2$

- RT: $167.8 \pm 7.8 / 73.3 \pm 15.5 / 25.8 \pm 4.0$

(3) MOCA score

- CON: $28.2 \pm 1.6$

- HIIT: $27.9 \pm 1.5$

- MCT: $27.6 \pm 1.3$

- RT: $27.5 \pm 1.3$

Electroencephalography

Hong et al. [188] (1) IS (RCT, between-group design) / CON (n), RT

(2) Healthy older adults / older adults with $\mathrm{MCl}$

(2.1) - HOA CON: $N=13(6 \mathrm{f} / 7 \mathrm{~m}) / 73.5 \pm 5.6$ $(\mathrm{f}) ; 73.0 \pm 4.8(\mathrm{~m})$

- HOA RT: $N=12(10 \mathrm{f} / 2 \mathrm{~m}) / 75.8 \pm 4.5$

$(\mathrm{f}) ; 76.5 \pm 6.4(\mathrm{~m})$

- MCl CON: $N=12(9 \mathrm{f} / 3 \mathrm{~m}) / 75.1 \pm 4.5$

$(\mathrm{f}) ; 78.3 \pm 5.5(\mathrm{~m})$

- MCI RT: $N=10(7 \mathrm{f} / 3 \mathrm{~m}) / 75.1 \pm 4.5$

(f); $78.3 \pm 5.5(\mathrm{~m})$

(2.2) - HOA CON: N.A. / $49.7 \pm 4.5(f) ; 63.4 \pm 10.7$ (m) / N.A.

- HOA RT: N.A. / $57.3 \pm 8.4$ (f); $68.9 \pm 4.7$ / N.A.

- MCI CON: N.A. / $56.3 \pm 5.4$ (f); $57.2 \pm 7.6$ (m) / N.A.

- MCI RT: NA. / $54.1+7.6$ (f) $65.0+3.3$ / N.A.

(3) MOCA score

- HOA CON: $26.0 \pm 1.7$ (f) / $26.3 \pm 1.6$ (m)

- HOA RT: $26.4 \pm 1.7$ (f) / $25.0 \pm 1.4(\mathrm{~m})$

- MCI CON: $18.8 \pm 5.6$ (f) / $21.3 \pm 2.4(\mathrm{~m})$

- MCI RT: $20.0 \pm 4.0(f) / 22.3 \pm 1.2(\mathrm{~m})$

Özkaya et al. [194] (1) IS (RCT, between-group design) / CON (n), AT, RT

(2) Healthy older adults

(2.1) - CON: $N=12$ (N.A.) / $72.3 \pm 2.1$

- AT $N=12$ (N.A.) / 70.9 \pm 3.1

- RT: $N=12$ (N.A.) / $75.8 \pm 2.8$

(2.2) - CON: N.A. / N.A. / $29.5 \pm 1.3$
(1) Dynamic

(2) 3 sets with 8 to 10 repetitions per exercise at $80 \%$ of $1 \mathrm{RM}$

(3) Work to rest ratio of $1: 2$

(4) N.A.

(5) Machines and free weights (e.g., leg extension, leg curl, lat pull-down, seated row, squat, bench press, and arm curl)

(6) Ca. 40 min (10 min warm-up, 30 min exercising)

(7) One single session

(8) N.A.

(9) N.A.

(10) Individual and supervised

(1) Dynamic

(2) 3 sets with 10 repetitions per exercise at 50,75, and $100 \%$ of $10 \mathrm{RM}$ (first 8 weeks) / at 75,85 , and $100 \%$ of 10RM (second 8 weeks)

(3) N.A.

(4) N.A.

(5) Machines and free weights (e.g., upper and lower body resistance exercises)

(6) Ca. 30 min (+ warm-up and cool-down)

(7) 3 days/week

(8) N.A.

(9) 16 weeks

(10) Group-based and supervised

(1) Dynamic

(2) 15 repetitions per exercise correspond to ca. $65 \%$ of 1RM

(3) N.A.

(4) N.A.

(5) Elastic bands

(6) Ca. $60 \mathrm{~min}$ (10 min warm-up, 40 min exercising, 10 min cool-down)

(7) 2 days/week

(8) N.A.

(9) 12 weeks

(10) N.A.
(1) Dynamic

(2) 1 set of 12 repetitions per exercise at $60 \%$ of 1 RM (in the first week); 3 sets of 12 repetitions per exercise at $60 \%$ of 1 RM (in the second week); increase in load of $5 \%$ every 2 weeks until participants lifted $80 \%$ of 1 RM 
Table 1 Overview of the population characteristics and resistance exercises and/or resistance training characteristics of the reviewed studies (Continued)

\begin{tabular}{|c|c|c|}
\hline First author [ref.] & Study design and sample characteristics & Resistance exercise characteristics \\
\hline & $\begin{array}{l}\text { - AT: N.A. / N.A. / } 29.1 \pm 1.4 \\
\text { - RT: N.A. / N.A. / 31.2 } \pm 2.9 \\
\text { (3) MMSE score } \\
\text { - CON: } 27.1 \pm 0.6 \\
\text { - AT: } 26.5 \pm 0.6 \\
\text { - RT: } 25.6 \pm 0.7\end{array}$ & $\begin{array}{l}\text { (4) N.A. } \\
\text { (5) Free weights (e.g., hip extension, knee flexion, seated } \\
\text { lower-leg lift, chair squat, arm raise, biceps curl, and } \\
\text { abdominal crunch) } \\
\text { (6) N.A. (10 min warm-up, N.A., } 10 \text { min cool-down) } \\
\text { (7) } 3 \text { days/week } \\
\text { (8) N.A. } \\
\text { (9) } 9 \text { weeks } \\
\text { (10) Group-based and supervised }\end{array}$ \\
\hline Tsai et al. [182] & $\begin{array}{l}\text { (1) IS (RCT, between-group design) / CON (r), HIRE, MIRE } \\
\text { (2) Healthy young adults } \\
\text { (2.1) - CON: } N=20(0 \mathrm{f} / 20 \mathrm{~m}) / 23.2 \pm 2.1 \\
\text { - MIRE: } N=20(0 \mathrm{f} / 20 \mathrm{~m}) / 23.2 \pm 2.5 \\
\text { - HIRE: } N=20(0 \mathrm{f} / 20 \mathrm{~m}) / 22.4 \pm 2.4 \\
\text { (2.2) - CON: N.A. / N.A. / } 22.0 \pm 2.6 \\
\text { - MIRE: N.A. / N.A. / } 20.8 \pm 1.5 \\
\text { - HIRE: N.A. / N.A. / } 21.5 \pm 1.8 \\
\text { (3) MMSE sCore } \\
\text { - CON: } 28.9 \pm 0.9 \\
\text { - MIRE: } 29.1 \pm 1.0 \\
\text { - HIRE: } 29.3 \pm 1.0\end{array}$ & $\begin{array}{l}\text { (1) Dynamic } \\
\text { (2) } 2 \text { sets of } 10 \text { repetitions per exercise at 50\% of } 1 \text { RM in } \\
\text { MIRT and at } 80 \% \text { of } 1 \mathrm{RM} \text { in HIRT } \\
\text { (3) } 90 \text { s between sets / } 2 \text { min between exercises } \\
\text { (4) "average speed" } \\
\text { (5) Machines and free weights (e.g., bench presses, } \\
\text { biceps curls, triceps extensions, leg presses, vertical } \\
\text { butterflies, and leg extensions) } \\
\text { (6) Ca. } 40 \text { min (10 min warm-up, } 30 \text { min exercising) } \\
\text { (7) One single session } \\
\text { (8) N.A. } \\
\text { (9) N.A. } \\
\text { (10) Individual and supervised }\end{array}$ \\
\hline Tsai et al. [187] & $\begin{array}{l}\text { (1) IS (RCT, between-group design) / CON (n), RT } \\
\text { (2) Older adults } \\
\text { (2.1) - CON: } N=24 \text { (0 f / } 24 \mathrm{~m}) / 72.0 \pm 4.1 \\
\text { - RT: } N=24(0 \mathrm{f} / 24 \mathrm{~m}) / 70.8 \pm 3.4 \\
\text { (2.2) - CON: N.A. / N.A. / } 24.6 \pm 3.6 \\
\text { - RT: N.A. / N.A. / } 26.0 \pm 2.5 \\
\text { (3) MMSE score } \\
\text { - CON: } 28.2 \pm 1.0 \\
\text { - RT: } 28.0 \pm 1.2\end{array}$ & $\begin{array}{l}\text { (1) Dynamic } \\
\text { (2) } 3 \text { sets of } 10 \text { repetitions per exercise at } 75 \text { to } 80 \% \text { of 1RM } \\
\text { (3) } 90 \text { s between sets / } 3 \text { min between exercises } \\
\text { (4) "average speed" } \\
\text { (5) Machines and free weights (e.g., biceps curls, leg presses, } \\
\text { triceps extensions, hamstring curls, latissimus dorsi } \\
\text { pull-downs, calf raises, seated rowing) } \\
\text { (6) Ca. } 60 \text { min ( } 10 \text { min warm-up, } 40 \text { min exercising, } 10 \text { min } \\
\text { cool-down) } \\
\text { (7) } 3 \text { days/week } \\
\text { (8) N.A. } \\
\text { (9) } 48 \text { weeks } \\
\text { (10) Group-based and supervised }\end{array}$ \\
\hline Tsai et al. [195] & $\begin{array}{l}\text { (1) IS (RCT, between-group design) / CON (r), AE, RE } \\
\text { (2) Older adults with amnestic MCl } \\
\text { (2.1) - CON: } N=20(12 \mathrm{f} / 8 \mathrm{~m}) / 64.5 \pm 7.0 \\
\text { - AE: } N=25(14 \mathrm{f} / 11 \mathrm{~m}) / 65.5 \pm 7.5 \\
\text { - RE: } N=21(12 \mathrm{f} / 9 \mathrm{~m}) / 66.1 \pm 6.6 \\
\text { (2.2) - CON: } 159.7 \pm 8.81 / 61.4 \pm 13.0 / 23.8 \pm 3.1 \\
\text { - AE: } 160.6 \pm 7.85 / 62.1 \pm 13.7 / 23.8 \pm 3.2 \\
\text { - RE: } 159.9 \pm 8.51 / 62.1 \pm 12.1 / 24.5 \pm 3.2 \\
\text { (3) MMSE score } \\
\text { - CON: } 27.00 \pm 1.59 \\
\text { - AE: } 26.96 \pm 1.21 \\
\text { - RE: } 26.76 \pm 1.38\end{array}$ & $\begin{array}{l}\text { (1) Dynamic } \\
\text { (2) } 2 \text { sets of } 10 \text { repetitions per exercise at } 75 \% \text { of } 1 \mathrm{RM} \\
\text { (3) } 90 \text { s between sets / } 2 \text { min between exercises } \\
\text { (4) "average speed" } \\
\text { (5) Machines and free weights (e.g., biceps curls, triceps } \\
\text { extensions, bench presses, leg presses, leg extensions, and } \\
\text { vertical butterflies) } \\
\text { (6) Ca. } 40 \text { min ( } 5 \text { min warm-up, } 30 \text { min exercising, } 5 \text { min } \\
\text { cool-down) } \\
\text { (7) One single session } \\
\text { (8) N.A. } \\
\text { (9) N.A. } \\
\text { (10) Individual and supervised }\end{array}$ \\
\hline Tsai et al. [191] & $\begin{array}{l}\text { (1) IS (RCT, between-group design) / BAST, AT, RT } \\
\text { (2) Older adults with amnestic MCl } \\
\text { (2.1) - CON: } N=18(13 \mathrm{f} / 5 \mathrm{~m}) / 65.2 \pm 7.0 \\
\text { - AT: } N=19(14 \mathrm{f} / 5 \mathrm{~m}) / 66.0 \pm 7.7 \\
\text { - RT: } N=18(11 \mathrm{f} / 7 \mathrm{~m}) / 65.4 \pm 6.8 \\
\text { (2.2) - CON: N.A. / N.A. / } 23.4 \pm 2.8 \\
\text { - AT: N.A. / N.A. / } 23.5 \pm 3.3 \\
\text { - RT: N.A. / N.A. / } 24.4 \pm 3.1 \\
\text { (3) MMSE sCore } \\
\text { - CON: } 27.00 \pm 1.65 \\
\text { - AT: } 27.16 \pm 1.26 \\
\text { - RT: } 26.56 \pm 1.34\end{array}$ & $\begin{array}{l}\text { (1) Dynamic } \\
\text { (2) } 3 \text { sets of } 10 \text { repetitions at } 60 \text { to } 70 \% \text { of } 1 \mathrm{RM} \text { in the first } 2 \\
\text { weeks and at } 75 \% \text { of } 1 \mathrm{RM} \text { in the remaining weeks } \\
\text { (3) } 90 \text { s between sets / } 2 \text { min between exercises } \\
\text { (4) N.A. } \\
\text { (5) Machines and free weights (e.g., biceps curls, vertical } \\
\text { butterflies, leg press, seated rowing, hamstring curls, and } \\
\text { calf raises) } \\
\text { (6) Ca. } 40 \text { min ( } 5 \text { min warm-up, } 30 \text { min exercising, } 5 \text { min } \\
\text { cool-down) } \\
\text { (7) } 3 \text { days/week } \\
\text { (8) N.A. } \\
\text { (9) } 16 \text { weeks } \\
\text { (10) Group-based and supervised }\end{array}$ \\
\hline Vonk et al. [183] & $\begin{array}{l}\text { (1) IS (RCT, within-subject design) / RE, LM } \\
\text { (2) Healthy younger adults }\end{array}$ & $\begin{array}{l}\text { (1) Dynamic } \\
\text { (2) } 2 \text { sets of } 10 \text { repetitions at } 70 \% \text { of } 10 \text { RM }\end{array}$ \\
\hline
\end{tabular}


Table 1 Overview of the population characteristics and resistance exercises and/or resistance training characteristics of the reviewed studies (Continued)

\begin{tabular}{|c|c|c|}
\hline First author [ref.] & Study design and sample characteristics & Resistance exercise characteristics \\
\hline & $\begin{array}{l}\text { (2.1) } N=20(11 \mathrm{f} / 9 \mathrm{~m}) / 23.0 \pm 2.0 \\
\text { (2.2) N.A. } \\
\text { (3) N.A. }\end{array}$ & $\begin{array}{l}\text { (3) } 60 \text { s between sets / } 90 \text { min between exercises } \\
\text { (4) N.A. } \\
\text { (5) Machines and free weights (e.g., leg press, pull-down, } \\
\text { hamstring curls, vertical chest press, bilateral bicep curl, } \\
\text { bilateral triceps extension) } \\
\text { (6) Ca. } 30 \text { min ( } 5 \text { min warm-up, ca. } 25 \text { min exercising) } \\
\text { (7) Two separate sessions (RE and LM) } \\
\text { (8) N.A. } \\
\text { (9) N.A. } \\
\text { (10) Individual and supervised }\end{array}$ \\
\hline $\begin{array}{l}\text { Yerokhin } \\
\text { et al. [192] }\end{array}$ & $\begin{array}{l}\text { (1) IS (no RCT, between-group design) / RT } \\
\text { (2) Healthy older adults } \\
\text { (2.1) - RT: } N=9 \text { [5] (1 f / } 8 \text { m) / } 62.8 \pm 7.2 \\
\text { (2.2) - RT: N.A. / N.A. / N.A. } \\
\text { Individuals with early dementia } \\
\text { (2.1) - RT: } N=13 \text { [9] (0 f /13 m) / } 79.3 \pm 11.0 \\
\text { (2.2) - RT: N.A. / N.A. / N.A. } \\
\text { (3) MMSE score } \\
\text { - N.A. in both groups }\end{array}$ & $\begin{array}{l}\text { (1) Dynamic } \\
\text { (2) N.A. (detailed information can be found in Seguin et al., [196]) } \\
\text { (3) N.A. (detailed information can be found in Seguin et al., [196]) } \\
\text { (4) N.A. (detailed information can be found in Seguin et al., [196]) } \\
\text { (5) Small free weights and body weight (e.g., different exercise } \\
\text { such as squat, toe stands, [detailed information could be } \\
\text { found in Seguin et al., [196]) } \\
\text { (6) Ca. } 45 \text { min } \\
\text { (7) } 3 \text { to } 5 \text { days/week } \\
\text { (8) N.A. } \\
\text { (9) } 10 \text { weeks } \\
\text { (10) Supervised (older adults with early dementia) / individual } \\
\text { and home-based (HC) }\end{array}$ \\
\hline
\end{tabular}

Functional and structural magnetic resonance imaging

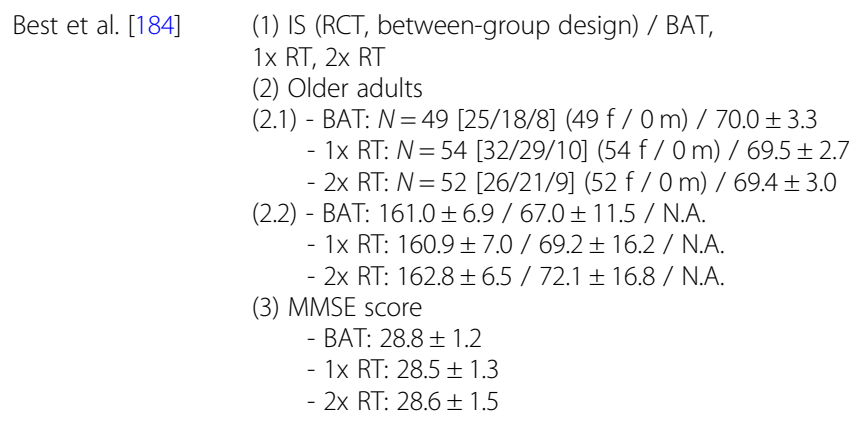

Brinke et al. [197] (1) IS (RCT, between-group-design) / BAT, AT, RT

(2) Older adults with probable $\mathrm{MCl}$

(2.1) - BAT: $N=28[13 / 11](28 \mathrm{f} / 0 \mathrm{~m}) / 75.5 \pm 3.9$

- AT: $N=30[14 / 10](30 \mathrm{f} / 0 \mathrm{~m}) / 76.1 \pm 3.4$

- RT: $N=28[12 / 8](30 \mathrm{f} / 0 \mathrm{~m}) / 73.8 \pm 3.8$

(2.2) - BAT: $157.5 \pm 8.1 / 64.8 \pm 13.8 /$ N.A.

- AT: $158.8 \pm 5.8 / 61.7 \pm 6.8 /$ N.A.

- RT: $161.6 \pm 8.1 / 63.3 \pm 7.5 /$ N.A.

(3) MMSE score

- BAT: $27.17 \pm 1.85$

- AT: $27.54 \pm 1.51$

- RT: $26.67 \pm 2.64$

Bolandzadeh et al. [185]
(1) IS (RCT, between-group design) / BAT,

1x RT, 2x RT

(2) Older adults

(2.1) - BAT: $N=15[11](15 \mathrm{f} / 0 \mathrm{~m}) / 69.3 \pm 2.8$

- 1XRT: $N=22[18](22 \mathrm{f} / 0 \mathrm{~m}) / 69.6 \pm 2.6$

- 2x RT: $N=17$ [13] (17 f/ $0 \mathrm{~m}) / 69.2 \pm 3.1$

(2.2) - BAT: $162.9 \pm 5.8 / 69.5 \pm 9.4$ / N.A.
(1) Dynamic

(2) 2 sets of 6 to 8 repetitions of 7RM per exercise (progressively increased)

(3) N.A.

(4) N.A.

(5) Exercises with pneumatic resistance machines (e.g., biceps curls, triceps extensions, seated rows, latissimus dorsi pull-downs, leg presses, hamstring curls, and calf raises) and free weights (e.g., mini-squats, mini-lunges, and lunge walks)

(6) Ca. $60 \mathrm{~min}$ (10 min warm-up, 40 min exercising, $10 \mathrm{~min}$ cool-down)

(7) 1 day/week (in 1x RT) or 2 days/week (in 2x RT)

(8) One week-in-between (in 1x RT) / N.A. (in 2x RT)

(9) 52 weeks

(10) Group-based and supervised

(1) Dynamic

(2) 2 sets of 6 to 8 repetitions of 7RM per exercise (progressively increased)

(3) N.A.

(4) N.A.

(5) Exercises with pneumatic resistance machines (e.g., biceps curls, triceps extensions, seated rows, latissimus dorsi pull-downs, leg presses, hamstring curls, and calf raises) and free weights (e.g., mini-squats, mini-lunges, and lunge walks)

(6) Ca. 60 min (10 min warm-up, 40 min exercising, 10 min cool-down)

(7) 2 days/week

(8) N.A.

(9) 26 weeks

(10) Group-based and supervised

(1) Dynamic

(2) 2 sets of 6 to 8 repetitions of 7RM per exercise (progressively increased)

(3) N.A.

(4) N.A.

(5) Exercises with pneumatic resistance machines (e.g., biceps curls, triceps extensions, seated rows, latissimus dorsi 
Table 1 Overview of the population characteristics and resistance exercises and/or resistance training characteristics of the reviewed studies (Continued)

\begin{tabular}{|c|c|c|}
\hline First author [ref.] & Study design and sample characteristics & Resistance exercise characteristics \\
\hline & $\begin{array}{l}\text { - 1x RT: } 160.7 \pm 6.4 / 68.2 \pm 14.6 \text { / N.A. } \\
\text { - 2x RT: } 161.3 \pm 7.4 / 68.1 \pm 12.5 \text { / N.A. } \\
\text { (3) MMSE (MOCA) score } \\
\text { - BAT: } 28.7(24.4) \pm 1.3(3.5) \\
\text { - 1x RT: } 28.9(25.8) \pm 1.0(2.9) \\
\text { - 2x RT: } 28.8(25.6) \pm 1.8(2.9)\end{array}$ & $\begin{array}{l}\text { pull-downs, leg presses, hamstring curls, and calf raises) } \\
\text { and free weights (e.g., mini-squats, mini-lunges, and } \\
\text { lunge walks) } \\
\text { (6) Ca. } 60 \text { min (10 min warm-up, } 40 \text { min exercising, } \\
10 \text { min cool-down) } \\
\text { (7) } 1 \text { day/week (in 1x RT) or } 2 \text { days/week (in 2x RT) } \\
\text { (8) One week-in-between (in 1x RT) / N.A. (in 2x RT) } \\
\text { (9) } 52 \text { weeks } \\
\text { (10) Group-based and supervised }\end{array}$ \\
\hline $\begin{array}{l}\text { Kjølhede } \\
\text { et al. [193] }\end{array}$ & $\begin{array}{l}\text { (1) IS (RCT, cross-over design) / WL, RT } \\
\text { (2) Adults with multiple sclerosis } \\
\text { (2.1) - WL: } N=17 \text { [12] (N.A.) } \\
\text { - RT: } N=18 \text { [17] (N.A.) } \\
\text { - mean of both groups: } 43.2 \pm 8.1 \\
\text { (2.2) - mean of both groups: } 171.0 \pm 8.0 / \\
\quad 75.0 \pm 13.0 \text { / N.A. } \\
\text { (3) EDSS score } \\
\text { - WL: } 2.9 \pm 0.2 \\
\text { - RT: } 2.9 \pm 0.2\end{array}$ & $\begin{array}{l}\text { (1) Dynamic } \\
\text { (2) Progressively increased with adjustment in sets, repetitions, } \\
\text { load [detailed information can be found in Kjølhede } \\
\text { et al. [198] } \\
\text { (3) } 2 \text { to } 3 \text { min [detailed information can be found in } \\
\text { Kjølhede et al. [198] } \\
\text { (4) N.A. } \\
\text { (5) Exercises with resistance machines (e.g., horizontal } \\
\text { leg press, hip flexion, leg extension, prone hamstring } \\
\text { curl, cable pull-down and cable triceps extension) } \\
\text { (6) N.A. } \\
\text { (7) } 2 \text { days/ week } \\
\text { (8) N.A. } \\
\text { (9) } 24 \text { weeks } \\
\text { (10) Group-based and supervised }\end{array}$ \\
\hline $\begin{array}{l}\text { Liu-Ambrose } \\
\text { et al. [186] }\end{array}$ & 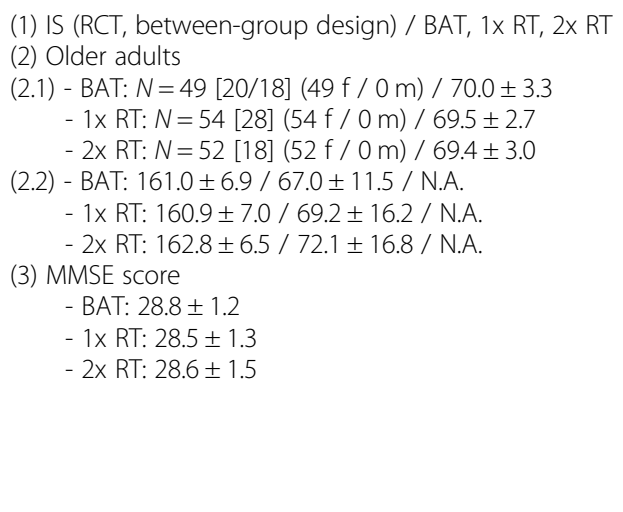 & $\begin{array}{l}\text { (1) Dynamic } \\
\text { (2) } 2 \text { sets of } 6 \text { to } 8 \text { repetitions of 7RM per exercise } \\
\text { (progressively increased) } \\
\text { (3) N.A. } \\
\text { (4) N.A. } \\
\text { (5) Exercises with pneumatic resistance machines (e.g., biceps } \\
\text { curls, triceps extensions, seated rows, latissimus dorsi } \\
\text { pull-downs, leg presses, hamstring curls, and calf raises) } \\
\text { and free weights } \\
\text { (e.g., mini-squats, mini-lunges, and lunge walks) } \\
\text { (6) Ca. } 60 \text { min ( } 10 \text { min warm-up, } 40 \text { min exercising, } \\
10 \text { min cool-down) } \\
\text { (7) } 1 \text { day/week (in } 1 \times \text { RT) or } 2 \text { days/week } \\
\text { (8) One week-in-between (in } 1 \times \text { RT) / N.A. (in } 2 x \text { RT) } \\
\text { (9) } 52 \text { weeks } \\
\text { (10) Group-based and supervised }\end{array}$ \\
\hline $\begin{array}{l}\text { Liu-Ambrose } \\
\text { et al. [45] }\end{array}$ & $\begin{array}{l}\text { (1) IS (RCT, between-group design) / BAT, } 1 \times \text { RT, } 2 x \text { RT } \\
\text { (2) Older adults } \\
\text { (2.1) - BAT: } N=17[17](17 \mathrm{f} / 0 \mathrm{~m}) / 69.2 \pm 3.2 \\
\text { - } 1 \times \text { RT: } N=20[20](20 \mathrm{f} / 0 \mathrm{~m}) / 69.7 \pm 2.8 \\
\text { - } 2 \text { RT: } N=15[15](15 \mathrm{f} / 0 \mathrm{~m}) / 68.9 \pm 3.2 \\
\text { (2.2) - BAT: } 162.4 \pm 5.9 / 67.3 \pm 9.5 / \text { N.A. } \\
\text { - } 1 \times \text { RT: } 161.7 \pm 7.5 / 70.7 \pm 13.8 / \text { N.A. } \\
\text { - 2x RT: } 162.7 \pm 6.6 / 68.7 \pm 10.9 / \text { N.A. } \\
\text { (3) MMSE score } \\
\text { - BAT: } 29.1 \pm 1.1 \\
\text { - 1X RT: } 28.6 \pm 1.2 \\
\text { - 2x RT: } 29.1 \pm 0.85\end{array}$ & $\begin{array}{l}\text { (1) Dynamic } \\
\text { (2) } 2 \text { sets of } 6 \text { to } 8 \text { repetitions of } 7 R M \text { per exercise } \\
\text { (progressively increased) } \\
\text { (3) N.A. } \\
\text { (4) N.A. } \\
\text { (5) Exercises with pneumatic resistance machines (e.g., biceps } \\
\text { curls, triceps extensions, seated rows, latissimus dorsi } \\
\text { pull-downs, leg presses, hamstring curls, and calf raises) } \\
\text { and free weights } \\
\text { (e.g., mini-squats, mini-lunges, and lunge walks) } \\
\text { (6) Ca. } 60 \text { min ( } 10 \text { min warm-up, } 40 \text { min exercising, } \\
10 \text { min cool-down) } \\
\text { (7) } 1 \text { day/week (in } 1 \times \text { RT) or } 2 \text { days/week (in } 2 \times \text { RT) } \\
\text { (8) One week-in-between (in 1x RT) / N.A. (in 2x RT) } \\
\text { (9) } 52 \text { weeks } \\
\text { (10) Group-based and supervised }\end{array}$ \\
\hline $\begin{array}{l}\text { Nagamatsu } \\
\text { et al. [189] }\end{array}$ & $\begin{array}{l}\text { (1) IS (RCT, between-group design) / BAT, 2x AT, 2x RT } \\
\text { (2) Older adults with probable mild cognitive } \\
\text { impairment and subjective memory complaints } \\
\text { (2.1) - BAT: } N=28 \text { [8] }(28 \mathrm{f} / 0 \mathrm{~m}) / 75.1 \pm 3.6 \\
\text { - AT: } N=30[7](30 \mathrm{f} / 0 \mathrm{~m}) / 75.6 \pm 3.6 \\
\text { - RT: } N=28[7](28 \mathrm{f} / 0 \mathrm{~m}) / 73.9 \pm 3.5 \\
\text { (2.2) - BAT: } 158.2 \pm 7.3 / 66.4 \pm 14.0 / \mathrm{N} . \mathrm{A} . \\
\text { - AT: } 159.2 \pm 5.9 / 64.8 \pm 12.8 / \mathrm{N} . \mathrm{A} . \\
\text { - RT: } 158.7 \pm 7.0 / 65.2 \pm 10.7 / \mathrm{N} . \mathrm{A} .\end{array}$ & $\begin{array}{l}\text { (1) Dynamic } \\
\text { (2) } 2 \text { sets of } 6 \text { to } 8 \text { repetitions of 7RM per exercise } \\
\text { (progressively increased) } \\
\text { (3) N.A. } \\
\text { (4) N.A. } \\
\text { (5) Exercises with pneumatic resistance machines (e.g., biceps } \\
\text { curls, triceps extensions, seated rows, latissimus dorsi } \\
\text { pull-downs, leg presses, hamstring curls, and calf raises) } \\
\text { and free weights (e.g., mini-squats, mini-lunges, and }\end{array}$ \\
\hline
\end{tabular}


Table 1 Overview of the population characteristics and resistance exercises and/or resistance training characteristics of the reviewed studies (Continued)

\begin{tabular}{|c|c|c|}
\hline First author [ref.] & Study design and sample characteristics & Resistance exercise characteristics \\
\hline & $\begin{array}{l}\text { (3) MMSE (MOCA) score } \\
\text { - BAT: } 27.1 \text { (22.5) } \pm 1.7(2.8) \\
\text { - AT: } 27.4(22.2) \pm 1.5(2.8) \\
\text { - RT: } 27.0(21.4) \pm 1.8(1.3)\end{array}$ & $\begin{array}{l}\text { lunge walks) } \\
\text { (6) Ca. } 60 \text { min (10 min warm-up, } 40 \text { min exercising, } \\
10 \text { min cool-down) } \\
\text { (7) } 2 \text { days/week } \\
\text { (8) N.A. } \\
\text { (9) } 52 \text { weeks } \\
\text { (10) Group-based and supervised }\end{array}$ \\
\hline Suo et al. [190] & $\begin{array}{l}\text { (1) IS (RCT, between-group design) / SHAM, RE + SHAM, } \\
\text { RE + CCT, CCT + SHAM } \\
\text { (2) Older adults with dementia prodrome mild } \\
\text { cognitive impairment } \\
\text { (2.1) - ALL: } N=100(68 \mathrm{f} / 32 \mathrm{~m}) / 70.1 \pm 6.7(55-87) \\
\text { - SHAM: } N=27 \text { [22] (N.A.) } \\
\text { - RE + SHAM: } N=22[19] \text { (N.A.) } \\
\text { - RE + CCT: } N=27 \text { [22] (N.A.) } \\
\text { - CCT + SHAM: } N=24 \text { [20] (N.A.) } \\
\text { (2.2) - N.A. } \\
\text { (3) MMSE score } \\
\text { - ALL: } 24-28 \text { (29 was acceptable only if error } \\
\text { noted in memory registration) }\end{array}$ & $\begin{array}{l}\text { (1) Dynamic } \\
\text { (2) } 5 \text { to } 6 \text { exercises with } 3 \text { sets of } 8 \text { repetitions per exercise at } \\
80 \text { to } 92 \% \text { of } 1 \text { RM } \\
\text { (3) N.A. } \\
\text { (4) N.A. } \\
\text { (5) Exercises with pneumatic resistance machines (e.g., chest } \\
\text { press, leg press, seated row, standing hip abduction, knee } \\
\text { extension, hip flexion, hip extension, calf raise) and free } \\
\text { weights (e.g., lateral raise, biceps curls) } \\
\text { (6) Ca. } 90 \text { min } \\
\text { (7) } 2 \text { days/week } \\
\text { (8) N.A. } \\
\text { (9) } 26 \text { weeks } \\
\text { (10) Group-based and supervised }\end{array}$ \\
\hline
\end{tabular}

Please note that the sham treatments in Suo et al. [190] were conducted as follows: (i) the cognitive training group (CCT + SHAM) included physical exercises that did not significantly increase heart rate or improve aerobic capacity balance or strength performance (e.g., stretching, toning, and seated calisthenics), and (ii) the resistances exercise group (RE + SHAM) included a computerized, active cognitive control training

AE Aerobic exercises, AT Aerobic training, BAT Balance and toning exercise, BAST Balance and stretching training, BMI Body mass index, $\mathrm{cm}$ Centimeters, CON ( $n$ ) Non-exercising control group, CON (r) Control group read magazines, EDSS Expanded disability status scale, $f$ Female, HIA High-intensity aerobic exercise, HIIT High-intensity aerobic interval training, HIRE High-intensity resistance exercises, HIRT High-intensity resistance training, HOA Healthy older adults, $\mathrm{kg}$ Kilogram, LM Loadless movement group, MCI Mild cognitive impairments, MIC Moderate-intensity exercise combining resistance training and walking, MCT Moderate continuous aerobic training, MIRE Moderate-intensity resistance exercises, $m$ Male, min Minute, MMSE Mini-mental state examination, MOCA Montreal cognitive assessment, $N$ Number of participants, N.A. Not applicable, $R C T$ Randomized controlled trials, RM Repetition maximum, RE Resistance exercises, RT Resistance training, SD Standard deviation, WL Wait list

With regard to resistance training, after a 16-week intervention with healthy older adults, oxygenated hemoglobin and total hemoglobin were lowered in the left prefrontal cortex during the Stroop task (Stroop interference effect, posttest compared with pretest), while cognitive task performance (i.e., reaction time) was improved [44]. At the end of 52 weeks of resistance training, older adults who had conducted resistance exercises twice a week exhibited better performance in tasks of executive functions (i.e., Stroop test) than those who had performed balance and toning exercises [45]. Furthermore, in the same study, the hemodynamic response during the incongruent flanker condition was increased in the left anterior insula and the left lateral orbitofrontal cortex, whereas the hemodynamic response during the congruent flanker condition decreased in the same areas [45].

In older individuals with mild cognitive impairment (MCI), the right lingual and occipital-fusiform gyri and the right frontal pole exhibited increased activation during the associative memory test after a twice-weekly performed resistance training lasting for 52 weeks when compared with older individuals conducting balance and toning exercises in this time period [189]. Furthermore, in this study, a positive correlation between increased hemodynamic activity in the right lingual gyrus and improved associative memory performance was observed [189]. After 26 weeks of resistance training, decreased resting-state functional connectivity of the $\mathrm{PC}_{\mathrm{FC}}$ with the left inferior temporal lobe and the anterior cingulate cortex and between the $\mathrm{HIP}_{\mathrm{FC}}$ and the right inferior temporal lobe was observed in older adults with MCI [190]. In the same study, an increase in restingstate functional connectivity between the $\mathrm{HIP}_{\mathrm{FC}}$ and the right middle frontal lobe was evident in older adults with MCI in the resistance training group [190].

\section{Neuroelectric functional brain changes and cognition}

With regard to an acute bout of resistance exercises, cognitive performance was improved in younger adults $[182,183]$ and older adults with MCI [195]. After exercising in younger adults, an increase in the P3 amplitude during a Go/No-Go task combined with the Eriksen Flanker paradigm was observed [182], and in older adults with MCI, the P3 amplitude across all electrode positions (except $\mathrm{Pz}$ ) during the Eriksen Flanker task was larger posttest compared with pretest [195]. Furthermore, in younger adults, a time-dependent and condition-dependent increase in P3 amplitude (obtained during the Stroop task) was observed [183]. In incongruent trials, larger P3 amplitudes were observed $30 \mathrm{~min}$ and $40 \mathrm{~min}$ after exercise cessation, whereas in congruent trials, larger P3 amplitudes were observed $10 \mathrm{~min}$ 
and $40 \mathrm{~min}$ after exercise cessation [183]. However, in the same study, no statistically significant differences between the resistance exercise group and the loadless movement group were observed [183]. Additionally, larger P3 amplitudes were associated with lower serum cortisol levels after an acute bout of resistance exercise in younger adults [182].

With regard to resistance training, after 9 weeks of training (three times per week), the elderly participants showed a significant decrease in $\mathrm{N} 1$ latencies at the $\mathrm{Fz}$ and $\mathrm{Cz}$ positions during an auditory task, whereas the N1-P2, P2-N2 and N2-P3 amplitudes (at Fz) and the N1-P2 amplitude (at Cz) increased [194]. In comparison to both an aerobic training group and an inactive control group, the resistance training group showed a greater absolute reduction in $\mathrm{P} 2$ and $\mathrm{N} 2$ latencies and larger absolute increase in N1-P2, P2-N2, and N2-P3 amplitudes [194]. Furthermore, after 10 weeks of resistance training in healthy older adults and in older adults at an early stage of dementia, a decrease in beta asymmetry, a decrease in N200 A asymmetry, and an increase in theta asymmetry was observed [192]. The decrease in N200 A asymmetry was significantly negatively correlated with improvements in the Fuld immediate recall score and the Fuld delayed recall score, while the increase in delta asymmetry was significantly positively correlated with a better Fuld delayed recall score [192]. After resistance training with elastic bands for 12 weeks, healthy older adults showed a decrease in relative theta power at P3 and $\mathrm{P} 4$, but their cognitive measures remained unchanged [188]. However, in the same study, exercising older adults with MCI exhibited significantly higher scores in the digit span backward test than their nonexercising counterparts [188]. Furthermore, from pre- to posttest, theta power at F3 increased and alpha power at T3 decreased in exercising older adults with MCI [188]. After 16 weeks of resistance training in older adults with amnestic MCI, larger P3 amplitudes during a taskswitching paradigm were observed [191]. Furthermore, in the same study, decreased reaction times (i.e., in the nonswitching condition and in the switching condition) and higher accuracy rates (i.e., in the pure condition, in the non-switching condition, and in the switching condition) were noticed in the resistance training group and the aerobic training group when the posttest was compared with the pretest [191]. Additionally, in the resistance training group, a positive correlation between changes in serum levels of insulin-like growth factor 1 (IGF-1) and P3 amplitudes (measured during switching condition) and a negative correlation between serum levels of tumor necrosis factor-alpha and accuracy rates in the switching condition were observed, which both barely failed to attain statistical significance [191]. In another study, 48 weeks of resistance training led to superior cognitive performance (i.e., reaction time) as well as to larger P3a and P3b amplitudes in an oddball task [187]. Moreover, serum IGF-1 concentrations increased and were correlated with faster reaction times and larger P3b amplitudes only in the resistance group [187].

\section{Structural brain changes and cognition}

After resistance training performed once or twice weekly for 52 weeks, compared with older adults conducting balance and toning exercises, older adults in the resistance training groups exhibited (i) an increased performance in Stroop test [186], (ii) a reduction in whole brain volume [186], (iii) a lower volume of cortical white matter atrophy [184], and (iv) a lower degree of cortical white matter lesions [185]. In older female adults with probable $\mathrm{MCI}$, resistance training over 26 weeks did not led to significant changes in hippocampal volume [197]. In another study, older adults with MCI resistance training performed twice a week for 26 weeks exhibited improved ADAS-Cog scores (global cognition assessed with Alzheimer's Disease Assessment Scale) and increased the cortical thickness of grey matter in the posterior cingulate gyrus [190]. Moreover, the increase in grey matter thickness was negatively correlated with ADAS-Cog scores, indicating better cognitive performance [190]. In individuals with multiple sclerosis (MS), resistance training lasting 24 weeks led to an increase in cortical thickness in the anterior cingulate sulcus and gyrus, the temporal pole, the inferior temporal sulcus, and the orbital H-shaped sulcus [193]. The increased thickness in the temporal pole was significantly negatively correlated with lower scores on the Expanded Disability Status Scale (i.e., lower disability) [193]. More detailed information on the main findings is provided in Table 2.

\section{Discussion \\ Risk of bias}

In general, our results regarding the source of the risk of bias are somewhat heterogeneous (see Fig. 3); nevertheless, the overall quality of the majority of the reviewed studies can be regarded as sufficiently high. However, the risk of bias could be further minimized by proper planning of the study, which would strengthen the plausibility of observed effects. To ensure and enhance the study quality, it appears imperative that future studies report their procedures in sufficient detail (e.g., exercise and training variables) and pay attention to established guidelines such as the CONSORT statement [202] or the STROBE statement [203].

\section{Selection of participants and study design}

The reviewed studies were conducted with healthy young adults, healthy older adults, or older adults with 
Table 2 Overview of the characteristics of cognitive testing and the main outcomes of the reviewed studies
First author [ref.]
(1) Cognitive testing
(2) Main findings (related to functional and/or structural brain changes in response to resistance exercises or resistance training)
Functional near-infrared spectroscopy
Chang et al. [43] (1) Executive functions (Stroop test) during fNIRS (conducted 15 min after exercise cessation)
(2) Between group comparisons (postexercise, neutral condition):
- $\downarrow$ TOI in It. PFC during CT (HIR vs. CON (n) / MIC)
- $\uparrow$ Solved items and $\downarrow$ response time during CT (HIR vs. CON (n))
Between group comparisons (postexercise, incongruent condition):
$-\downarrow$ TOI in It. PFC (HIR vs. CON (n) / MIC)
$-\downarrow$ TOI in rt. PFC (HIR vs. CON (n) / MIC / HIA)
(ROI: It. and. rt. PFC)
Coetsee et al. [44] $\quad$ (1) Executive functions (Stroop test) during fNIRS
(2) Posttest vs. pretest:
- $\downarrow$ OxyHb in It. PFC in RT during CT (Stroop interference effect)
- $\downarrow$ THI in It. PFC in RT and MCT during CT (Stroop interference effect)
- $\downarrow$ Reaction time in RT during CT (naming and executive condition)
(ROI: It. and rt. PFC)

Electroencephalography

Hong et al. [188]

(1) Cognitive test battery (Stroop test, COWAT, DFDB; Rey 15-Item Memory Test) and resting EEG

(2) Posttest versus pretest:

$-\downarrow$ Relative theta power (at F3) in MCI RT

- $\uparrow$ Relative alpha power (at T3) in MCI RT

- $\downarrow$ Relative theta power (at P3 and at P4) in HOA RT

- DB scores were significantly higher in MCI RT than in MCI CON (at posttest)

Özkaya et al. [194] $\quad$ (1) Auditory task during EEG

(2) Posttest vs. pretest:

- $\downarrow$ Latencies of N1 (at Fz) and N1 (at Cz) in RT and AT

- $\uparrow$ Amplitudes of N1-P2, P2-N2 and N2-P3 (at Fz) and N1-P2 (at Cz) in RT

Between group comparisons:

- $\downarrow$ Absolute changes in latencies of P2 and N2 (at Fz and at Cz) in RT compared with AT and CON

- $\uparrow$ Absolute changes in amplitudes of N1-P2, P2-N2, and N2-P3 (at Fz) and N1-P2 and N2-P3 (at Cz) in RT compared with AT and CON

Tsai et al. [182]

(1) Executive functions (Go/No-Go task combined with the Eriksen Flanker paradigm) during EEG measurements (CT was conducted after exercise cessation when the participant's body temperature and HR had returned to within $10 \%$ of pre-exercise levels, which was on average approximately 5 min after acute resistance exercise cessation.)

(2) Posttest vs. pretest:

- $\uparrow$ P3 amplitude (i.e., at Fz, Cz, and Pz) in MIRT and HIRT during CT

- $\downarrow$ Reaction time in MIRT and HIRT during CT (Go condition)

- $\uparrow$ Accuracy in MIRT and HIRT during CT (incongruent No-Go condition)

- $\uparrow$ Serum GH and serum IGF-1 in MIRE and HIRE (prior to cognitive testing at pretest vs. prior to cognitive testing at posttest)

- $\downarrow$ Serum cortisol in MIRE and HIRE (prior to cognitive testing at pretest vs. prior cognitive testing at posttest)

- $\downarrow$ Serum GH and serum IGF-1 in HIRE (prior to cognitive testing at posttest vs. after cognitive testing at posttest)

- $\uparrow$ Serum GH in MIRE and HIRE, serum IGF in MIRE (prior to cognitive testing at pretest vs. after cognitive testing at posttest) 
Table 2 Overview of the characteristics of cognitive testing and the main outcomes of the reviewed studies (Continued)

- $\downarrow$ Serum cortisol in MIRE (prior to cognitive testing at pretest vs. after cognitive testing at posttest)

- Lower serum cortisol levels were associated with higher P3 amplitude

Tsai et al. [187]

(1) Executive functions (oddball task) during EEG measurements

(2) Between group comparisons:

- $\uparrow$ P3a amplitude (i.e., at F3 and F4) and P3b amplitude (i.e., at Cz, Pz, and Oz) in RT during CT compared with CON (n)

- $\uparrow$ Accuracy in RT during CT compared with CON (n)

- $\downarrow$ Reaction time in RT during CT compared with CON (n)

Posttest vs. pretest:

- $\downarrow$ Reaction time in RT during CT

- $\uparrow$ Serum IGF-1 levels in RT

- $\downarrow$ Serum homocysteine levels in RT

- Higher serum IGF-1 levels in RT were associated with the faster reaction times and larger P3b amplitudes

Tsai et al. [195]

(1) Working memory (Memory span from WAIS-IV); executive functions (Flanker task) during EEG measurements (CT was conducted after exercise cessation when the participant's body temperature and HR had returned to within $10 \%$ of pre-exercise levels, which was on average approximately 5 min after acute resistance exercise cessation.)

(2) Posttest vs. pretest:

- $\uparrow$ P3 amplitudes (i.e., at Fz, Cz, and Pz, except the Pz electrode in RE) in AE and RE during CT (in all conditions)

- $\downarrow$ Reaction time in AE and RT during CT (congruent and incongruent condition)

- $\uparrow$ Serum IGF-1 in AE and RE; serum BDNF and serum VEGF in AE (prior to cognitive testing at pretest vs. prior to cognitive testing at posttest)

- $\downarrow$ IGF-1 in AE and RE and serum BDNF in AE (prior to cognitive testing at posttest vs. after cognitive testing at posttest)

- Lower P3 latency across all participants was associated with higher IGF-1 levels (prior to cognitive testing at posttest)

Tsai et al. [191]

(1) Working memory (Memory span from WAIS-IV); executive functions (Task switching) during EEG measurements

(2) Posttest vs. pretest:

- $\uparrow$ P3 amplitudes in AE and RT

- $\downarrow$ Reaction time in AE and RT during CT (non-switching condition and switching condition)

- $\uparrow$ Accuracy rate in AE and RT during $\mathrm{CT}$ (pure condition, non-switching condition, and switching condition)

- $\uparrow$ Serum IGF-1 in RT and serum BDNF in AT

- $\downarrow$ Serum TNF-a and serum IL-15 in RT and AT / $\uparrow$ serum TNF-a in CON

- Higher levels of $\mathrm{VO}_{2 \max }$ are associated with higher levels of serum BDNF in RT and AT

Vonk et al. [183]

(1) Executive functions (Stroop test) during EEG measurements (conducted $10 \mathrm{~min}, 20 \mathrm{~min}, 30 \mathrm{~min}$, and 40 min after exercise cessation)

(2) Posttest vs. pretest:

- $\downarrow$ Response time in RE and LM during CT (congruent and incongruent condition, 10 min after exercise cessation vs. pretest)

- $\downarrow$ Response time in RE and LM during CT (congruent condition, 10 min vs. 30 min after exercise cessation)

- $\downarrow$ Accuracy in RE and LM during CT (incongruent condition, 30 min after exercise cessation vs. pretest)

- $\uparrow$ P3 amplitude in RE and LM during CT (incongruent condition, 30 min and 40 min after exercise cessation vs. pretest)

- P P3 amplitude in RE and LM during CT (congruent condition, 10 min and 30 min after exercise cessation vs. pretest) 
Table 2 Overview of the characteristics of cognitive testing and the main outcomes of the reviewed studies (Continued)

(2) Posttest vs. pretest:

- $\downarrow$ Beta asymmetry and $\downarrow$ N200 A asymmetry

- $\uparrow$ Delta asymmetry

- $\uparrow$ Figure delayed recall and Fuld immediate recall

- Decreased N200 A asymmetry was significantly correlated with improvements in Fuld immediate and Fuld delayed recall

- Increase in delta asymmetry was significantly correlated with an improvement in Fuld delayed recall (ROI: frontal lobe [FP1, FP2, F7, F8])

Functional and structural magnetic resonance imaging

Best et al. [184]

(1) Cognitive test battery (Stroop test, TMT A\&B, DB, RAVLT, DSST)

(2) Between group comparisons:

- $\downarrow$ Cortical WM atrophy 2x RT compared with BAT at 2-year follow-up

- $\uparrow$ Executive functions in 1x RT compared with BAT considering changes from baseline to postintervention

- $\uparrow$ Executive functions in 1x RT and 2x RT compared with BAT considering changes from baseline to a 2-year follow-up

- $\uparrow$ Memory performance in 2x RT compared with BAT considering changes from baseline to 2-year follow-up

- $\uparrow$ Peak muscle power in 2x RT compared with BAT considering changes from baseline to postintervention and to a 2-year follow-up

Brinke et al. [197] $\quad$ (1) Memory (RAVLT)

(2) Between group comparisons:

- No significant differences between AT and RT in hippocampal volume after 26 weeks

- $\uparrow$ Hippocampal volume in rt. and It. hemisphere / total hippocampal volume in AT compared with AT after 26 weeks

- Positive partial correlation between increase in left hippocampal volume and change in RAVLT (loss after interference condition)

Bolandzadeh et al. [185] (1) Executive functions (Stroop test)

(2) Between group comparisons:

- $\downarrow$ Cortical WML volume 2x RT compared with BAT at 2-year follow-up

- $\downarrow$ WML progression in 2x RT at postintervention was associated with maintenance of gait speed

Kjølhede et al. [193] (1) Working memory \& auditory information processing speed (PASAT)

(2) Changes in cortical thickness in response to RT:

- $\uparrow$ E.g., in subcentral sulcus and gyrus; anterior cingulate sulcus and gyrus, middle anterior cingulate sulcus and gyrus, inferior parietal angular gyrus, inferior temporal gyrus, middle temporal gyrus, temporal pole, superior circular sulcus of insula, superior and transverse occipital sulcus, inferior temporal sulcus, orbital H-shaped sulcus, inferior and superior parts of the precentral sulcus, inferior and superior temporal sulcus

Between group comparisons regarding cortical thickness:

- $\uparrow$ Anterior cingulate sulcus and gyrus, temporal pole, inferior temporal sulcus, orbital H-shaped sulcus in RT compared with WL after 24 weeks

- Greater thickness in the temporal pole was correlated with lower EDSS scores

Liu-Ambrose et al. [186] (1) Cognitive test battery (Stroop test, TMT A\&B, DFDB)

(2) Between group comparisons:

- $\uparrow$ Stroop test performance in 1x RT and 2x RT compared with BAT at 2-year follow-up

- $\uparrow$ Peak muscle power in 2x RT compared with BAT at postintervention and to a 2-year follow-up

- $\downarrow$ Whole brain volume (from baseline) in 1x RT and 2x RT compared with BAT at a 2-year follow-up

- Improvement in Stroop test performance during intervention was significantly associated with increased gait speed

Liu-Ambrose et al. [45] (1) Executive functions test (modified Eriksen Flanker task) during fMRl

(2) Between group comparisons:

- $\uparrow$ Activation of the left anterior insula extending into the lateral orbital frontal cortex in 2x RT compared with BAT at posttest in the incongruent condition 
Table 2 Overview of the characteristics of cognitive testing and the main outcomes of the reviewed studies (Continued)

$-\downarrow$ Activation of the left anterior insula extending into the lateral orbital frontal cortex and anterior portion of the left middle temporal gyrus in 2x RT compared with BAT at posttest in the congruent condition

$-\downarrow$ Reduction in interference score (better performance) in 2x RT compared with BAT

Nagamatsu et al. [189] (1) Cognitive test battery (Stroop test, TMT A\&B, DFDB; EPT) and associative memory (memorizing face-scene pairs) during fMRI

(2) Between group comparisons:

- $\uparrow$ Stroop test performance and associate memory task performance in RT compared with BAT at postintervention

- $\uparrow$ Activation of the right lingual and occipital-fusiform gyri and the right frontal pole in $2 x$ RT during CT compared with BAT at postintervention (encoding and recall of associations)

- Higher hemodynamic activity in the right lingual gyrus was correlated with better performance in the associative memory test

Suo et al. [190]

(1) Cognitive test battery (e.g. ADAS, TMT A\&B, BVRT, COWAT, Category Fluency, SDMT, Logical Memory WMS-III, Matrices WMS-III, Similarities WMS-III)

(2) Between group comparisons:

- $\downarrow$ ADAS-Cog score (i.e., improved cognition) at posttest in the RT groups compared with all other groups

- $\uparrow$ Posterior cingulate cortex grey matter thickness at postintervention in RT groups compared with all other groups

- $\downarrow$ White matter hyperintensities volumes in the rt. periventricular zone and the rt. parietal zone in RT groups compared with all other groups (significant when analyzed at the regional level / not-significant when whole brain-corrected)

- Greater posterior cingulate cortex grey matter thickness was significantly correlated with lower ADAS-Cog score (i.e. improved cognition)

Functional connectivity changes:

- $\downarrow P C_{F C}$ connectivity with the left inferior temporal lobe and the anterior cingulate cortex in RT + SHAM / $\downarrow P C_{F C}$ connectivity between the PC and the anterior cingulate cortex in CCT + SHAM

- $\downarrow P C_{F C}$ between the $P C$ and the anterior cingulate cortex in $R T+C C T$

- $\uparrow \mathrm{HIP}_{\mathrm{FC}}$ connectivity with the right middle frontal lobe and $\downarrow$ connectivity with the right inferior temporal lobe in RT + SHAM

- $\uparrow H_{\mathrm{HPFC}}$ connectivity between the hippocampus and the left superior frontal lobe in CCT + SHAM

- $\uparrow$ Hippocampal-anterior cingulate cortex connectivity and the hippocampal-right superior frontal lobe connectivity in RT + CCT

- $\uparrow$ Superior functional connectivity between the hippocampus and the superior frontal lobe is associated with improved memory domain performance

Please note that the sham treatments in Suo et al. [190] were conducted as follows: (i) the cognitive training group (CCT + SHAM) included physical exercises that did not significantly increase heart rate or improve aerobic capacity balance or strength performance (e.g., stretching, toning, and seated calisthenics), and (ii) the resistances exercise group (RE + SHAM) included a computerized, active cognitive control training.

ADAS-Cog Alzheimer's disease assessment scale, AE Aerobic exercises, AT Aerobic training, BAT Balance and toning exercise, BDNF Brain-derived neurotrophic factor, BVRT Benton visual retention test, CFT Complex figure test, CON (n) Non-exercising control group, CON ( $r$ ) Control group read magazines, COWAT Controlled oral word association test, CT Cognitive test, $D B$ Verbal digits backward test, DFDB Verbal digits forward and verbal digits backward tests, DSST Digit symbol substitution test, EEG Electroencephalography, EDSS Expanded disability status scale, EPT Everyday problem solving test, $f M R I$ Functional magnetic resonance imaging, fNIRS Functional near-infrared spectroscopy, FOME Fuld object memory evaluation, GH Growth hormone, HIA High-intensity aerobic exercise, HIIT Highintensity aerobic interval training, HIRE High-intensity resistance exercises, HIRT High-intensity resistance training, HOA Healthy older adults, IGF-1 Insulin-like growth factor 1, MCI Mild cognitive impairments, MIC Moderate-intensity exercise combining resistance training and walking, MCT Moderate continuous aerobic training, MIRE Moderate-intensity resistance exercises, LM Loadless movement group, It. Left, min Minute, oxyHb Oxygenated hemoglobin, PASAT Paced auditory serial addition test, PFC Prefrontal cortex, RAVLT Rey auditory verbal learning test, RCT Randomized controlled trials, RM Repetition maximum, RE Resistance exercises, RT Resistance training, rt. Right, SDMT Symbol digit modalities test, THI Total hemoglobin index, TMT A\&B Trail making test A\&B, TOI Tissue oxygenation index, TNF- $a$ Tumor necrosis factor-alpha, VEGF Vascular endothelial growth factor, $V_{2 m a x}$ Maximal oxygen uptake during a graded exercise test, vs. Versus, WL Wait list, WM White matter, WML White matter lesion volume, WAIS-IV Wechsler-IV adult intelligence test, WMS Wechsler memory scale, $\uparrow:$ significant increase; $\downarrow$ : significant decrease / F3, F4, F7, F8, FP1, FP2, P3, T3, Cz, Fz, Oz and Pz are specific positions in the international system for EEG electrode placement [199], whereas N1, N2, P1, P2, P3 (P300) constitute specific EEG parameters [200, 201]

MCI or beginning dementia. Therefore, our knowledge about the effect of resistance exercises and/or resistance training on cognitive functions is limited to these cohorts, and further investigations with other cohorts are required. In particular, older adults with sarcopenia are a key group because there is a high prevalence (ranging from 1 to $33 \%$ ) of this condition in various older populations [204], which poses major economic costs to the 
welfare system [205]. Sarcopenia comprises the agerelated loss of muscle mass [206-210] but in the literature the term has often been (incorrectly) extended to the age-related loss of muscle function (e.g., muscle strength) [210-219]. The latter one should be referred to as dynapenia which encompasses the age-related loss of muscle function (e.g., loss of muscular strength and power) [209-211, 220]. However, age-related muscular changes (e.g., sarcopenia) could also lead to a decline in cognitive performance $[221,222]$. Hence, older adults with sarcopenia and/or dynapenia may profit in two ways (physically and cognitively) from resistance exercises/resistance training.

In the terms of study design, in future resistance exercise and/or resistance training studies, moderator variables such as gender [223-226] or genotype [227, 228], which may influence the effectiveness of the resistance exercise and/or resistance training, should be considered and analyzed. The assessment and analysis of moderators may help provide a better understanding of the observed inter-individual variability regarding the effect of physical exercise (e.g., resistance training) on the brain and on cognitive functions and help to foster the optimization of physical exercise interventions [125]. Furthermore, chronobiological factors (such as circadian variability) should be considered since they affect muscular adaptions in response to resistance exercises [229-232] and affect cognitive performance [233-235]. However, hemodynamic responses are reported to be relatively unaffected by, for instance, circadian variability [236].

Moreover, larger cohorts and longer intervention intervals could be beneficial (especially in [f] MRI studies) for increasing the external validity and for adaptation processes to manifest [237]. In addition, concerning cognitive testing, it seems advisable to use standardized sets of cognitive tests or to employ the latent variable approach (create an unobserved [latent] variable for a distinct set of cognitive tests) [238]. In this context, the 'human baseline hypothesis' should be considered, which claims that the baseline values of strength (e.g., grip strength, knee extensor strength) assessed prior to resistance training and/or after a detraining period are a more appropriate indicator of health outcomes than the training-related increase in strength values [239].

With regard to upcoming cross-sectional studies, neuroimaging methods (e.g., fNIRS, see [179]) should be employed as they help to better understand the association between superior cognitive performance (e.g., in global cognitive abilities) and superior muscular performance previously operationalized by (i) hand grip strength [86, 88, 89], (ii) isokinetic quadriceps strength [82, 83], (iii) leg power [84], or (iv) whole-body muscular strength [85].
Functional brain changes and cognition in response to resistance exercises or resistance training Hemodynamic functional brain changes and cognition

Currently, only a few studies have investigated the influence of resistance exercises and/or resistance training on functional brain parameters in healthy adults during standardized cognitive tasks. However, regardless of whether resistance exercises were conducted as an acute bout [43] or over a period of 16 weeks [44], proxies of cortical activation in the prefrontal cortex during the Stroop test were found to be decreased. In another resistance training study (52 weeks), a decrease in brain activation was observed exclusively during the relatively easy task condition, whereas increased activation was found in the more difficult task condition [45]. These observations stand in contrast to the findings of acute aerobic exercise studies $[28,29,43]$ and aerobic training studies [44], in which, in general, increased activation of prefrontal areas during cognitive testing was observed after exercising [180]. Notably, similar to the findings of most aerobic exercise or aerobic training studies, the reviewed resistance exercise and/or resistance training studies also reported improved cognitive functions [43-45]. Hence, decreases in the applied proxies of neuronal activity might indicate more efficient processing or automatization of cognitive processes. Moreover, it is likely that the decrease in brain activation in response to resistance exercises and/or resistance training is related to neurobiological mechanisms different from those induced by aerobic exercises or aerobic training [107, 223, 240]. Future studies are urgently needed to investigate the underlying neurobiological mechanisms of different types of acute physical exercises (e.g., resistance exercises vs. aerobic exercises) and chronic physical training (e.g., resistance training vs. aerobic training). Analysis of the neurobiological changes in response to different physical exercise/training interventions will also contribute to a better understanding of the functional changes in the brain. In this regard, Liu-Ambrose et al. [45] noticed that after the completion of a 52-week long resistance training program, functional brain activations in the left anterior insula extending from the lateral orbital frontal cortex and in the anterior portion of the left middle temporal gyrus during execution of a cognitive task were altered [45]. The left anterior insula, for instance, plays an important role in successful performance in response inhibition tasks [241], which may be based on their involvement in (i) the stopping ability [242], (ii) the assurance of general task accuracy [242], and (iii) maintaining a stable task set control [243, 244]. The left middle temporal gyrus is especially activated in complex Go-/No-Go situations [245]. However, in contrast, in comparable aerobic training, higher task-related 
activation in prefrontal areas and parietal cortices and decreased activation of the anterior cingulate cortex was observed [246]. Parietal areas [247] and prefrontal areas [248, 249] are involved in a variety of cognitive processes, among them attention [250, 251]. In particular, the parietal areas $[252,253]$ and the prefrontal areas $[254,255]$ are strongly involved in selective attention and the frontoparietal network in maintaining and manipulating task-relevant information in working memory [243]. In the context of attentional processes, the anterior cingulate cortex is also an important structure because it allocates attentional resources based on the recruitment of task-appropriate processing centers [256]. Moreover, the anterior cingulate cortex is activated in conflict processing where erroneous responses are highly probable [257-260]. Taken together, resistance training might be beneficial for cognitive processes that aim to avoid unwanted responses (e.g., maintaining stable task set control and increased stop efficacy), whereas aerobic exercises may enhance cognitive processes such as selective attention (e.g., maintaining task-relevant information) [45]. Further research is needed to verify this assumption.

The positive effect of resistance training on brain health is also underpinned by findings of Nagamatsu et al. [189], who observed higher cortical activation during an associative memory task in older individuals with MCI after they had undergone long-term resistance training (52 weeks). Moreover, this higher cortical activity was positively correlated with improvements in cognitive performance [189]. Another mechanism through which resistance training may ensure or/and improve brain health in MCI may be related to the modulation of functional connectivity. It was observed that (i) the resting-state functional connectivity between posterior cingulate cortex and other brain regions is generally decreased in individuals with MCI [261-264], (ii) functional connectivity between the posterior parietal cortex and the temporal cortex is associated with performance on neuropsychological tests [261], and (iii) the restingstate functional connectivity between the hippocampus and other brain regions is disturbed in individuals with MCI [265] or Alzheimer's disease [266, 267]. Notably, resistance training lasting 26 weeks increases the functional connectivity among the posterior cingulate cortex, the left inferior temporal lobe, and the anterior cingulate cortex and between the hippocampus and the right middle frontal lobe [190]. Based on the mentioned changes in resting-state functional connectivity in neurological diseases (e.g., MCI) and the positive influence of resistance training on resting-state functional connectivity, it can be speculated that resistance training may be a beneficial intervention strategy for ensuring or/and improving brain health and cognition in those cohorts.

\section{Neuroelectric functional brain changes and cognition}

A higher P3 amplitude (also known as P 300) was observed in younger adults after an acute bout of resistance exercises [182, 183] and in healthy older adults after 48 weeks of resistance training [187]. Furthermore, a higher P3 amplitude was observed in individuals with MCI after an acute bout of resistance exercises [195] or after 16 weeks of resistance training [191]. Elevated P3 amplitudes are generally associated with neural activity and cognitive processes [268, 269]. Upregulation of the P3 amplitude after resistance exercises and/or resistance training may be beneficial for brain health because diminished P3 amplitudes were observed in older individuals $[270,271]$ and individuals with neurological diseases (e.g., Alzheimer's disease) [272]. The associations between event-related potentials (e.g., P3 amplitude) and neurotrophic factors obtained after acute resistance exercises [182, 195] and/or resistance training [191] support the "neurotropic hypotheses" [114-117]. Profound changes in neuroelectric outcomes were also observed after 12 weeks of resistance training with decreased resting-state theta power in older adults with and without MCI and increased resting-state alpha power in older adults with MCI [188]. The relevance of these findings is currently unclear because contradictory observations regarding meaningful changes in alpha and theta power are found in the literature. For instance, on the one hand, more resting-state alpha power and less resting-state theta power were associated with better cognitive performance [273, 274], whereas, on the other hand, it has also been reported that higher resting-state theta power is linked to superior cognitive performance (e.g., in category fluency task) [275, 276]. Nevertheless, the notion that resistance training positively affects brain health was clearly confirmed by the observation of statistically significant correlations between neuroelectric changes (e.g., in asymmetry index) and changes in memory performance in older adults in response to a resistance intervention lasting 10 weeks [192]. In addition, Özkaya et al. [194] observed differences in neuroelectric parameters as a function of the type of physical training. This observation supports the idea that resistance and aerobic training have different impacts on the underlying neurobiological processes [223, 225, 240].

In sum, based on the small number of studies, it is too early to draw generalizable conclusions with respect to functional brain changes, but the available results suggest that resistance exercises and/or resistance training can be a promising strategy to ensure brain health. However, further studies are urgently needed to investigate the effect of an acute bout of resistance exercises and/or resistance training on functional brain changes. Here, upcoming studies should also pay attention to the investigation of neurobiological processes that may cause functional brain changes. 


\section{Structural brain changes and cognition in response to resistance training}

In response to resistance training over an intervention period of 52 weeks (performed two times per week), (i) a reduction in whole brain volume [186], (ii) a reduction in cortical white matter atrophy [184], and (iii) a reduction in white matter lesions [185] were observed in comparison to training with balance or toning exercises. The reduction in whole brain volume is surprising because, in general, 'more' is often associated with 'better'. However, it is assumed that the reduction in whole brain volume is perhaps caused by the improvement of certain brain pathologies, in particular the removal of amyloid plaques and shifts in cerebral fluids [186, 277, 278], which, in turn, might positively influence brain health. This view is supported by the recent findings of Yoon et al. [279], who observed a relationship between brain amyloid- $\beta$ levels and hand grip strength (e.g., high levels of brain amyloid- $\beta$ and low grip strength). The removal of amyloid plaques could be one possible neurobiological mechanism explaining the observed improvements in executive functions [186] because accumulation of amyloid- $\beta$ plaque is commonly linked to worsened domain-specific cognitive functions (e.g., executive functions and memory) [280-282], and neurological diseases such as Alzheimer's disease [283-286].

Furthermore, given that white matter abnormalities (e.g., high load of white matter lesions) are linked to a decline in cognitive functions (i.e., global cognition and processing speed) [13, 287-290] and are associated with neurological diseases such as dementia [291, 292], the resistance training-induced changes in white matter (e.g., reduced volume of lesions and reduced atrophy) are likely to be beneficial for brain health. Notably, the reduced volumes of white matter lesions after 52 weeks of resistance training are linked to increased gait speed [185]. Based on the findings that both slower gait speed [293] and white matter lesion load [294] are linked to an increased fall risk, the positive changes within the white matter in response to resistance training suggest that engaging in resistance training could play a substantial role in preservation of the neural correlates of all-day tasks (e.g., safe walking).

In response to resistance training, which was performed twice a week for 26 weeks, grey matter thickness in the posterior cingulate cortex was found to increase significantly [190]. This increase in cortical thickness of the posterior cingulate cortex was linked to improved global cognitive performance [190]. This neurobiobehavioral relationship underpins the assumption that the posterior cingulate cortex is important for cognition, although there is still no agreement about its exact role [295]. However, reductions in metabolism [296] and volume [297] were observed in the posterior cingulate cortex in Alzheimer's disease. Hence, the possible ability to shape this cortical structure by engaging in resistance training is a promising approach to ensure brain health and to prevent neurological diseases. In the context of neurological diseases, it was also observed that resistance training for 24 weeks increased the cortical thickness in distinct areas, such as the temporal pole, in individuals with MS. The increased cortical thickness in the temporal pole was associated with better scores on the Expanded Disability Status Scale (EDSS), suggesting that resistance training has a positive impact on brain health and functional abilities in this cohort. There are even reports in the literature that a single resistance exercise (leg press) has profound effects on brain volumes (but without a relation to cognitive functions) in healthy older adults. Here, statistically significant increases in grey matter density in the posterior and anterior lobe of the cerebellum, the superior frontal gyrus in the frontal lobe, and the anterior cingulate cortex in the limbic lobe were observed [131]. In summary, these results support the view that robust neuroplastic changes can be evoked through resistance training, which contribute to the maintenance of brain health.

Interestingly, one of the reviewed studies directly compared resistance and aerobic trainings and found no statistically significant difference in hippocampal volume changes between trainings [197]. Although an increase in hippocampal volume was reported after both aerobic [24] and resistance training in older adults [130], few brain imaging studies are currently available that directly compare different types of physical training. For instance, it was observed that dancing conducted for several months led to a greater increase in cortical grey matter in frontal and temporal regions [298-300] and in hippocampal volumes [301] than a combination of resistance, endurance, and flexibility training. Hence, comparing different types of physical interventions (e.g., resistance training vs. aerobic training vs. dancing) with regard to their effectiveness in evoking structural and functional brain changes is an interesting topic for further studies. Such knowledge is necessary to foster the development of individualized physical interventions, which are deemed to be more effective than the 'onesize-fits-all approach' [125, 223, 302].

Taken together, resistance training reduces white matter atrophy and increases grey matter volumes in distinct brain areas. Based on the observed relationship between structural changes and behavior [185, 190], the positive role of resistance training in ensuring (and improving) brain health is reinforced. Further studies comparing different types of physical interventions with respect to structural brain changes are required. 


\section{Neurophysiological adaptation processes in connection with resistance exercises and resistance training}

Structural brain changes in response to resistance training rely at least partly on the modulation of specific molecular and cellular pathways that are involved in neuroplasticity and - consequently - in positive effects of cognitive performance [112, 240]. In this context, the modulating role of resistance exercises and/or resistance training on the release of neurochemicals such as BDNF, IGF-1, and homocysteine is discussed in the literature [121, 223, 303, 304]. In the following, we briefly outline how these neurochemicals may contribute to the observed functional and structural brain changes.

\section{BDNF}

In particular, structural brain changes after physical interventions are assumed to be mediated by BDNF [114, $118,119,223,240]$. In addition, serum BDNF concentrations have been linked to spatial memory performance [21] and higher serum BDNF concentrations in response to acute physical exercises [305] or physical training [306] have been associated with improvements in executive functions. Furthermore, BDNF is involved in many neuroplastic processes, such as synaptogenesis, longterm potentiation of synaptic transmission, regulation of the differentiation of neuronal precursor cells, and neuronal survival [120]. The important role of BDNF in neuroplasticity is underpinned by the findings that reduced serum BDNF concentrations were linked to a decline in hippocampal volume and that changes in serum BDNF concentrations after aerobic training were associated with hippocampal volume changes [24]. Although hippocampal changes could not be observed in one of the reviewed studies after 26 weeks of resistance training [197], there is solid evidence that resistance exercises (especially at high-load conditions) [307-311] and resistance training (especially in males) [308, 312] upregulate serum BDNF concentrations. Such an increase in response to resistance exercise and resistance training was also reported for plasma BDNF [313]. Notably, it is assumed that concentrations of BDNF stored in immune cells and/or platelets are mirrored in the level of serum BNDF, while plasma BDNF is a marker of the concentration of freely circulating BDNF [314, 315]. Based on the previously mentioned connections between (serum) BDNF, brain physiology, and cognition (i.e., executive functions), it can be speculated that BDNF-driven mechanisms might contribute to neurocognitive changes after resistance exercises and/or resistance training. However, further studies are urgently needed to deepen our knowledge regarding the interrelationship between resistance exercises and/or resistance training-induced expression of (serum) BDNF in humans and its relation to functional and structural brain changes as well as to cognitive performance (as a function of age).

\section{IGF-1}

Engaging in resistance exercises [316] and resistance training $[187,317]$ fosters the expression of IGF-1, which is predominantly released by the liver (global output, 70\% of total circulating IGF-1), the musculature (local output), and the brain (local output) itself [318, 319]. Because circulating IGF-1 can cross the blood-brain barrier (BBB), locally expressed IGF-1 (e.g., from musculature) is likely to be available in the brain [318, 319]. IGF-1 triggers various mechanisms that contribute to neuroplasticity in the human brain, such as synaptic processes (e.g., long-term potentiation) [320, 321], angiogenesis in the brain, axon outgrowth, dendritic maturation, and synaptogenesis [319, 322]. Moreover, IGF-1 likely plays an important role in structural grey matter changes because it is involved in neuroplastic mechanisms that foster neuronal survival [323] such as (i) proliferation of neural cells [324, 325], (ii) inhibition of apoptosis of neural cells [324, 325], and (iii) protection of neurons against toxicity by, for instance, amyloid peptides [324]. While there is some evidence that higher serum IGF-1 levels are linked to greater total brain volumes [326] or hippocampal volume [327], the exact roles of IGF-1 in the central nervous system remain elusive [328]. However, the assumption that IGF-1-activated pathways play an important role in changing brain function is underpinned by the findings of a reviewed study that reported higher peripheral serum IGF-1 concentrations after 52 weeks of resistance training in healthy older individuals alongside behavioral (e.g., improved accuracy and reaction times in executive function tests) and functional improvements (e.g., P3 amplitude) [187, 191]. Such a relationship between cognitive performance and peripheral serum IGF-1 concentrations would be in accordance with previous findings linking peripheral serum IGF-1 levels to cognitive performance (e.g., global cognition assessed by MMSE) in older individuals [329] and individuals with MCI [330]. Notably, it has also been reported that solely an optimal concentration of peripheral serum IGF-1 is associated with superior global cognition (assessed by MMSE) and processing capacity [331], which could be related to the multiple and divergent roles that IGF-1 plays in the human brain $[319,332]$. On the one hand, IGF-1 is linked to beneficial processes (e.g., stimulating synaptogenesis and contributing to neuronal cell survival), but on the other hand, IGF-1 is also associated with detrimental processes (e.g., generation of reactive oxygen species and inhibition of autophagy) [319]. There is currently insufficient evidence to draw firm conclusions regarding the relationship between physical exercise, modulation of IGF-1, structural and functional brain changes, and cognitive functions [333]. Hence, further 
studies are urgently needed to gain deeper insights into the relationship between exercise-induced modulation of IGF-1 release, functional and structural brain changes, and cognitive performance [332, 333].

\section{Homocysteine}

A possible neurobiological mechanism that elucidates, at least partly, the effects of resistance training on white matter and cognition could be derived from the known effects of resistance training on the amino acid homocysteine. First, it is important to remember that a higher total homocysteine level is linked to (i) a higher extent of white matter lesions [334], (ii) a higher (faster) brain atrophy rate [335-337], (iii) an increased risk of neurological diseases [338-344], and (iv) poorer global cognitive performance and executive functioning [345-350]. Second, it is known that resistance training decreases the level of plasma [351] and serum homocysteine [187, 352]. Hence, it could be speculated that reducing the homocysteine level in response to resistance training may, at least partly, have positive effects on brain structure (e.g., white matter changes such as reduced atrophy) and/or cognitive functions. However, such relationships have not been directly observed in the studies reviewed [187] and have to be investigated in future studies.

\section{Influence of exercise variables and training variables on neurocognition}

With regard to all studies reviewed, the exercise and training variables of the resistance intervention protocols were chosen as to induce muscle hypertrophy and muscle strength improvements, which is not surprising, as resistance training programs generally focus on improving these two factors. Moreover, this observation is consistent with two other reviews summarizing the results of resistance exercise and resistance training studies on outcomes on a behavioral level [107, 353]. However, given that the dose provided by a physical intervention (e.g., resistance exercise or resistance training) is a function of exercise variables and training variables and that the reviewed studies are relatively homogenous regarding the selection of exercise variables and training variables, our knowledge about the doseresponse relationship in resistance exercise and resistance training is relatively meager (especially in view of the fact that resistance exercises and resistance training can be designed in many different ways to focus on different aims for muscular performance). A deeper understanding of the dose-response relationship is needed $[105,108,110]$ because the dose (the design of exercise variables and training variables, see Table 3 ) is a key factor influencing responsiveness $[357,358]$ and individualizing physical interventions [123, 124, 359].
Table 3 Overview of exercise variables and training variables $[60,113,354-356]$

Variables for structuring a single resistance exercise session (exercise variables)

(i) Load (amount of weight that is used for an exercise; usually given as a percentage of the one repetition maximum [1RM])

(ii) Number of repetitions

(iii) Number of sets

(iv) Inter-set rest period

(v) Inter-exercise rest period

(vi) Number of exercises (for the whole training session or for a muscle or a muscle group with the same function)

(vii) Repetition velocity (with respect to the conducted resistance exercise and the starting position, temporal details should be given as follows: i.e., biceps curls starting with fully extended arms [e.g., bench press starting with fully extended arms]: concentric phase [eccentric phase] - inter-repetition rest periods - eccentric phase [concentric phase] - rest period up to the start of the next repetition, e.g., 2-0-2-1 s)

(viii) Muscle action (concentric, eccentric, isometric)

(ix) Exercise selection (e.g., multi-joint or single-joint exercises)

(x) Exercise order (e.g., squat, leg extension, biceps curl, and concentration curl or squat, biceps curl, leg extension, and concentration curl)

(xi) Volitional muscle failure

(xii) Range of motion

Variables for structuring resistance training (training variables)

(1.) Frequency (number of training sessions per week)

(2.) Density (distribution of training sessions across a week with regard to recovery time in-between training sessions)

(3.) Duration (duration over which a training program is carried out; e.g., before exercise variables will be changed)

Please note, that some exercise variables are usually summarized into variables with different designations: e.g., volume [exercise variables (ii), (iii), and (iv)], time under tension [TUT, sum of the exercise variables (ii) and (vii)] or duration of an exercise session [depends on exercise variables (ii), (iii), (iv), (v), (vi), (vii), and the duration of warm-up and cool-down] [354, 356]

In the following section, we outline promising starting points for investigating the dose-response relationship in resistance exercise and/or resistance training studies.

With regard to load, on the behavioral level, it was observed that an acute bout of moderate-load resistance exercises ( 70 to $100 \%$ of the 10RM, 10RM = the load needed for 10 repetitions until maximum exhaustion) improves the speed of processing, while resistance exercises with low load (40\% of the 10RM) improve executive functions [138]. Furthermore, it was reported that improvements in executive functions were larger after moderate-load (70\% of $10 \mathrm{RM})$ than low-load $(40 \%$ of 10RM) resistance exercises [156]. The finding that resistance exercises with moderate loads are especially beneficial for cognitive performance is supported by the observation that resistance exercises with moderate loads $(60 \% 1 \mathrm{RM})$ lead to larger positive effects on higher cognitive functions (i.e., Stroop interference score) 
compared with resistance exercises with heavier loads $(\geq$ $75 \%$ 1RM) [360]. In another study, it was noticed that a single bout of high-load (100\% of 10RM) resistance exercises resulted in less interference and fastened reaction times for the Stroop task 15 min after exercise cessation, while $180 \mathrm{~min}$ after exercise cessation, low-load (40\% of 10RM) and moderate-load (70\% of 10RM) resistance exercises were associated with increased performance on the plus-minus and the Simon task [146]. However, at the moment, only two studies have employed neuroimaging methods to investigate the dose-response relationship with respect to the exercise load [182, 183]. In this study, no statistically significant differences in neuroelectric outcomes between conditions were observed [182, 183]. Based on the sparse evidence in this area, further research is required to investigate whether such loaddependent cognitive improvements are mirrored in acute processes of the central nervous system (e.g., measured prior and after resistance exercises by fNIRS [180] or EEG [201, 360-362].

With regard to number of sets, on the behavioral level, it was reported that younger adults performing three or five sets of a resistance exercise showed after a 8-week intervention period greater improvements in inhibitory control (i.e., assessed by accuracy and mean response time in the Stroop test) than younger adults performing one set of the same resistance exercise [363]. Because the abovementioned study did not apply neuroimaging techniques or quantify neurotrophic markers (e.g., BDNF) [363], future investigations are needed to elucidate the underlying neurobiological mechanisms.

With regard to frequency, on the behavioral level, resistance training three times a week was more efficient than training twice a week [109]. Since most reviewed studies conducted resistance training twice a week $[45,184-186$, $189,190]$ and observed beneficial results or did not compare a training with two sessions per week to other training frequencies [44, 187], the findings of Li et al. [109] are not supported by functional or structural data. Hence, future studies are required to investigate the influence of training frequency on functional and structural brain changes (e.g., one time per week vs. three times per week).

Since changes at the molecular and cellular levels (e.g., metabolic response, such as peripheral blood lactate concentration) are linked to behavioral changes, a promising approach to positively influence neurocognition could be the alteration of molecular and cellular processes by adjusting the exercise prescription via exercise and training variables.

In particular, after an acute bout of physical exercise, postexercise concentrations of peripheral blood lactate were found to be linked to improvements in executive functions [364-366]. In this context, peripherally (e.g., in the musculature) released lactate is expected to be utilized as 'fuel' for cognitive processes because it can cross the BBB with the help of monocarboxylate transporters [367371]. Furthermore, peripheral lactate may trigger the release of serum BDNF [309, 311, 372], but this relationship seems to be highly reliant on the correct selection of resistance exercise variables [309]. Notwithstanding, it has been well demonstrated that serum BDNF contributes significantly to changes in brain structure [21,24] and performance (e.g., cognition) [21, 305, 306]. Consequently, given that the peripheral concentration of blood lactate is a function of resistance exercise variables such as repetition velocity [373, 374] or inter-set rest periods [375], it seems reasonable to speculate that a purposeful modification of these exercise variables may also influence neurocognition outcomes. Notably, in this context, it was also hypothesized that resistance exercises with blood flow restriction (BFR) could be beneficial for neurocognition because resistance exercises with BFR or resistance training with BFR induce beneficial processes on a molecular and cellular level (for review see [113]). However, further research in this area with a strong focus on underlying neurobiological processes, functional and structural brain changes, and cognition is required.

Finally, similar to the major ongoing discussions regarding which variables may be optimal to improve muscular adaptions, such as muscle hypertrophy or strength [376390], the optimal exercise prescription (e.g., exercise variables and training variables) for resistance exercises and/ or resistance training with respect to brain health (including appropriate functional and structural brain changes as well as enhancement of cognitive functions) are largely unknown and have to be elucidated in future studies [105, $108,110]$. In addition, the interested reader may find further and more detailed information regarding the design of resistance exercise sessions or resistance training in the referenced literature [355, 391-394].

\section{Recommendations for future studies}

- Based on the available evidence derived from the reviewed studies and other recommendations [107], resistance exercises and/or resistance training aiming to enhance cognitive functions and evoke positive functional and structural brain changes should be designed to induce muscle hypertrophy.

- Future studies are needed to investigate the influence of the adjustment of different resistance exercise variables (e.g., load, number of sets, training frequency, training duration) on functional and structural brain changes in conjunction with cognitive functions.

- To understand the time-course of functional and structural brain changes, neuroimaging should be performed at several time points after an acute bout 
of resistance exercise or during the resistance training intervention.

- The inclusion of further cohorts (e.g., older individuals with sarcopenia and/or dynapenia) is needed to verify whether resistance exercise-induced improvements also occur in such needy cohorts and how this is related to functional and structural brain changes.

- Interventional studies (or cross-sectional studies) investigating the relationship of resistance exercises (or strength, muscle function/structure) and cognition should utilize different neuroimaging methods during standardized cognitive testing and assess neurochemical substances (e.g., neurotransmitters, neurotrophic factors) to elucidate underlying neurobiological mechanisms.

- Bed rest studies, which reported a worsening of executive functions [395-397], profound brain changes [397-399], and a decrease in muscle mass as well as muscle strength [400-408], could be an interesting model to study the relationship between the muscular system, functional and structural brain changes, and cognition.

\section{Conclusions}

In summary, resistance exercises and resistance training are powerful physical intervention strategies to induce meaningful functional brain changes, especially in the frontal lobe, which are accompanied by improvements in executive functions. Furthermore, based on the studies reviewed, resistance training leads to lower white matter atrophy and lower volumes of white matter lesions. However, given the small number of available studies that have mostly been part of greater study projects (Brain Power Study and SMART [Study of Mental and Resistance Training]), further research investigating the influence of an acute bout of resistance exercise and chronic resistance training on cognition and the underlying neurobiological mechanisms (e.g., functional and/or structural brain changes) is needed. This future research should also focus on the effects of systematically manipulating exercise and training variables (dose-response relationship) and further including specific cohorts with the greatest need (e.g., older individuals with sarcopenia and/or dynapenia). Most importantly, engaging regularly in resistance exercises and/or resistance training across the whole lifespan appears to be imperative for ensuring physical and brain health because muscular weakness in the early years of life (e.g., adolescence) has been shown to be associated with disability in later life (e.g., after 30 years) [409] and even 4 weeks of detraining (being physical inactive) completely reversed the physical and cognitive improvements of 22-week resistance training in older adults [410]. Hence, to summarize in a metaphorical sense: "May the force be with you across your lifespan."
Acknowledgments

The authors have nothing to acknowledge.

\section{Authors' contributions}

FH and AT wrote the manuscript. LS and NGM reviewed the drafted versions. All authors have read and approved the final version.

Funding

No funding information applicable.

Availability of data and materials

Not applicable.

Ethics approval and consent to participate

Not applicable.

Consent for publication

Not applicable.

\section{Competing interests}

The authors declare that they have no competing interests.

\section{Author details}

${ }^{1}$ Research Group Neuroprotection, German Center for Neurodegenerative Diseases (DZNE), Leipziger Str. 44, 39120 Magdeburg, Germany. ${ }^{2}$ Center for Behavioral Brain Sciences (CBBS), Brenneckestraße 6, 39118 Magdeburg, Germany. ${ }^{3}$ Department of Neurology, Medical Faculty, Otto von Guericke University, Leipziger Str. 44, 39120 Magdeburg, Germany. ${ }^{4}$ Institute III, Department of Sport Science, Otto von Guericke University Magdeburg, Zschokkestr. 32, 39104 Magdeburg, Germany.

Received: 5 March 2019 Accepted: 26 June 2019

Published online: 10 July 2019

\section{References}

1. Raz N. Regional brain changes in aging healthy adults: general trends, individual differences and modifiers. Cereb Cortex. 2005;15:1676-89. https:// doi.org/10.1093/cercor/bhi044.

2. Raz N, Ghisletta P, Rodrigue KM, Kennedy KM, Lindenberger U. Trajectories of brain aging in middle-aged and older adults: regional and individual differences. Neurolmage. 2010;51:501-11. https://doi.org/10.1016/j. neuroimage.2010.03.020.

3. Raz N, Schmiedek F, Rodrigue KM, Kennedy KM, Lindenberger U, Lövdén M. Differential brain shrinkage over 6 months shows limited association with cognitive practice. Brain Cogn. 2013:82:171-80. https://doi.org/10.1016/j. bandc.2013.04.002.

4. Raz N, Rodrigue KM, Head D, Kennedy KM, Acker JD. Differential aging of the medial temporal lobe: a study of a five-year change. Neurology. 2004; 62:433-8.

5. Raz N, Gunning FM, Head D, Dupuis JH, McQuain J, Briggs SD, et al. Selective aging of the human cerebral cortex observed in vivo: differential vulnerability of the prefrontal gray matter. Cereb Cortex. 1997;7:268-82.

6. Tisserand DJ, Pruessner JC, Sanz Arigita EJ, van Boxtel MPJ, Evans AC, Jolles J, Uylings HBM. Regional frontal cortical volumes decrease differentially in aging: an MRI study to compare volumetric approaches and voxel-based morphometry. Neurolmage. 2002;17:657-69. https://doi.org/10.1006/nimg.2002.1173.

7. Resnick SM, Pham DL, Kraut MA, Zonderman AB, Davatzikos C. Longitudinal magnetic resonance imaging studies of older adults: a shrinking brain. J Neurosci. 2003;23:3295-301.

8. Allen JS, Bruss J, Brown CK, Damasio H. Normal neuroanatomical variation due to age: the major lobes and a parcellation of the temporal region. Neurobiol Aging. 2005;26:1245-60. https://doi.org/10.1016/j. neurobiolaging.2005.05.023 discussion 1279-82.

9. Salat DH, Kaye JA, Janowsky JS. Prefrontal gray and white matter volumes in healthy aging and Alzheimer disease. Arch Neurol. 1999;56:338-44.

10. Bartzokis G, Beckson M, Lu PH, Nuechterlein KH, Edwards N, Mintz J. Agerelated changes in frontal and temporal lobe volumes in men: a magnetic resonance imaging study. Arch Gen Psychiatry. 2001;58:461-5.

11. DeCarli C, Murphy DG, Gillette JA, Haxby JV, Teichberg D, Schapiro MB, Horwitz B. Lack of age-related differences in temporal lobe volume of very healthy adults. AJNR Am J Neuroradiol. 1994;15:689-96. 
12. Raz N. Aging of the brain and its impact on cognitive performance: integration of structural and functional findings. In: The handbook of aging and cognition. 2nd ed. Mahwah: Lawrence Erlbaum Associates Publishers; 2000. p. 1-90.

13. Gunning-Dixon FM, Brickman AM, Cheng JC, Alexopoulos GS. Aging of cerebral white matter: a review of MRI findings. Int J Geriatr Psychiatry. 2009;24:109-17. https://doi.org/10.1002/gps.2087.

14. Salat DH, Tuch DS, Hevelone ND, Fischl B, Corkin S, Rosas HD, Dale AM. Age-related changes in prefrontal white matter measured by diffusion tensor imaging. Ann N Y Acad Sci. 2005;1064:37-49. https://doi.org/10.1196/ annals.1340.009.

15. Fjell AM, Walhovd KB. Structural brain changes in aging: courses, causes and cognitive consequences. Rev Neurosci. 2010;21:187-221.

16. Reuter-Lorenz PA, Park DC. How does it STAC up? Revisiting the scaffolding theory of aging and cognition. Neuropsychol Rev. 2014;24:355-70. https:// doi.org/10.1007/s11065-014-9270-9.

17. Albert MS. The ageing brain: Normal and abnormal memory. Philos Trans R Soc Lond Ser B Biol Sci. 1997;352:1703-9. https://doi.org/10.1 098/rstb.1997.0152.

18. Park DC, Lautenschlager G, Hedden T, Davidson NS, Smith AD, Smith PK Models of visuospatial and verbal memory across the adult life span. Psychol Aging. 2002;17:299-320. https://doi.org/10.1037/0882-7974.17.2.299.

19. Buckner RL. Memory and executive function in aging and AD: multiple factors that cause decline and reserve factors that compensate. Neuron. 2004:44:195-208. https://doi.org/10.1016/j.neuron.2004.09.006.

20. Hedden T, Gabrieli JDE. Insights into the ageing mind: a view from cognitive neuroscience. Nat Rev Neurosci. 2004;5:87-96. https://doi.org/10.1 038/nrn1323.

21. Erickson KI, Prakash RS, Voss MW, Chaddock L, Heo S, McLaren M, et al Brain-derived neurotrophic factor is associated with age-related decline in hippocampal volume. J Neurosci. 2010;30:5368-75. https://doi.org/10.1523/ JNEUROSCI.6251-09.2010.

22. O'Shea A, Cohen RA, Porges EC, Nissim NR, Woods AJ. Cognitive aging and the Hippocampus in older adults. Front Aging Neurosci. 2016;8:298. https:// doi.org/10.3389/fnagi.2016.00298.

23. Kramer JH, Rosen HJ, Du A-T, Schuff N, Hollnagel C, Weiner MW, et al. Dissociations in hippocampal and frontal contributions to episodic memory performance. Neuropsychology. 2005;19:799-805. https://doi.org/10.1037/ 0894-4105.19.6.799.

24. Erickson Kl, Voss MW, Prakash RS, Basak C, Szabo A, Chaddock L, et al. Exercise training increases size of hippocampus and improves memory. Proc Natl Acad Sci U S A. 2011;108:3017-22. https://doi.org/10.1073/ pnas.1015950108

25. Reuter-Lorenz PA. New visions of the aging mind and brain. Trends Cogn Sci. 2002;6:394-400. https://doi.org/10.1016/S1364-6613(02)01957-5.

26. Reuter-Lorenz PA, Cappell KA. Neurocognitive aging and the compensation hypothesis. Curr Dir Psychol Sci. 2008;17:177-82. https://doi.org/10.1111/ j.1467-8721.2008.00570.x

27. Cabeza R. Hemispheric asymmetry reduction in older adults: the HAROLD model. Psychol Aging. 2002;17:85-100. https://doi.org/10.1037// 0882-7974.17.1.85

28. Byun K, Hyodo K, Suwabe K, Ochi G, Sakairi Y, Kato M, et al. Positive effect of acute mild exercise on executive function via arousal-related prefrontal activations: an fNIRS study. Neurolmage. 2014;98:336-45. https://doi.org/10.1 016/j.neuroimage.2014.04.067.

29. Hyodo K, Dan I, Suwabe K, Kyutoku Y, Yamada Y, Akahori M, et al. Acute moderate exercise enhances compensatory brain activation in older adults. Neurobiol Aging. 2012;33:2621-32. https://doi.org/10.1016/j. neurobiolaging.2011.12.022.

30. Kujach S, Byun K, Hyodo K, Suwabe K, Fukuie T, Laskowski R, et al. A transferable high-intensity intermittent exercise improves executive performance in association with dorsolateral prefrontal activation in young adults. Neurolmage. 2017. https://doi.org/10.1016/j.neuroimage.2017.12.003.

31. Yanagisawa H, Dan I, Tsuzuki D, Kato M, Okamoto M, Kyutoku Y, Soya H. Acute moderate exercise elicits increased dorsolateral prefrontal activation and improves cognitive performance with Stroop test. Neurolmage. 2010; 50:1702-10. https://doi.org/10.1016/j.neuroimage.2009.12.023.

32. Bierre KL, Lucas SJE, Guiney H, Cotter JD, Machado L. Cognitive difficulty intensifies age-related changes in anterior frontal hemodynamics: novel evidence from near-infrared spectroscopy. J Gerontol A Biol Sci Med Sci. 2017;72:181-8. https://doi.org/10.1093/gerona/glw061.
33. Ogawa Y, Kotani K, Jimbo Y. Relationship between working memory performance and neural activation measured using near-infrared spectroscopy. Brain Behav. 2014;4:544-51. https://doi.org/10.1002/brb3.238.

34. Yamamoto U, Mashima N, Hiroyasu T. Evaluating working memory capacity with functional near-infrared spectroscopy measurement of brain activity. J Cogn Enhanc. 2018;49:5. https://doi.org/10.1007/s41465-017-0063-y.

35. Yasumura A, Inagaki M, Hiraki K. Relationship between neural activity and executive function: an NIRS study. ISRN Neurosci. 2014;2014:734952. https:// doi.org/10.1155/2014/734952.

36. Cabeza R. Task-independent and task-specific age effects on brain activity during working memory, visual attention and episodic retrieval. Cereb Cortex. 2004;14:364-75. https://doi.org/10.1093/cercor/bhg133.

37. Reuter-Lorenz PA, Lustig C. Brain aging: reorganizing discoveries about the aging mind. Curr Opin Neurobiol. 2005;15:245-51. https://doi.org/10.1016/j. conb.2005.03.016.

38. Schneider-Garces NJ, Gordon BA, Brumback-Peltz CR, Shin E, Lee Y, Sutton $\mathrm{BP}$, et al. Span, CRUNCH, and beyond: working memory capacity and the aging brain. J Cogn Neurosci. 2010;22:655-69. https://doi.org/10.1162/jocn.2 009.21230.

39. Reuter-Lorenz PA, Park DC. Human neuroscience and the aging mind: a new look at old problems. J Gerontol B Psychol Sci Soc Sci. 2010;65:405-15. https://doi.org/10.1093/geronb/gbq035.

40. Park DC, Reuter-Lorenz P. The adaptive brain: aging and neurocognitive scaffolding. Annu Rev Psychol. 2009;60:173-96. https://doi.org/10.1146/ annurev.psych.59.103006.093656.

41. Lague-Beauvais M, Brunet J, Gagnon L, Lesage F, Bherer L. A fNIRS investigation of switching and inhibition during the modified Stroop task in younger and older adults. Neurolmage. 2013;64:485-95. https://doi.org/10.1 016/j.neuroimage.2012.09.042.

42. Suwabe K, Byun K, Hyodo K, Reagh ZM, Roberts JM, Matsushita A, et al. Rapid stimulation of human dentate gyrus function with acute mild exercise. Proc Natl Acad Sci U S A. 2018. https://doi.org/10.1073/pnas.1805668115.

43. Chang $H$, Kim K, Jung $Y$-J, Kato M. Effects of acute high-intensity resistance exercise on cognitive function and oxygenation in prefrontal cortex. J Exerc Nutrition Biochem. 2017;21:1-8. https://doi.org/10.20463/jenb.2017.0012.

44. Coetsee C, Terblanche E. Cerebral oxygenation during cortical activation: the differential influence of three exercise training modalities. A randomized controlled trial. Eur J Appl Physiol. 2017. https://doi.org/10.1007/s00421-01 7-3651-8.

45. Liu-Ambrose T, Nagamatsu LS, Voss MW, Khan KM, Handy TC. Resistance training and functional plasticity of the aging brain: a 12-month randomized controlled trial. Neurobiol Aging. 2012;33:1690-8. https://doi. org/10.1016/j.neurobiolaging.2011.05.010.

46. Anderson-Hanley C, Barcelos NM, Zimmerman EA, Gillen RW, Dunnam M, Cohen BD, et al. The aerobic and cognitive exercise study (ACES) for community-dwelling older adults with or at-risk for mild cognitive impairment (MCl): neuropsychological, neurobiological and neuroimaging outcomes of a randomized clinical trial. Front Aging Neurosci. 2018;10:876 https://doi.org/10.3389/fnagi.2018.00076.

47. Wu M-T, Tang P-F, JOS G, Chou T-L, Chang Y-K, Hsu Y-C, et al. Taskswitching performance improvements after Tai Chi Chuan training are associated with greater prefrontal activation in older adults. Front Aging Neurosci. 2018:10:280. https://doi.org/10.3389/fnagi.2018.00280.

48. Hillman CH, Erickson Kl, Kramer AF. Be smart, exercise your heart: exercise effects on brain and cognition. Nat Rev Neurosci. 2008;9:58-65. https://doi. org/10.1038/nrn2298.

49. Gomes-Osman J, Cabral DF, Morris TP, Mclnerney K, Cahalin LP, Rundek T, et al. Exercise for cognitive brain health in aging. Neurol Clin Pract. 2018;8:25765. https://doi.org/10.1212/CPJ.0000000000000460.

50. Hötting K, Röder B. Beneficial effects of physical exercise on neuroplasticity and cognition. Neurosci Biobehav Rev. 2013;37:2243-57. https://doi.org/10.1 016/j.neubiorev.2013.04.005.

51. Voelcker-Rehage C, Niemann C. Structural and functional brain changes related to different types of physical activity across the life span. Neurosci Biobehav Rev. 2013;37:2268-95. https://doi.org/10.1016/j. neubiorev.2013.01.028.

52. Rolland $Y$, van Abellan $K G$, Vellas $B$. Healthy brain aging: role of exercise and physical activity. Clin Geriatr Med. 2010;26:75-87. https://doi.org/10.1016/j. cger.2009.11.002.

53. Keller $\mathrm{K}$, Engelhardt M. Strength and muscle mass loss with aging process. Age and strength loss. MLTJ. 2013;3:346-50. 
54. Kyle UG, Genton L, Hans D, Karsegard L, Slosman DO, Pichard C. Age-related differences in fat-free mass, skeletal muscle, body cell mass and fat mass between 18 and 94 years. Eur J Clin Nutr. 2001;55:663-72. https://doi.org/1 0.1038/sj.ejcn. 1601198

55. Lexell J. Human aging, muscle mass, and fiber type composition. J Gerontol A Biol Sci Med Sci. 1995;50 Spec No:11-6.

56. Janssen I, Heymsfield SB, Wang ZM, Ross R. Skeletal muscle mass and distribution in 468 men and women aged 18-88 yr. J Appl Physiol. 2000;89: 81-8. https://doi.org/10.1152/jappl.2000.89.1.81

57. Frontera WR, Hughes VA, Lutz KJ, Evans WJ. A cross-sectional study of muscle strength and mass in 45- to 78-yr-old men and women. J Appl Physiol. 1991;71:644-50. https://doi.org/10.1152/jappl.1991.71.2.644.

58. Rogers MA, Evans WJ. Changes in skeletal muscle with aging: effects of exercise training. Exerc Sport Sci Rev. 1993;21:65-102.

59. Mayer F, Scharhag-Rosenberger F, Carlsohn A, Cassel M, Müller S, Scharhag J. The intensity and effects of strength training in the elderly. Dtsch Arztebl Int. 2011;108:359-64. https://doi.org/10.3238/arztebl.2011.0359.

60. Haff G, Triplett NT, editors. Essentials of strength training and conditioning Champaign: Human Kinetics; 2016

61. Goodpaster BH, Park SW, Harris TB, Kritchevsky SB, Nevitt M, Schwartz AV, et al. The loss of skeletal muscle strength, mass, and quality in older adults: the health, aging and body composition study. J Gerontol Ser A Biol Med Sci. 2006:61:1059-64.

62. Dey DK, Bosaeus I, Lissner L, Steen B. Changes in body composition and its relation to muscle strength in 75 -year-old men and women: a 5 -year prospective follow-up study of the NORA cohort in Göteborg, Sweden. Nutrition. 2009;25:613-9. https://doi.org/10.1016/.nut.2008.11.023.

63. Koster A, Ding J, Stenholm S, Caserotti P, Houston DK, Nicklas BJ, et al. Does the amount of fat mass predict age-related loss of lean mass, muscle strength, and muscle quality in older adults? I Gerontol A Biol Sci Med Sci. 2011;66:888-95. https://doi.org/10.1093/gerona/glr070.

64. Frontera WR, Hughes VA, Fielding RA, Fiatarone MA, Evans WJ, Roubenoff R. Aging of skeletal muscle: a 12-yr longitudinal study. J Appl Physiol. 2000;88: 1321-6. https://doi.org/10.1152/jappl.2000.88.4.1321.

65. Landers KA, Hunter GR, Wetzstein CJ, Bamman MM, Weinsier RL. The interrelationship among muscle mass, strength, and the ability to perform physical tasks of daily living in younger and older women. J Gerontol Ser A Biol Med Sci. 2001;56:B443-8.

66. Amaral JF, Alvim FC, Castro EA, Doimo LA, Silva MV, Novo Júnior JM. Influence of aging on isometric muscle strength, fat-free mass and electromyographic signal power of the upper and lower limbs in women. Braz J Phys Ther. 2014; 18:183-90. https://doi.org/10.1590/S1413-35552012005000145.

67. Viitasalo JT, Era P, Leskinen A-L, Heikkinen E. Muscular strength profiles and anthropometry in random samples of men aged $31-35,51-55$ and $71-75$ years. Ergonomics. 1985;28:1563-74. https://doi.org/10.1080/001401385 08963288

68. Kemmler W, von Stengel S, Schoene D, Kohl M. Changes of maximum leg strength indices during adulthood a cross-sectional study with non-athletic men aged 19-91. Front Physiol. 2018;9:1524. https://doi.org/10.3389/fphys.2018.01524.

69. Harbo T, Brincks J, Andersen H. Maximal isokinetic and isometric muscle strength of major muscle groups related to age, body mass, height, and sex in 178 healthy subjects. Eur J Appl Physiol. 2012;112:267-75. https://doi. org/10.1007/s00421-011-1975-3.

70. Larsson L, Grimby G, Karlsson J. Muscle strength and speed of movement in relation to age and muscle morphology. J Appl Physiol Respir Environ Exerc Physiol. 1979;46:451-6. https://doi.org/10.1152/jappl.1979.46.3.451.

71. Overend TJ, Cunningham DA, Kramer JF, Lefcoe MS, Paterson DH. Knee extensor and knee flexor strength: cross-sectional area ratios in young and elderly men. J Gerontol. 1992;47:M204-10.

72. Faulkner JA, Larkin LM, Claflin DR, Brooks SV. Age-related changes in the structure and function of skeletal muscles. Clin Exp Pharmacol Physiol. 2007; 34:1091-6. https://doi.org/10.1111/j.1440-1681.2007.04752.x.

73. Lexell J, Taylor CC, Sjöström M. What is the cause of the ageing atrophy? J Neurol Sci. 1988;84:275-94. https://doi.org/10.1016/0022-510X(88)90132-3.

74. Wolfson L, JUDGE J, Whipple R, King M. Strength is a major factor in balance, gait, and the occurrence of falls. J Gerontol A Biol Sci Med Sci. 1995;50 Spec No:64-7.

75. Hicks GE, Shardell M, Alley DE, Miller RR, Bandinelli S, Guralnik J, et al. Absolute strength and loss of strength as predictors of mobility decline in older adults: the InCHIANTI study. J Gerontol Ser A Biol Med Sci. 2012;67A: 66-73. https://doi.org/10.1093/gerona/glr055 .
76. Manini TM, Visser M, Won-Park S, Patel KV, Strotmeyer ES, Chen H, et al. Knee extension strength cutpoints for maintaining mobility. J Am Geriatr Soc. 2007;55:451-7. https://doi.org/10.1111/j.1532-5415.2007.01087.x

77. Roshanravan B, Patel KV, Fried LF, Robinson-Cohen C, de Boer IH, Harris T, et al. Association of muscle endurance, fatigability, and strength with functional limitation and mortality in the health aging and body composition study. J Gerontol A Biol Sci Med Sci. 2017;72:284-91. https:// doi.org/10.1093/gerona/glw210.

78. Visser M, Goodpaster BH, Kritchevsky SB, Newman AB, Nevitt M, Rubin SM, et al. Muscle mass, muscle strength, and muscle fat infiltration as predictors of incident mobility limitations in well-functioning older persons. I Gerontol Ser A Biol Med Sci. 2005;60:324-33. https://doi.org/10.1093/gerona/60.3.324.

79. Newman AB, Kupelian V, Visser M, Simonsick EM, Goodpaster BH, Kritchevsky SB, et al. Strength, but not muscle mass, is associated with mortality in the health, aging and body composition study cohort. J Gerontol Ser A Biol Med Sci. 2006;61:72-7. https://doi.org/10.1093/ gerona/61.1.72.

80. Swallow EB, Reyes D, Hopkinson NS, Man WD-C, Porcher R, Cetti EJ, et al. Quadriceps strength predicts mortality in patients with moderate to severe chronic obstructive pulmonary disease. Thorax. 2007;62:115-20. https://doi. org/10.1136/thx.2006.062026

81. Nakamoto H, Yoshitake Y, Takai Y, Kanehisa H, Kitamura T, Kawanishi M, Mori S. Knee extensor strength is associated with mini-mental state examination scores in elderly men. Eur J Appl Physiol. 2012;112:1945-53. https://doi.org/10.1007/s00421-011-2176-9.

82. Chen W-L, Peng T-C, Sun Y-S, Yang H-F, Liaw F-Y, Wu L-W, et al. Examining the association between quadriceps strength and cognitive performance in the elderly. Medicine (Baltimore). 2015;94:e1335. https://doi.org/10.1097/MD. 0000000000001335 .

83. Frith $\mathrm{E}$, Loprinzi PD. The association between lower extremity muscular strength and cognitive function in a national sample of older adults. J Lifestyle Med. 2018;8:99-104. https://doi.org/10.15280/Jlm.2018.8.2.99.

84. Steves CJ, Mehta MM, Jackson SHD, Spector TD. Kicking back cognitive ageing: leg power predicts cognitive ageing after ten years in older female twins. Gerontology. 2016;62:138-49. https://doi.org/10.1159/000441029.

85. Pentikäinen $\mathrm{H}$, Savonen $\mathrm{K}$, Komulainen $\mathrm{P}$, Kiviniemi V, Paajanen T, Kivipelto $M$, et al. Muscle strength and cognition in ageing men and women: the DR's EXTRA study. Eur Geriatr Med. 2017;8:275-7. https://doi.org/10.1016/j. eurger.2017.04.004.

86. Alfaro-Acha A, Al Snih S, Raji MA, Kuo Y-F, Markides KS, Ottenbacher KJ. Handgrip strength and cognitive decline in older Mexican Americans. J Gerontol Ser A Biol Med Sci. 2006;61:859-65.

87. van Dam R, van Ancum JM, Verlaan S, Scheerman K, Meskers CGM, Maier $A B$. Lower cognitive function in older patients with lower muscle strength and muscle mass. Dement Geriatr Cogn Disord. 2018:45:243-50. https://doi. org/10.1159/000486711.

88. Firth J, Firth JA, Stubbs B, Vancampfort D, Schuch FB, Hallgren M, et al. Association between muscular strength and cognition in people with major depression or bipolar disorder and healthy controls. JAMA Psychiatry. 2018. https://doi.org/10.1001/jamapsychiatry.2018.0503.

89. Firth J, Stubbs B, Vancampfort D, Firth JA, Large M, Rosenbaum S, et al. Grip strength is associated with cognitive performance in schizophrenia and the general population: a UK biobank study of 476559 participants. Schizophr Bull. 2018;44:728-36. https://doi.org/10.1093/schbul/sby034.

90. Sternäng O, Reynolds CA, Finkel D, Ernsth-Bravell M, Pedersen NL, Dahl Aslan AK. Grip strength and cognitive abilities: associations in old age. J Gerontol B Psychol Sci Soc Sci. 2016;71:841-8. https://doi.org/10.1093/ geronb/gbv017.

91. Mavros Y, Gates N, Wilson GC, Jain N, Meiklejohn J, Brodaty H, et al. Mediation of cognitive function improvements by strength gains after resistance training in older adults with mild cognitive impairment: outcomes of the study of mental and resistance training. J Am Geriatr Soc. 2017;65:550-9. https://doi.org/10.1111/jgs.14542.

92. Forte R, Boreham CAG, Leite JC, de Vito G, Brennan L, Gibney ER, Pesce C. Enhancing cognitive functioning in the elderly: multicomponent vs resistance training. Clin Interv Aging. 2013;8:19-27. https://doi.org/10.2147/ CIA.S36514.

93. Kilgour AHM, Todd OM, Starr JM. A systematic review of the evidence that brain structure is related to muscle structure and their relationship to brain and muscle function in humans over the lifecourse. BMC Geriatr. 2014;14:85. https://doi.org/10.1186/1471-2318-14-85. 
94. Ciolac EG, Rodrigues-da-Silva JM. Resistance training as a tool for preventing and treating musculoskeletal disorders. Sports Med. 2016;46:1239-48. https://doi.org/10.1007/s40279-016-0507-z.

95. Hunter GR, McCarthy JP, Bamman MM. Effects of resistance training on older adults. Sports Med. 2004;34:329-48. https://doi.org/10.2165/ 00007256-200434050-00005.

96. Hurley BF, Hanson ED, Sheaff AK. Strength training as a countermeasure to aging muscle and chronic disease. Sports Med. 2011;41:289-306. https://doi. org/10.2165/11585920-000000000-00000.

97. Hurley BF, Roth SM. Strength training in the elderly. Sports Med. 2000;30: 249-68. https://doi.org/10.2165/00007256-200030040-00002.

98. Hurley B. Does strength training improve health status? Strength Cond J. 1994:16:7-13.

99. Kraemer WJ, Ratamess NA, French DN. Resistance training for health and performance. Curr Sports Med Rep. 2002;1:165-71. https://doi.org/10.1249/ 00149619-200206000-00007.

100. Latham NK, Bennett DA, Stretton CM, Anderson CS. Systematic review of progressive resistance strength training in older adults. J Gerontol Ser A Biol Med Sci. 2004:59:48-61.

101. Seguin R, Nelson ME. The benefits of strength training for older adults. Am J Prev Med. 2003;25:141-9. https://doi.org/10.1016/S0749-3797(03)00177-6.

102. Shaw BS, Shaw I, Brown GA. Resistance exercise is medicine: strength training in health promotion and rehabilitation. Int J Ther Rehabil. 2015;22: 385-9. https://doi.org/10.12968/ijtr.2015.22.8.385.

103. Westcott WL. Resistance training is medicine: effects of strength training on health. Curr Sports Med Rep. 2012;11:209-16. https://doi.org/10.1249/JSR. Ob013e31825dabb8.

104. Winett RA, Carpinelli RN. Potential health-related benefits of resistance training. Prev Med. 2001;33:503-13. https://doi.org/10.1006/pmed.2001.0909.

105. Wilke J, Giesche F, Klier K, Vogt L, Herrmann E, Banzer W. Acute effects of resistance exercise on cognitive function in healthy adults: a systematic review with multilevel meta-analysis. Sports Med. 2019. https://doi.org/10.1 007/s40279-019-01085-x

106. Köppel M, Hamacher D. Kräftigung wider das Altern. B \& G. 2018;34:218-24. https://doi.org/10.1055/a-0670-5030

107. Chang Y-K, Pan C-Y, Chen F-T, Tsai C-L, Huang C-C. Effect of resistanceexercise training on cognitive function in healthy older adults: a review. J Aging Phys Act. 2012;20:497-517. https://doi.org/10.1123/japa.20.4.497.

108. Soga K, Masaki H, Gerber M, Ludyga S. Acute and long-term effects of resistance training on executive function. J Cogn Enhanc. 2018:56:729. https://doi.org/10.1007/s41465-018-0079-y.

109. Li Z, Peng $X$, Xiang W, Han J, Li K. The effect of resistance training on cognitive function in the older adults: a systematic review of randomized clinical trials. Aging Clin Exp Res. 2018. https://doi.org/10.1007/s40520-0180998-6.

110. Landrigan J-F, Bell T, Crowe M, Clay OJ, Mirman D. Lifting cognition: a metaanalysis of effects of resistance exercise on cognition. Psychol Res. 2019. https://doi.org/10.1007/s00426-019-01145-X.

111. Wang S, Yin H, Wang $X$, Jia $Y$, Wang C, Wang L, Chen L. Efficacy of different types of exercises on global cognition in adults with mild cognitive impairment: a network meta-analysis. Aging Clin Exp Res. 2019. https://doi. org/10.1007/s40520-019-01142-5.

112. Stillman CM, Cohen J, Lehman ME, Erickson Kl. Mediators of physical activity on neurocognitive function: a review at multiple levels of analysis. Front Hum Neurosci. 2016;10:626. https://doi.org/10.3389/fnhum.2016.00626.

113. Törpel A, Herold F, Hamacher D, Müller NG, Schega L. Strengthening the brain-is resistance training with blood flow restriction an effective strategy for cognitive improvement? J Clin Med. 2018;7:377. https://doi.org/10.3390/ jem7100337.

114. Stimpson NJ, Davison G, Javadi A-H. Joggin' the noggin: towards a physiological understanding of exercise-induced cognitive benefits. Neurosci Biobehav Rev. 2018;88:177-86. https://doi.org/10.1016/j.neubiorev.2 018.03.018.

115. Audiffren M, André N. The exercise-cognition relationship: a virtuous circle. J Sport Health Sci. 2019. https://doi.org/10.1016/j.jshs.2019.03.001.

116. Basso JC, Suzuki WA. The effects of acute exercise on mood, cognition, neurophysiology, and neurochemical pathways: a review. BPL. 2017;2:12752. https://doi.org/10.3233/BPL-160040.

117. Voss MW, Vivar C, Kramer AF, van Praag H. Bridging animal and human models of exercise-induced brain plasticity. Trends Cogn Sci. 2013;17:52544. https://doi.org/10.1016/j.tics.2013.08.001
118. Cotman CW, Berchtold NC. Exercise: a behavioral intervention to enhance brain health and plasticity. Trends Neurosci. 2002;25:295-301.

119. Cotman CW, Berchtold NC, Christie L-A. Exercise builds brain health: key roles of growth factor cascades and inflammation. Trends Neurosci. 2007;30: 464-72. https://doi.org/10.1016/j.tins.2007.06.011.

120. Brigadski T, Leßmann V. BDNF: a regulator of learning and memory processes with clinical potential. e-Neuroforum. 2014;5:1-11. https://doi. org/10.1007/s13295-014-0053-9.

121. Marston KJ, Brown BM, Rainey-Smith SR, Peiffer JJ. Resistance exerciseinduced responses in physiological factors linked with cognitive health. J Alzheimers Dis. 2019. https://doi.org/10.3233/JAD-181079.

122. Stillman CM, Erickson Kl. Physical activity as a model for health neuroscience. Ann N Y Acad Sci. 2018. https://doi.org/10.1111/nyas.13669.

123. Buford TW, Pahor M. Making preventive medicine more personalized: implications for exercise-related research. Prev Med. 2012:55:34-6. https:// doi.org/10.1016/j.ypmed.2012.05.001.

124. Buford TW, Roberts MD, Church TS. Toward exercise as personalized medicine. Sports Med. 2013;43:157-65. https://doi.org/10.1007/s40279013-0018-0.

125. Müller P, Rehfeld K, Schmicker M, Müller N. P52. Future directions for physical exercise as personalized medicine. Clin Neurophysiol. 2018;129:e88. https://doi.org/10.1016/j.clinph.2018.04.689.

126. Moher D, Liberati A, Tetzlaff J, Altman DG. Preferred reporting items for systematic reviews and meta-analyses: the PRISMA statement. J Clin Epidemiol. 2009;62:1006-12. https://doi.org/10.1016/j.jclinepi.2009.06.005.

127. Harris JD, Quatman CE, Manring MM, Siston RA, Flanigan DC. How to write a systematic review. Am J Sports Med. 2014;42:2761-8. https://doi.org/10.11 77/0363546513497567.

128. Formenti D, Perpetuini D, lodice P, Cardone D, Michielon G, Scurati R, et al. Effects of knee extension with different speeds of movement on muscle and cerebral oxygenation. PeerJ. 2018;6:e5704. https://doi.org/10.7717/peerj.5704.

129. Woodward ML, Gicas KM, Warburton DE, White RF, Rauscher A, Leonova O, et al. Hippocampal volume and vasculature before and after exercise in treatment-resistant schizophrenia. Schizophr Res. 2018;202:158-65. https:// doi.org/10.1016/j.schres.2018.06.054

130. Kim YS, Shin SK, Hong SB, Kim HJ. The effects of strength exercise on hippocampus volume and functional fitness of older women. Exp Gerontol. 2017:97:22-8. https://doi.org/10.1016/j.exger.2017.07.007.

131. Fontes EB, Libardi CA, Castellano G, Okano AH, Fernandes PT, Chacon-Mikahil $M P$, et al. Effects of resistance training in gray matter density of elderly. Sport Sci Health. 2017;13:233-8. https://doi.org/10.1007/s11332-016-0298-5.

132. Palmer HS, Håberg AK, Fimland MS, Solstad GM, Moe Iversen V, Hoff J, et al. Structural brain changes after 4 wk of unilateral strength training of the lower limb. J Appl Physiol. 2013;115:167-75. https://doi.org/10.1152/ japplphysiol.00277.2012.

133. Griffin L, Cafarelli E. Resistance training: cortical, spinal, and motor unit adaptations. Can J Appl Physiol. 2005;30:328-40. https://doi.org/10.1139/ h05-125.

134. Olsson C-J, Hedlund M, Sojka P, Lundström R, Lindström B. Increased prefrontal activity and reduced motor cortex activity during imagined eccentric compared to concentric muscle actions. Front Hum Neurosci. 2012;6:255. https://doi.org/10.3389/fnhum.2012.00255.

135. Matsuura C, Gomes PSC, Haykowsky M, Bhambhani Y. Cerebral and muscle oxygenation changes during static and dynamic knee extensions to voluntary fatigue in healthy men and women: a near infrared spectroscopy study. Clin Physiol Funct Imaging. 2011;31:114-23. https://doi.org/10.1111/ j.1475-097X.2010.00986.X.

136. Alves CR, Gualano B, Takao PP, Avakian P, Fernandes RM, Morine D, Takito MY. Effects of acute physical exercise on executive functions: a comparison between aerobic and strength exercise. J Sport Exerc Psychol. 2012;34:539-49.

137. Cassilhas RC, Viana VAR, Grassmann V, Santos RT, Santos RF, Tufik SE, Mello MT. The impact of resistance exercise on the cognitive function of the elderly. Med Sci Sports Exerc. 2007;39:1401-7. https://doi.org/10.1249/mss. ob013e318060111f.

138. Chang Y-K, Etnier JL. Exploring the dose-response relationship between resistance exercise intensity and cognitive function. J Sport Exerc Psychol. 2009;31:640-56. https://doi.org/10.1123/jsep.31.5.640

139. Gates NJ, Valenzuela M, Sachdev PS, Singh NA, Baune BT, Brodaty H, et al. Study of mental Activity and regular training (SMART) in at risk individuals: a randomised double blind, sham controlled, longitudinal trial. BMC Geriatr. 2011;11:19. https://doi.org/10.1186/1471-2318-11-19. 
140. Johnson L, Addamo PK, Selva Raj I, Borkoles E, Wyckelsma V, Cyarto E, Polman RC. An acute bout of exercise improves the cognitive performance of older adults. J Aging Phys Act. 2016;24:591-8. https://doi.org/10.1123/ japa.2015-0097.

141. Schega L, Peter B, Törpel A, Mutschler H, Isermann B, Hamacher D. Effects of intermittent hypoxia on cognitive performance and quality of life in elderly adults: a pilot study. Gerontology. 2013;59:316-23. https://doi.org/10.1159/ 000350927.

142. Weinberg L, Hasni A, Shinohara M, Duarte A. A single bout of resistance exercise can enhance episodic memory performance. Acta Psychol. 2014; 153:13-9. https://doi.org/10.1016/j.actpsy.2014.06.011.

143. Marzolini S, Oh P, Mcllroy W, Brooks D. The effects of an aerobic and resistance exercise training program on cognition following stroke. Neurorehabil Neural Repair. 2013;27:392-402. https://doi.org/10.1177/154596 8312465192.

144. Anderson-Hanley C, Nimon JP, Westen SC. Cognitive health benefits of strengthening exercise for community-dwelling older adults. J Clin Exp Neuropsychol. 2010;32:996-1001. https://doi.org/10.1080/13803391003662702.

145. Ansai JH, Rebelatto JR. Effect of two physical exercise protocols on cognition and depressive symptoms in oldest-old people: a randomized controlled trial. Geriatr Gerontol Int. 2015;15:1127-34. https://doi.org/1 $0.1111 /$ ggi.12411.

146. Brush CJ, Olson RL, Ehmann PJ, Osovsky S, Alderman BL. Dose-response and time course effects of acute resistance exercise on executive function. J Sport Exerc Psychol. 2016;38:396-408. https://doi.org/10.1123/jsep.2016-0027.

147. Chang Y-K, Etnier JL. Effects of an acute bout of localized resistance exercise on cognitive performance in middle-aged adults: a randomized controlled trial study. Psychol Sport Exerc. 2009;10:19-24. https://doi.org/10.1016/j. psychsport.2008.05.004

148. Chang Y-K, Tsai C-L, Huang C-C, Wang C-C, Chu I-H. Effects of acute resistance exercise on cognition in late middle-aged adults: general or specific cognitive improvement? J Sci Med Sport. 2014;17:51-5. https://doi. org/10.1016/j.jsams.2013.02.007.

149. Cuttler C, Connolly CP, LaFrance EM, Lowry TM. Resist forgetting: effects of aerobic and resistance exercise on prospective and retrospective memory. Sport Exerc Perform Psychol. 2018;7:205-17. https://doi.org/10.1037/ spy0000112.

150. Helmes $\mathrm{E}$, Harris S. Exercise and executive functioning in older women. J Women Aging. 2017;29:376-84. https://doi.org/10.1080/08952841.2 016.1256736.

151. Hsieh S-S, Chang Y-K, Fang C-L, Hung T-M. Acute resistance exercise facilitates attention control in adult males without an age-moderating effect. J Sport Exerc Psychol. 2016;38:247-54. https://doi.org/10.1123/jsep.2015-0282.

152. Hsieh S-S, Chang Y-K, Hung T-M, Fang C-L. The effects of acute resistance exercise on young and older males' working memory. Psychol Sport Exerc. 2016;22:286-93. https://doi.org/10.1016/j.psychsport.2015.09.004.

153. Kierkegaard $M$, Lundberg IE, Olsson T, Johansson S, Ygberg S, Opava C, et al. High-intensity resistance training in multiple sclerosis - an exploratory study of effects on immune markers in blood and cerebrospinal fluid, and on mood, fatigue, health-related quality of life, muscle strength, walking and cognition. J Neurol Sci. 2016;362:251-7. https://doi.org/10.1016/j.jns.2016.01.063.

154. Lachman ME, Neupert SD, Bertrand R, Jette AM. The effects of strength training on memory in older adults. JAPA. 2006;14:59-73.

155. Loprinzi PD. Epidemiological investigation of muscle-strengthening activities and cognitive function among older adults. Chronic IIIn. 2016;12:157-62. https://doi.org/10.1177/1742395316641998.

156. Naderi A, Shaabani F, Esmaeili A, Salman Z, Borella E, Degens H. Effects of low and moderate acute resistance exercise on executive function in community-living older adults. Sport Exerc Perform Psychol. 2018. https:// doi.org/10.1037/spy0000135.

157. Quintero AP, Bonilla-Vargas KJ, Correa-Bautista JE, Domínguez-Sanchéz MA, Triana-Reina HR, Velasco-Orjuela GP, et al. Acute effect of three different exercise training modalities on executive function in overweight inactive men: a secondary analysis of the BrainFit study. Physiol Behav. 2018;197:228. https://doi.org/10.1016/j.physbeh.2018.09.010.

158. Ruiz JR, Gil-Bea F, Bustamante-Ara N, Rodríguez-Romo G, Fiuza-Luces C, Serra-Rexach JA, et al. Resistance training does not have an effect on cognition or related serum biomarkers in nonagenarians: a randomized controlled trial. Int J Sports Med. 2015:36:54-60. https://doi.org/10.1055/s0034-1375693.
159. Taheri M, Irandoost K, Yousefi S, Jamali A. Effect of 8-week lower extremity weight-bearing exercise protocol and acute caffeine consumption on reaction time in postmenopausal women. Salmand. 2017;12:16-27. https:// doi.org/10.21859/sija-120116.

160. Ikudome S, Mori S, Unenaka S, Kawanishi M, Kitamura T, Nakamoto H. Effect of long-term body-mass-based resistance exercise on cognitive function in elderly people. J Appl Gerontol. 2017;36:1519-33. https://doi.org/10.1177/ 0733464815625834

161. Sandroff BM, Motl RW. Fitness and cognitive processing speed in persons with multiple sclerosis: a cross-sectional investigation. J Clin Exp Neuropsychol. 2012;34:1041-52. https://doi.org/10.1080/13803395.2012.715144.

162. Strassnig MT, Signorile JF, Potiaumpai M, Romero MA, Gonzalez C, Czaja S, Harvey PD. High velocity circuit resistance training improves cognition, psychiatric symptoms and neuromuscular performance in overweight outpatients with severe mental illness. Psychiatry Res. 2015;229:295-301. https://doi.org/10.1016/j.psychres.2015.07.007.

163. Vital TM, Hernández SSS, Pedroso RV, Teixeira CVL, Garuffi M, Stein AM, et al. Effects of weight training on cognitive functions in elderly with Alzheimer's disease. Dement Neuropsychol. 2012;6:253-9. https://doi.org/10.1590/S1 980-57642012DN06040009.

164. Fanning J, Walkup MP, Ambrosius WT, Brawley LR, Ip EH, Marsh AP, Rejeski WJ. Change in health-related quality of life and social cognitive outcomes in obese, older adults in a randomized controlled weight loss trial: does physical activity behavior matter? J Behav Med. 2018;41:299-308. https://doi. org/10.1007/s10865-017-9903-6.

165. Davis JC, Bryan S, Marra CA, Sharma D, Chan A, Beattie BL, et al. An economic evaluation of resistance training and aerobic training versus balance and toning exercises in older adults with mild cognitive impairment. PLoS One. 2013;8:e63031. https:/doi.org/10.1371/journal.pone.0063031.

166. Dao E, Davis JC, Sharma D, Chan A, Nagamatsu LS, Liu-Ambrose T. Change in body fat mass is independently associated with executive functions in older women: a secondary analysis of a 12-month randomized controlled trial. PLoS One. 2013;8:e52831. https://doi.org/10.1371/journal.pone.0052831.

167. Timmons JF, Minnock D, Hone M, Cogan KE, Murphy JC, Egan B. Comparison of time-matched aerobic, resistance, or concurrent exercise training in older adults. Scand J Med Sci Sports. 2018;28:2272-83. https:// doi.org/10.1111/sms.13254.

168. Lee DR, Kim YH, Kim DA, Lee JA, Hwang PW, Lee MJ, You SH. Innovative strength training-induced neuroplasticity and increased muscle size and strength in children with spastic cerebral palsy: an experimenter-blind case study -three-month follow-up. NeuroRehabilitation. 2014;35:131-6. https:// doi.org/10.3233/NRE-131036.

169. Best JR, Nagamatsu LS, Liu-Ambrose T. Improvements to executive function during exercise training predict maintenance of physical activity over the following year. Front Hum Neurosci. 2014;8:97. https://doi.org/10.3389/ fnhum.2014.00353.

170. Fernandez-Gonzalo R, Fernandez-Gonzalo S, Turon M, Prieto C, Tesch PA, García-Carreira MC. Muscle, functional and cognitive adaptations after flywheel resistance training in stroke patients: a pilot randomized controlled trial. J Neuroeng Rehabil. 2016;13:37. https://doi.org/10.1186/s12984-016-0144-7.

171. Broman-Fulks JJ, Kelso K, Zawilinski L. Effects of a single bout of aerobic exercise versus resistance training on cognitive vulnerabilities for anxiety disorders. Cogn Behav Ther. 2015;44:240-51. https://doi.org/10.1080/16506 073.2015.1020448.

172. The Cochrane Collaboration. Review Manager (RevMan 5.3) [Computer program]. 2014. https://community.cochrane.org/help/tools-and-software/revman-5.

173. Hecksteden A, Faude O, Meyer T, Donath L. How to construct, conduct and analyze an exercise training study? Front Physiol. 2018;9:239. https://doi. org/10.3389/fphys.2018.01007.

174. Budde H, Schwarz R, Velasques B, Ribeiro P, Holzweg M, Machado S, et al. The need for differentiating between exercise, physical activity, and training. Autoimmun Rev. 2016;15:110-1. https://doi.org/10.1016/j.autrev.2015.09.004.

175. Ainsworth BE, Haskell WL, Whitt MC, Irwin ML, Swartz AM, Strath SJ, et al. Compendium of physical activities: an update of activity codes and MET intensities. Med Sci Sports Exerc. 2000;32:S498-504

176. Caspersen CJ, Powell KE, Christenson GM. Physical activity, exercise, and physical fitness: definitions and distinctions for health-related research. Public Health Rep. 1985;100:126-31.

177. Howley ET. Type of activity: resistance, aerobic and leisure versus occupational physical activity. Med Sci Sports Exerc. 2001;33:S364-9 discussion S419-20. 
178. Herold F, Hamacher D, Schega L, Müller NG. Thinking while moving or moving while thinking - concepts of motor-cognitive training for cognitive performance enhancement. Front Aging Neurosci. 2018;10:1-11. https://doi. org/10.3389/fnagi.2018.00228.

179. Pontifex MB, McGowan AL, Chandler MC, Gwizdala KL, Parks AC, Fenn K, Kamijo K. A primer on investigating the after effects of acute bouts of physical activity on cognition. Psychol Sport Exerc. 2018. https://doi.org/10.1 016/j.psychsport.2018.08.015.

180. Herold F, Wiegel P, Scholkmann F, Müller NG. Applications of functional near-infrared spectroscopy ( $\mathrm{fNIRS)}$ neuroimaging in exercise-cognition science: a systematic, methodology-focused review. J Clin Med. 2018. https://doi.org/10.3390/jcm7120466

181. Higgins JPT, Altman DG, Gotzsche PC, Juni P, Moher D, Oxman AD, et al. The Cochrane Collaboration's tool for assessing risk of bias in randomised trials. BMJ. 2011;343:d5928. https://doi.org/10.1136/bmj.d5928.

182. Tsai C-L, Wang C-H, Pan C-Y, Chen F-C, Huang T-H, Chou F-Y. Executive function and endocrinological responses to acute resistance exercise. Front Behav Neurosci. 2014;8:262. https://doi.org/10.3389/fnbeh.2014.00262.

183. Vonk M, Wikkerink S, Regan K, Middleton LE. Similar changes in executive function after moderate resistance training and loadless movement. PLoS One. 2019;14:e0212122. https://doi.org/10.1371/journal.pone.0212122.

184. Best JR, Chiu BK, Liang Hsu C, Nagamatsu LS, Liu-Ambrose T. Long-term effects of resistance exercise training on cognition and brain volume in older women: results from a randomized controlled trial. J Int Neuropsychol Soc. 2015;21:745-56. https://doi.org/10.1017/S1355617715000673.

185. Bolandzadeh N, Tam R, Handy TC, Nagamatsu LS, Hsu CL, Davis JC, et al. Resistance training and White matter lesion progression in older women: exploratory analysis of a 12-month randomized controlled trial. J Am Geriatr Soc. 2015;63:2052-60. https://doi.org/10.1111/jgs.13644.

186. Liu-Ambrose T, Nagamatsu LS, Graf P, Beattie BL, Ashe MC, Handy TC Resistance training and executive functions: a 12-month randomized controlled trial. Arch Intern Med. 2010;170:170-8. https://doi.org/10.1001/ archinternmed.2009.494.

187. Tsai C-L, Wang C-H, Pan C-Y, Chen F-C. The effects of long-term resistance exercise on the relationship between neurocognitive performance and $\mathrm{GH}$, IGF-1, and homocysteine levels in the elderly. Front Behav Neurosci. 2015;9: 471. https://doi.org/10.3389/fnbeh.2015.00023.

188. Hong S-G, Kim J-H, Jun T-W. Effects of 12-week resistance exercise on electroencephalogram patterns and cognitive function in the elderly with mild cognitive impairment: a randomized controlled trial. Clin J Sport Med. 2017. https://doi.org/10.1097/JSM.0000000000000476.

189. Nagamatsu LS, Handy TC, Hsu CL, Voss M, Liu-Ambrose T. Resistance training promotes cognitive and functional brain plasticity in seniors with probable mild cognitive impairment. Arch Intern Med. 2012;172:666-8. https://doi.org/10.1001/archinternmed.2012.379.

190. Suo C, Singh MF, Gates N, Wen W, Sachdev P, Brodaty H, et al. Therapeutically relevant structural and functional mechanisms triggered by physical and cognitive exercise. Mol Psychiatry. 2016;21:1633-42. https://doi. org/10.1038/mp.2016.19.

191. Tsai C-L, Pai M-C, Ukropec J, Ukropcová B. Distinctive effects of aerobic and resistance exercise modes on neurocognitive and biochemical changes in individuals with mild cognitive impairment. Curr Alzheimer Res. 2019. https://doi.org/10.2174/1567205016666190228125429.

192. Yerokhin V, Anderson-Hanley C, Hogan MJ, Dunnam M, Huber D, Osborne S, Shulan M. Neuropsychological and neurophysiological effects of strengthening exercise for early dementia: a pilot study. Neuropsychol Dev Cogn B Aging Neuropsychol Cogn. 2012;19:380-401. https://doi.org/10.1 080/13825585.2011.628378.

193. Kjølhede T, Siemonsen S, Wenzel D, Stellmann J-P, Ringgaard S, Pedersen $\mathrm{BG}$, et al. Can resistance training impact MRI outcomes in relapsingremitting multiple sclerosis? Mult Scler. 2018;24:1356-65. https://doi.org/1 $0.1177 / 1352458517722645$

194. Özkaya GY, Aydin H, Toraman FN, Kizilay F, Ozdemir O, Cetinkaya V. Effect of strength and endurance training on cognition in older people. J Sports Sci Med. 2005:4:300-13.

195. Tsai C-L, Ukropec J, Ukropcová B, Pai M-C. An acute bout of aerobic or strength exercise specifically modifies circulating exerkine levels and neurocognitive functions in elderly individuals with mild cognitive impairment. Neuroimage Clin. 2018;17:272-84. https://doi.org/10.1016/j.nicl.2017.10.028.

196. Seguin R, Epping JN, Buchner DM, Bloch R, Nelson ME. Growing Stronger Strength Training for Older Adults. Boston: US Department of Health; 2002.
197. ten Brinke LF, Bolandzadeh N, Nagamatsu LS, Hsu CL, Davis JC, Miran-Khan K, Liu-Ambrose T. Aerobic exercise increases hippocampal volume in older women with probable mild cognitive impairment: a 6-month randomised controlled trial. Br J Sports Med. 2015;49:248-54. https://doi.org/10.1136/ bjsports-2013-093184.

198. Kjølhede T, Vissing K, de Place L, Pedersen BG, Ringgaard S, Stenager E, et al. Neuromuscular adaptations to long-term progressive resistance training translates to improved functional capacity for people with multiple sclerosis and is maintained at follow-up. Mult Scler. 2015;21:599-611. https://doi. org/10.1177/1352458514549402.

199. Klem GH, Lüders HO, Jasper HH, Elger C. The ten-twenty electrode system of the international federation. The International Federation of Clinical Neurophysiology. Electroencephalogr Clin Neurophysiol Suppl. 1999;52:3-6.

200. Hillman CH, Kamijo K, Pontifex MB. The relation of ERP indices of exercise to brain health and cognition. In: Boecker H, Hillman CH, Scheef L, Strüder HK, editors. Functional neuroimaging in exercise and sport sciences. New York: Springer New York; 2012. p. 419-46. https://doi.org/10.1007/978-1-4614-3293-7_18.

201. Kamijo K. Physical activity, fitness, and cognition. In: Exercise-cognition interaction: Elsevier; 2016. p. 211-26. https://doi.org/10.1016/B978-0-12800778-5.00010-4.

202. Schulz KF, Altman DG, Moher D. CONSORT 2010 statement: updated guidelines for reporting parallel group randomised trials. Trials. 2010;11:32. https://doi.org/10.1186/1745-6215-11-32.

203. von Elm E, Altman DG, Egger M, Pocock SJ, Gotzsche PC, Vandenbroucke JP. Strengthening the reporting of observational studies in epidemiology (STROBE) statement: guidelines for reporting observational studies: guidelines for reporting observational studies. BMJ. 2007;335:806-8. https:// doi.org/10.1136/bmj.39335.541782.AD.

204. Cruz-Jentoft AJ, Landi F, Schneider SM, Zúñiga C, Arai H, Boirie Y, et al. Prevalence of and interventions for sarcopenia in ageing adults: a systematic review. Report of the international sarcopenia initiative (EWGSOP and IWGS). Age Ageing. 2014;43:748-59. https://doi.org/10.1093/ageing/afu115.

205. Janssen I, Shepard DS, Katzmarzyk PT, Roubenoff R. The healthcare costs of sarcopenia in the United States. J Am Geriatr Soc. 2004;52:80-5. https://doi. org/10.1111/j.1532-5415.2004.52014.x

206. Bülow J, Ulijaszek SJ, Holm L. Rejuvenation of the term sarcopenia. J App Physiol. 2019;126:255-6. https://doi.org/10.1152/japplphysiol.00400.2018.

207. Evans WJ. What is sarcopenia? J Gerontol A Biol Sci Med Sci. 1995;50 Spec No:5-8

208. Evans WJ. Skeletal muscle loss: cachexia, sarcopenia, and inactivity. Am J Clin Nutr. 2010;91:1123S-7S. https://doi.org/10.3945/ajcn.2010.28608A.

209. Visser M, Schaap LA. Consequences of sarcopenia. Clin Geriatr Med. 2011;27: 387-99. https://doi.org/10.1016/j.cger.2011.03.006.

210. Clark BC, Manini TM. Sarcopenia =/= dynapenia. J Gerontol Ser A Biol Med Sci. 2008:63:829-34. https://doi.org/10.1093/gerona/63.8.829.

211. von Haehling S, Morley JE, Anker SD. An overview of sarcopenia: facts and numbers on prevalence and clinical impact. J Cachexia Sarcopenia Muscle. 2010;1:129-33. https://doi.org/10.1007/s13539-010-0014-2.

212. Cruz-Jentoft AJ, Baeyens JP, Bauer JM, Boirie Y, Cederholm T, Landi F, et al. Sarcopenia: European consensus on definition and diagnosis: report of the European working group on sarcopenia in older people. Age Ageing. 2010; 39:412-23. https://doi.org/10.1093/ageing/afq034.

213. Doherty TJ. Invited review: aging and sarcopenia. J Appl Physiol. 2003;95: 1717-27. https://doi.org/10.1152/japplphysiol.00347.2003.

214. Greenlund L. Sarcopenia_consequences, mechanisms, and potential therapies. Mech Ageing Dev. 2003;124:287-99. https://doi.org/10.1016/S004 7-6374(02)00196-3.

215. Rolland Y, Czerwinski S, van Kan GA, Morley JE, Cesari M, Onder G, et al. Sarcopenia: its assessment, etiology, pathogenesis, consequences and future perspectives. J Nutr Health Aging. 2008;12:433-50. https:/doi.org/10.1007/BF02982704.

216. Roubenoff R. Sarcopenia and its implications for the elderly. Eur J Clin Nutr. 2000:54:S40-7. https://doi.org/10.1038/sj.ejen.1601024.

217. Roubenoff R, Hughes VA. Sarcopenia: current concepts. J Gerontol Ser A Biol Med Sci. 2000;55:M716-24.

218. Sayer AA, Robinson SM, Patel HP, Shavlakadze T, Cooper C, Grounds MD. New horizons in the pathogenesis, diagnosis and management of sarcopenia. Age Ageing. 2013;42:145-50. https://doi.org/10.1093/ageing/afs191.

219. Narici MV, Maffulli N. Sarcopenia: characteristics, mechanisms and functional significance. Br Med Bull. 2010;95:139-59. https:/doi.org/10.1093/bmb/ldq008.

220. Clark BC, Manini TM. What is dynapenia? Nutrition. 2012:28:495-503. https:// doi.org/10.1016/j.nut.2011.12.002. 
221. Chang K-V, Hsu T-H, Wu W-T, Huang K-C, Han D-S. Association between sarcopenia and cognitive impairment: a systematic review and metaanalysis. J Am Med Dir Assoc. 2016;17:1164.e7-1164.e15. https://doi.org/10.1 016/j.jamda.2016.09.013.

222. Nishiguchi S, Yamada M, Shirooka H, Nozaki Y, Fukutani N, Tashiro Y, et al. Sarcopenia as a risk factor for cognitive deterioration in communitydwelling older adults: a 1-year prospective study. J Am Med Dir Assoc. 2016; 17:372.e5-8. https://doi.org/10.1016/j.jamda.2015.12.096.

223. Barha CK, Galea LA, Nagamatsu LS, Erickson Kl, Liu-Ambrose T. Personalising exercise recommendations for brain health: considerations and future directions. Br J Sports Med. 2017;51:636-9. https://doi.org/10.1136/bjsports-2 016-096710.

224. Loprinzi PD, Frith $\mathrm{E}$. The role of sex in memory function: considerations and recommendations in the context of exercise. J Clin Med. 2018. https://doi. org/10.3390/jcm7060132.

225. Barha CK, Davis JC, Falck RS, Nagamatsu LS, Liu-Ambrose T. Sex differences in exercise efficacy to improve cognition: a systematic review and metaanalysis of randomized controlled trials in older humans. Front Neuroendocrinol. 2017. https://doi.org/10.1016/j.yfrne.2017.04.002.

226. Barha CK, Liu-Ambrose T. Exercise and the aging brain: considerations for sex differences. BPL. 2018;3:1-11. https://doi.org/10.3233/BPL-1867.

227. Jones N, Kiely J, Suraci B, Collins D, de Lorenzo D, Pickering C, Grimaldi K. A genetic-based algorithm for personalized resistance-training. Biol Sport. 2016;33:117-26. https://doi.org/10.5604/20831862.1198210.

228. Pickering C, Kiely J. Understanding personalized training responses: can genetic assessment help? Open Sports Sci J. 2017;10:191-213. https://doi. org/10.2174/1875399X01710010191.

229. Camera DM. Anabolic heterogeneity following resistance training: a role for circadian rhythm? Front Physiol. 2018;9:569. https://doi.org/10.3389/fphys.2 018.00569.

230. Chtourou H, Souissi $N$. The effect of training at a specific time of day: a review. J Strength Cond Res. 2012;26:1984-2005. https://doi.org/10.1519/JSC. Ob013e31825770a7.

231. Grgic J, Lazinica B, Garofolini A, Schoenfeld BJ, Saner NJ, Mikulic P. The effects of time of day-specific resistance training on adaptations in skeletal muscle hypertrophy and muscle strength: a systematic review and meta-analysis. Chronobiol Int. 2019:1-12. https://doi.org/10.1080/07420528.2019.1567524.

232. Wolff CA, Esser KA. Exercise timing and circadian rhythms. Curr Opin Physiol. 2019. https://doi.org/10.1016/j.cophys.2019.04.020.

233. Burke TM, Scheer FAJL, Ronda JM, Czeisler CA, Wright KP. Sleep inertia, sleep homeostatic and circadian influences on higher-order cognitive functions. J Sleep Res. 2015;24:364-71. https://doi.org/10.1111/jsr.12291.

234. Anderson JAE, Campbell KL, Amer T, Grady CL, Hasher L. Timing is everything: age differences in the cognitive control network are modulated by time of day. Psychol Aging. 2014;29:648-57. https://doi. org/10.1037/a0037243.

235. Hodyl NA, Schneider L, Vallence A-M, Clow A, Ridding MC, Pitcher JB. The cortisol awakening response is associated with performance of a serial sequence reaction time task. Int J Psychophysiol. 2016;100:12-8. https://doi. org/10.1016/j.ijpsycho.2015.12.007.

236. Schroeter ML, Bücheler MM, Scheid R. Circadian variability is negligible in primary visual cortices as measured by fNIRS. Int J Psychophysiol. 2006;62:913. https://doi.org/10.1016/j.ijpsycho.2005.11.003.

237. Young J, Angevaren M, Rusted J, Tabet N. Aerobic exercise to improve cognitive function in older people without known cognitive impairment. Cochrane Database Syst Rev. 2015:CD005381. https://doi.org/10.1002/14651 858.CD005381.pub4.

238. Liu-Ambrose T, Barha CK, Best JR. Physical activity for brain health in older adults. Appl Physiol Nutr Metab. 2018:1-8. https://doi.org/10.1139/ apnm-2018-0260.

239. Buckner SL, Dankel SJ, Mouser JG, Mattocks KT, Jessee MB, Loenneke JP. Chasing the top quartile of cross-sectional data: is it possible with resistance training? Med Hypotheses. 2017;108:63-8. https://doi.org/10.1 016/j.mehy.2017.08.009.

240. Voss MW, Nagamatsu LS, Liu-Ambrose T, Kramer AF. Exercise, brain, and cognition across the life span. J Appl Physiol. 2011;111:1505-13. https://doi. org/10.1152/japplphysiol.00210.2011.

241. Swick D, Ashley V, Turken U. Are the neural correlates of stopping and not going identical? Quantitative meta-analysis of two response inhibition tasks. Neurolmage. 2011;56:1655-65. https://doi.org/10.1016/j. neuroimage.2011.02.070.
242. Boehler CN, Appelbaum LG, Krebs RM, Hopf JM, Woldorff MG. Pinning down response inhibition in the brain-conjunction analyses of the stopsignal task. Neurolmage. 2010;52:1621-32. https://doi.org/10.1016/j. neuroimage.2010.04.276.

243. Dosenbach NUF, Fair DA, Cohen AL, Schlaggar BL, Petersen SE. A dualnetworks architecture of top-down control. Trends Cogn Sci. 2008;12:99105. https://doi.org/10.1016/j.tics.2008.01.001.

244. Dosenbach NUF, Fair DA, Miezin FM, Cohen AL, Wenger KK, Dosenbach RAT, et al. Distinct brain networks for adaptive and stable task control in humans. Proc Natl Acad Sci U S A. 2007;104:11073-8. https://doi.org/10.1 073/pnas.0704320104.

245. Simmonds DJ, Pekar JJ, Mostofsky SH. Meta-analysis of go/no-go tasks demonstrating that $\mathrm{fMRI}$ activation associated with response inhibition is task-dependent. Neuropsychologia. 2008;46:224-32. https://doi.org/10.1016/ j.neuropsychologia.2007.07.015.

246. Colcombe SJ, Kramer AF, Erickson KI, Scalf P, McAuley E, Cohen NJ, et al. Cardiovascular fitness, cortical plasticity, and aging. Proc Natl Acad Sci. 2004; 101:3316-21. https://doi.org/10.1073/pnas.0400266101.

247. Culham JC, Kanwisher NG. Neuroimaging of cognitive functions in human parietal cortex. Curr Opin Neurobiol. 2001;11:157-63.

248. Miller EK. The prefrontal cortex and cognitive control. Nat Rev Neurosci. 2000;1:59-65. https://doi.org/10.1038/35036228.

249. Carlén M. What constitutes the prefrontal cortex? Science. 2017;358:478-82. https://doi.org/10.1126/science.aan8868

250. Buschman TJ, Miller EK. Top-down versus bottom-up control of attention in the prefrontal and posterior parietal cortices. Science. 2007;315:1860-2. https://doi.org/10.1126/science.1138071.

251. Posner MI, Dehaene S. Attentional networks. Trends Neurosci. 1994;17:75-9. https://doi.org/10.1016/0166-2236(94)90078-7.

252. Banich MT, Milham MP, Atchley R, Cohen NJ, Webb A, Wszalek T, et al. fMRI studies of Stroop tasks reveal unique roles of anterior and posterior brain systems in attentional selection. J Cogn Neurosci. 2000;12:988-1000. https:// doi.org/10.1162/08989290051137521

253. Magen H, Emmanouil T-A, McMains SA, Kastner S, Treisman A. Attentional demands predict short-term memory load response in posterior parietal cortex. Neuropsychologia. 2009;47:17990-8. https://doi.org/10.1016/j.neuropsychologia.2 009.02.015

254. Banich MT, Milham MP, Atchley RA, Cohen NJ, Webb A, Wszalek T, et al. Prefrontal regions play a predominant role in imposing an attentional 'set': evidence from fMRI. Cogn Brain Res. 2000;10:1-9. https://doi.org/10.1016/ S0926-6410(00)00015-X.

255. Morishima Y, Akaishi R, Yamada Y, Okuda J, Toma K, Sakai K. Task-specific signal transmission from prefrontal cortex in visual selective attention. Nat Neurosci. 2009;12:85-91. https://doi.org/10.1038/nn.2237.

256. Pardo JV, Pardo PJ, Janer KW, Raichle ME. The anterior cingulate cortex mediates processing selection in the Stroop attentional conflict paradigm. Proc Natl Acad Sci. 1990;87:256-9. https://doi.org/10.1073/pnas.87.1.256.

257. Braver TS. Anterior cingulate cortex and response conflict: effects of frequency, inhibition and errors. Cereb Cortex. 2001;11:825-36. https://doi. org/10.1093/cercor/11.9.825.

258. Carter CS. Anterior cingulate cortex, error detection, and the online monitoring of performance. Science. 1998;280:747-9. https://doi.org/1 $0.1126 /$ science.280.5364.747.

259. Carter CS, van Veen V. Anterior cingulate cortex and conflict detection: an update of theory and data. Cogn Affect Behav Neurosci. 2007;7:367-79. https://doi.org/10.3758/CABN.7.4.367.

260. van Veen V, Cohen JD, Botvinick MM, Stenger VA, Carter CS. Anterior cingulate cortex, conflict monitoring, and levels of processing. Neurolmage. 2001;14:1302-8. https://doi.org/10.1006/nimg.2001.0923.

261. Bai F, Watson DR, Yu H, Shi Y, Yuan Y, Zhang Z. Abnormal resting-state functional connectivity of posterior cingulate cortex in amnestic type mild cognitive impairment. Brain Res. 2009;1302:167-74. https://doi.org/10.1016/j. brainres.2009.09.028.

262. Lau WKW, Leung M-K, Lee TMC, Law ACK. Resting-state abnormalities in amnestic mild cognitive impairment: a meta-analysis. Transl Psychiatry. 2016; 6:e790. https://doi.org/10.1038/tp.2016.55.

263. Yang H, Wang C, Zhang Y, Xia L, Feng Z, Li D, et al. Disrupted causal connectivity anchored in the posterior cingulate cortex in amnestic mild cognitive impairment. Front Neurol. 2017;8:10. https://doi.org/10.3389/fneur.2017.00010.

264. Yu E, Liao Z, Mao D, Zhang Q, Ji G, Li Y, Ding Z. Directed functional connectivity of posterior cingulate cortex and whole brain in Alzheimer's disease and mild 
cognitive impairment. Curr Alzheimer Res. 2017;14:628-35. https://doi.org/10.21 74/1567205013666161201201000

265. Wang Z, Liang P, Jia X, Qi Z, Yu L, Yang Y, et al. Baseline and longitudinal patterns of hippocampal connectivity in mild cognitive impairment: evidence from resting state fMRI. J Neurol Sci. 2011;309:79-85. https://doi. org/10.1016/j.jns.2011.07.017

266. Allen G, Barnard H, McColl R, Hester AL, Fields JA, Weiner MF, et al. Reduced hippocampal functional connectivity in Alzheimer disease. Arch Neurol. 2007;64:1482-7. https://doi.org/10.1001/archneur.64.10.1482.

267. Wang L, Zang Y, He Y, Liang M, Zhang X, Tian L, et al. Changes in hippocampal connectivity in the early stages of Alzheimer's disease: evidence from resting state fMRI. Neurolmage. 2006;31:496-504. https://doi. org/10.1016/j.neuroimage.2005.12.033

268. Polich J, Kok A. Cognitive and biological determinants of P300: an integrative review. Biol Psychol. 1995;41:103-46. https://doi.org/10.1016/03 01-0511(95)05130-9.

269. Linden DEJ. The p300: where in the brain is it produced and what does it tell us? Neuroscientist. 2005;11:563-76. https://doi.org/10.1177/1073858405280524.

270. Kügler CF, Taghavy A, Platt D. The event-related P300 potential analysis of cognitive human brain aging: a review. Gerontology. 1993;39:280-303. https:// doi.org/10.1159/000213544.

271. van Dinteren R, Arns M, Jongsma MLA, Kessels RPC. P300 development across the lifespan: a systematic review and meta-analysis. PLoS One. 2014; 9:e87347. https://doi.org/10.1371/journal.pone.0087347.

272. Hedges D, Janis R, Mickelson S, Keith C, Bennett D, Brown BL. P300 amplitude in Alzheimer's disease: a meta-analysis and meta-regression. Clin EEG Neurosci. 2016;47:48-55. https://doi.org/10.1177/1550059414550567.

273. Hanslmayr S, Sauseng P, Doppelmayr M, Schabus M, Klimesch W. Increasing individual upper alpha power by neurofeedback improves cognitive performance in human subjects. Appl Psychophysiol Biofeedback. 2005;30: 1-10. https://doi.org/10.1007/s10484-005-2169-8.

274. Klimesch W. EEG alpha and theta oscillations reflect cognitive and memory performance: a review and analysis. Brain Res Rev. 1999;29:169-95. https:// doi.org/10.1016/S0165-0173(98)00056-3.

275. Finnigan S, Robertson $\mathbb{H}$. Resting EEG theta power correlates with cognitive performance in healthy older adults. Psychophysiology. 2011;48:1083-7. https://doi.org/10.1111/j.1469-8986.2010.01173.x.

276. Brickman AM, Paul RH, Cohen RA, Williams LM, MacGregor $K L$, Jefferson $A L$, et al. Category and letter verbal fluency across the adult lifespan: relationship to EEG theta power. Arch Clin Neuropsychol. 2005;20:561-73. https://doi.org/10.1016/j.acn.2004.12.006

277. Lautenschlager NT. Twelve months of resistance training can improve the cognitive functioning of older women living in the community. J Phys. 2010;56:200. https://doi.org/10.1016/S1836-9553(10)70026-6.

278. Fox NC, Black RS, Gilman S, Rossor MN, Griffith SG, Jenkins L, Koller M. Effects of Abeta immunization (AN1792) on MRI measures of cerebral volume in Alzheimer disease. Neurology. 2005;64:1563-72. https://doi.org/1 0.1212/01.WNL.0000159743.08996.99.

279. Yoon DH, Lee J-Y, Shin SA, Kim YK, Song W. Physical frailty and amyloid- $\beta$ deposits in the brains of older adults with cognitive frailty. J Clin Med. 2018. https://doi.org/10.3390/jcm7070169.

280. Akhtar RS, Xie SX, Chen YJ, Rick J, Gross RG, Nasrallah IM, et al. Regional brain amyloid- $\beta$ accumulation associates with domain-specific cognitive performance in Parkinson disease without dementia. PLoS One. 2017;12: e0177924. https://doi.org/10.1371/journal.pone.0177924.

281. Dao E, Best JR, Hsiung G-YR, Sossi V, Jacova C, Tam R, Liu-Ambrose T. Associations between cerebral amyloid and changes in cognitive function and falls risk in subcortical ischemic vascular cognitive impairment. BMC Geriatr. 2017;17:133. https://doi.org/10.1186/s12877-017-0522-4.

282. Gunstad J, Spitznagel MB, Glickman E, Alexander T, Juvancic-Heltzel J, Walter K, Murray L. beta-Amyloid is associated with reduced cognitive function in healthy older adults. J Neuropsychiatry Clin Neurosci. 2008;20:327-30. https://doi.org/10.1176/jnp.2008.20.3.327.

283. Wang J, Gu BJ, Masters CL, Wang Y-J. A systemic view of Alzheimer disease insights from amyloid- $\beta$ metabolism beyond the brain. Nat Rev Neurol. 2017;13: 612-23. https:/doi.org/10.1038/nrneurol.2017.111.

284. Drew L. An age-old story of dementia. Nature. 2018;559:S2-3. https://doi. org/10.1038/d41586-018-05718-5

285. Hardy J, Selkoe DJ. The amyloid hypothesis of Alzheimer's disease: progress and problems on the road to therapeutics. Science. 2002;297:353-6. https:// doi.org/10.1126/science.1072994.
286. Palop JJ, Mucke L. Amyloid-beta-induced neuronal dysfunction in Alzheimer's disease: from synapses toward neural networks. Nat Neurosci. 2010;13:812-8. https://doi.org/10.1038/nn.2583.

287. de Groot JC, de Leeuw FE, Oudkerk M, van Gijn J, Hofman A, Jolles J, Breteler MM. Cerebral white matter lesions and cognitive function: the Rotterdam scan study. Ann Neurol. 2000;47:145-51.

288. Bolandzadeh N, Davis JC, Tam R, Handy T, Liu-Ambrose T. The association between cognitive function and white matter lesion location in older adults: a systematic review. Alzheimers Dement. 2012;8:P528. https:/doi.org/10.1016/j.jalz.2012.05.2162.

289. de Groot JC, de Leeuw F-E, Oudkerk M, van Gijn J, Hofman A, Jolles J, Breteler MMB. Periventricular cerebral white matter lesions predict rate of cognitive decline. Ann Neurol. 2002;52:335-41. https://doi.org/10.1002/ana.10294.

290. Turken A, Whitfield-Gabrieli S, Bammer R, Baldo JV, Dronkers NF, Gabrieli JDE. Cognitive processing speed and the structure of white matter pathways: convergent evidence from normal variation and lesion studies. Neurolmage. 2008:42:1032-44. https://doi.org/10.1016/j.neuroimage.2008.03.057.

291. Prins ND, van Dijk EJ, den Heijer T, Vermeer SE, Koudstaal PJ, Oudkerk M, et al. Cerebral white matter lesions and the risk of dementia. Arch Neurol. 2004;61:1531-4. https://doi.org/10.1001/archneur.61.10.1531.

292. Medina D, DeToledo-Morrell L, Urresta F, Gabrieli JDE, Moseley M, Fleischman $D$, et al. White matter changes in mild cognitive impairment and AD: a diffusion tensor imaging study. Neurobiol Aging. 2006;27:663-72. https://doi.org/10.1016/j.neurobiolaging.2005.03.026.

293. Verghese J, Holtzer R, Lipton RB, Wang C. Quantitative gait markers and incident fall risk in older adults. J Gerontol Ser A Biol Med Sci. 2009;64A: 896-901. https://doi.org/10.1093/gerona/glp033.

294. Srikanth V, Beare R, Blizzard L, Phan T, Stapleton J, Chen J, et al. Cerebral white matter lesions, gait, and the risk of incident falls: a prospective population-based study. Stroke. 2009;40:175-80. https://doi.org/10.1161/ STROKEAHA.108.524355.

295. Leech R, Sharp DJ. The role of the posterior cingulate cortex in cognition and disease. Brain. 2014;137:12-32. https://doi.org/10.1093/brain/awt162.

296. Minoshima S, Giordani B, Berent S, Frey KA, Foster NL, Kuhl DE. Metabolic reduction in the posterior cingulate cortex in very early Alzheimer's disease. Ann Neurol. 1997:42:85-94. https://doi.org/10.1002/ana.410420114.

297. Choo IH, Lee DY, Oh JS, Lee JS, Lee DS, Song IC, et al. Posterior cingulate cortex atrophy and regional cingulum disruption in mild cognitive impairment and Alzheimer's disease. Neurobiol Aging. 2010;31:772-9. https://doi.org/10.1016/j.neurobiolaging.2008.06.015.

298. Müller P, Rehfeld K, Lüders A, Schmicker M, Hökelmann A, Kaufman J, Müller NG. Effekte eines Tanz- und eines Gesundheitssporttrainings auf die graue Hirnsubstanz gesunder Senioren. Sportwiss. 2016. https://doi.org/10.1007/ s12662-016-0411-6.

299. Müller P, Rehfeld K, Schmicker M, Hökelmann A, Dordevic M, Lessmann V, et al. Evolution of neuroplasticity in response to physical activity in old age: the case for dancing. Front Aging Neurosci. 2017;9:805. https://doi.org/10.33 89/fnagi.2017.00056

300. Rehfeld K, Lüders A, Hökelmann A, Lessmann V, Kaufmann J, Brigadski T, et al. Dance training is superior to repetitive physical exercise in inducing brain plasticity in the elderly. PLoS One. 2018;13:e0196636. https://doi.org/10.13 71/journal.pone.0196636.

301. Rehfeld K, Müller P, Aye N, Schmicker M, Dordevic M, Kaufmann J, et al. Dancing or fitness sport?: the effects of two training programs on hippocampal plasticity and balance abilities in healthy seniors. Front Hum Neurosci. 2017;11:261. https://doi.org/10.3389/fnhum.2017.00305.

302. Müller P, Schmicker M, Müller NG. Präventionsstrategien gegen Demenz. Z Gerontol Geriatr. 2017. https://doi.org/10.1007/s00391-017-1202-x.

303. Liu-Ambrose T, Donaldson MG. Exercise and cognition in older adults: is there a role for resistance training programmes? Br J Sports Med. 2009;43: 25-7. https://doi.org/10.1136/bjsm.2008.055616.

304. Basso JC, Shang A, Elman M, Karmouta R, Suzuki WA. Acute exercise improves prefrontal cortex but not hippocampal function in healthy adults. J Int Neuropsychol Soc. 2015;21:791-801. https://doi.org/10.1017/S135561771500106X.

305. Hwang J, Brothers RM, Castelli DM, Glowacki EM, Chen YT, Salinas MM, et al. Acute high-intensity exercise-induced cognitive enhancement and brainderived neurotrophic factor in young, healthy adults. Neurosci Lett. 2016; 630:247-53. https://doi.org/10.1016/j.neulet.2016.07.033.

306. Leckie RL, Oberlin LE, Voss MW, Prakash RS, Szabo-Reed A, ChaddockHeyman $L$, et al. BDNF mediates improvements in executive function following a 1-year exercise intervention. Front Hum Neurosci. 2014;8:985. https://doi.org/10.3389/fnhum.2014.00985. 
307. Yarrow JF, White LJ, McCoy SC, Borst SE. Training augments resistance exercise induced elevation of circulating brain derived neurotrophic factor (BDNF). Neurosci Lett. 2010;479:161-5. https://doi.org/10.1016/j. neulet.2010.05.058.

308. Church DD, Hoffman JR, Mangine GT, Jajtner AR, Townsend JR, Beyer KS, et al. Comparison of high-intensity vs. high-volume resistance training on the BDNF response to exercise. J Appl Physiol. 2016;121:123-8. https://doi.org/1 0.1152/japplphysiol.00233.2016.

309. Marston KJ, Newton MJ, Brown BM, Rainey-Smith SR, Bird S, Martins RN, Peiffer $\mathrm{JJ}$. Intense resistance exercise increases peripheral brain-derived neurotrophic factor. J Sci Med Sport. 2017;20:899-903. https://doi.org/10.1 016/j.jsams.2017.03.015.

310. Walsh JJ, Scribbans TD, Bentley RF, Kellawan JM, Gurd B, Tschakovsky ME. Neurotrophic growth factor responses to lower body resistance training in older adults. Appl Physiol Nutr Metab. 2016;41:315-23. https://doi.org/10.113 9/apnm-2015-0410.

311. Lira FS, Conrado de Freitas M, Gerosa-Neto J, Cholewa JM, Rossi FE. Comparison between full-body vs. split-body resistance exercise on the brain-derived neurotrophic factor and immunometabolic response. J Strength Cond Res. 2018. https://doi.org/10.1519/JSC.0000000000002653.

312. Forti LN, van Roie E, Njemini R, Coudyzer W, Beyer I, Delecluse C, Bautmans I. Dose-and gender-specific effects of resistance training on circulating levels of brain derived neurotrophic factor (BDNF) in community-dwelling older adults. Exp Gerontol. 2015;70:144-9. https://doi.org/10.1016/j.exger.2015.08.004.

313. Urzi F, Marusic U, Ličen S, Buzan E. Effects of elastic resistance training on functional performance and Myokines in older women-a randomized controlled trial. J Am Med Dir Assoc. 2019. https://doi.org/10.1016/j.jamda.2 019.01.151.

314. Piepmeier AT, Etnier UL. Brain-derived neurotrophic factor (BDNF) as a potential mechanism of the effects of acute exercise on cognitive performance. J Sport Health Sci. 2015;4:14-23. https://doi.org/10.1016/j.jshs.2 014.11.001.

315. Knaepen K, Goekint M, Heyman EM, Meeusen R. Neuroplasticity - exerciseinduced response of peripheral brain-derived neurotrophic factor: a systematic review of experimental studies in human subjects. Sports Med. 2010:40:765-801. https://doi.org/10.2165/11534530-000000000-00000.

316. Rojas Vega S, Knicker A, Hollmann W, Bloch W, Strüder HK. Effect of resistance exercise on serum levels of growth factors in humans. Horm Metab Res. 2010;42:982-6. https://doi.org/10.1055/s-0030-1267950.

317. Borst SE, de Hoyos DV, Garzarella L, Vincent K, Pollock BH, Lowenthal DT, Pollock ML. Effects of resistance training on insulin-like growth factor-I and IGF binding proteins. Med Sci Sports Exerc. 2001;33:648-53.

318. Ohlsson C, Mohan S, Sjögren K, Tivesten A, Isgaard J, Isaksson O, et al. The role of liver-derived insulin-like growth factor-I. Endocr Rev. 2009;30:494535. https://doi.org/10.1210/er.2009-0010.

319. Gubbi S, Quipildor GF, Barzilai N, Huffman DM, Milman S. 40 YEARS of IGF1: IGF1: the Jekyll and Hyde of the aging brain. J Mol Endocrinol. 2018;61: T171-85. https://doi.org/10.1530/JME-18-0093.

320. Dyer AH, Vahdatpour C, Sanfeliu A, Tropea D. The role of insulin-like growth factor 1 (IGF-1) in brain development, maturation and neuroplasticity. Neuroscience. 2016;325:89-99. https://doi.org/10.1016/.j.neuroscience.2016.03.056.

321. Deak F, Sonntag WE. Aging, synaptic dysfunction, and insulin-like growth factor (IGF)-1. J Gerontol Ser A Biol Med Sci. 2012;67A:611-25. https://doi. org/10.1093/gerona/gls118.

322. Aberg ND, Brywe KG, Isgaard J. Aspects of growth hormone and insulin-like growth factor-I related to neuroprotection, regeneration, and functional plasticity in the adult brain. ScientificWorldJournal. 2006;6:53-80. https://doi. org/10.1100/tsw.2006.22.

323. Bassil F, Fernagut P-O, Bezard E, Meissner WG. Insulin, IGF-1 and GLP-1 signaling in neurodegenerative disorders: targets for disease modification? Prog Neurobiol. 2014;118:1-18. https://doi.org/10.1016/j. pneurobio.2014.02.005.

324. Doré S, Kar S, Quirion R. Rediscovering an old friend, IGF-I: potential use in the treatment of neurodegenerative diseases. Trends Neurosci. 1997;20:326-31.

325. Popken GJ, Hodge RD, Ye P, Zhang J, Ng W, O'Kusky JR, D'Ercole AJ. In vivo effects of insulin-like growth factor-I (IGF-I) on prenatal and early postnatal development of the central nervous system. Eur J Neurosci. 2004;19:205668. https://doi.org/10.1111/j.0953-816X.2004.03320.X.

326. Westwood AJ, Beiser A, DeCarli C, Harris TB, Chen TC, He X-M, et al. Insulinlike growth factor-1 and risk of Alzheimer dementia and brain atrophy. Neurology. 2014;82:1613-9. https://doi.org/10.1212/WNL.0000000000000382.
327. Maass A, Düzel S, Brigadski T, Goerke M, Becke A, Sobieray U, et al. Relationships of peripheral IGF-1, VEGF and BDNF levels to exercise-related changes in memory, hippocampal perfusion and volumes in older adults. Neurolmage. 2015. https://doi.org/10.1016/..neuroimage.2015.10.084.

328. Sonntag WE, Deak F, Ashpole N, Toth P, Csiszar A, Freeman W, Ungvari Z. Insulin-like growth factor-1 in CNS and cerebrovascular aging. Front Aging Neurosci. 2013. https://doi.org/10.3389/fnagi.2013.00027.

329. Arwert LI, Deijen JB, Drent ML. The relation between insulin-like growth factor I levels and cognition in healthy elderly: a meta-analysis. Growth Hormon IGF Res. 2005;15:416-22. https://doi.org/10.1016/j.ghir.2005.09.001.

330. Calvo D, Gunstad J, Miller LA, Glickman E, Spitznagel MB. Higher serum insulin-like growth factor- 1 is associated with better cognitive performance in persons with mild cognitive impairment. Psychogeriatrics. 2013;13:170-4. https://doi.org/10.1111/psyg.12023.

331. Tumati S, Burger H, Martens S, van der Schouw YT, Aleman A. Association between cognition and serum insulin-like growth factor-1 in middle-aged \& older men: an 8 year follow-up study. PLoS One. 2016;11:e0154450. https:// doi.org/10.1371/journal.pone.0154450.

332. Kim S, Choi J-Y, Moon S, Park D-H, Kwak H-B, Kang J-H. Roles of myokines in exercise-induced improvement of neuropsychiatric function. Pflugers Arch. 2019. https://doi.org/10.1007/s00424-019-02253-8.

333. Stein AM, Silva TMV, Coelho FGM, Arantes FJ, Costa JLR, Teodoro E, SantosGalduróz RF. Physical exercise, IGF-1 and cognition. A systematic review of experimental studies in the elderly. Dement Neuropsychol. 2018;12:114-22. https://doi.org/10.1590/1980-57642018dn12-020003.

334. Vermeer SE, van Dijk EJ, Koudstaal PJ, Oudkerk M, Hofman A, Clarke R, Breteler MMB. Homocysteine, silent brain infarcts, and white matter lesions: the Rotterdam scan study. Ann Neurol. 2002;51:285-9.

335. Hooshmand B, Mangialasche F, Kalpouzos G, Solomon A, Kåreholt I, Smith $A D$, et al. Association of vitamin B12, folate, and sulfur amino acids with brain magnetic resonance imaging measures in older adults: a longitudinal population-based study. JAMA Psychiatry. 2016;73:606-13. https://doi.org/1 0.1001/jamapsychiatry.2016.0274

336. Narayan SK, Firbank MJ, Saxby BK, Stansby G, Hansrani M, O'Brien JT, Ford GA. Elevated plasma homocysteine is associated with increased brain atrophy rates in older subjects with mild hypertension. Dement Geriatr Cogn Disord. 2011;31:341-8. https://doi.org/10.1159/000328118.

337. Smith AD, Smith SM, de Jager CA, Whitbread P, Johnston C, Agacinski $G$, et al. Homocysteine-lowering by $B$ vitamins slows the rate of accelerated brain atrophy in mild cognitive impairment: a randomized controlled trial. PLoS One. 2010;5:e12244. https://doi.org/10.1371/journal.pone.0012244.

338. Maroto-Sanchez B, Lopez-Torres O, Palacios G, Gonzalez-Gross M. What do we know about homocysteine and exercise? A review from the literature. Clin Chem Lab Med. 2016. https://doi.org/10.1515/cclm-2015-1040.

339. Herrmann W, Obeid R. Homocysteine: a biomarker in neurodegenerative diseases. Clin Chem Lab Med. 2011;49:435-41. https://doi.org/10.1515/ CCLM.2011.084.

340. Obeid R, Herrmann W. Mechanisms of homocysteine neurotoxicity in neurodegenerative diseases with special reference to dementia. FEBS Lett. 2006;580:2994-3005. https://doi.org/10.1016/j.febslet.2006.04.088.

341. Sharma M, Tiwari M, Tiwari RK. Hyperhomocysteinemia: impact on neurodegenerative diseases. Basic Clin Pharmacol Toxicol. 2015;117:287-96. https://doi.org/10.1111/bcpt.12424.

342. Seshadri S, Beiser A, Selhub J. Plasma homocysteine as a risk marker for dementia and Alzheimer's disease. ACC Curr J Rev. 2002;11:30. https://doi. org/10.1016/S1062-1458(02)00690-6.

343. Ostrakhovitch EA, Tabibzadeh S. Homocysteine and age-associated disorders. Ageing Res Rev. 2019;49:144-64. https://doi.org/10.1016/j.arr.2018.10.010.

344. Clarke R, Smith AD, Jobst KA, Refsum H, Sutton L, Ueland PM. Folate, vitamin B12, and serum total homocysteine levels in confirmed Alzheimer disease. Arch Neurol. 1998;55:1449. https://doi.org/10.1001/ archneur.55.11.1449.

345. Dufouil C, Alpérovitch A, Ducros V, Tzourio C. Homocysteine, white matter hyperintensities, and cognition in healthy elderly people. Ann Neurol. 2003; 53:214-21. https://doi.org/10.1002/ana.10440.

346. Wright CB, Lee H-S, Paik MC, Stabler SP, Allen RH, Sacco RL. Total homocysteine and cognition in a tri-ethnic cohort: the northern Manhattan study. Neurology. 2004;63:254-60.

347. McCaddon A, Hudson P, Davies G, Hughes A, Williams JH, Wilkinson C. Homocysteine and cognitive decline in healthy elderly. Dement Geriatr Cogn Disord. 2001;12:309-13. https://doi.org/10.1159/000051275 
348. Garcia A, Haron Y, Pulman K, Hua L, Freedman M. Increases in homocysteine are related to worsening of stroop scores in healthy elderly persons: a prospective follow-up study. J Gerontol Ser A Biol Med Sci. 2004; 59:1323-7.

349. Schafer JH, Glass TA, Bolla KI, Mintz M, Jedlicka AE, Schwartz BS. Homocysteine and cognitive function in a population-based study of older adults. J Am Geriatr Soc. 2005;53:381-8. https://doi.org/10.1111/j.1532-5415.2005.53153.x

350. West RK, Beeri MS, Schmeidler J, Mitchell DB, Carlisle KR, Angelo G, et al. Homocysteine and cognitive function in very elderly nondemented subjects. Am J Geriatr Psychiatry. 2011;19:673-7. https://doi.org/10.1097/JGP. 0b013e3181faee37.

351. Deminice R, Ribeiro DF, Frajacomo FTT. The effects of acute exercise and exercise training on plasma homocysteine: a meta-analysis. PLoS One. 2016; 11:e0151653. https://doi.org/10.1371/journal.pone.0151653.

352. Vincent KR, Braith RW, Bottiglieri T, Vincent HK, Lowenthal DT. Homocysteine and lipoprotein levels following resistance training in older adults. Prev Cardiol. 2003;6:197-203. https://doi.org/10.1111/j.1520-037X.2 003.01723.x

353. Altug Z. Resistance exercise to improve cognitive function. J Strength Cond. 2014;36:46-50. https://doi.org/10.1519/SSC.0000000000000109.

354. Bird SP, Tarpenning KM, Marino FE. Designing resistance training programmes to enhance muscular fitness: a review of the acute programme variables. Sports Med. 2005;35:841-51.

355. Ratamess N, Alvar BA, Evetoch TK, Housh TJ, Kibler WB, Kraemer WJ, Triplett NT. American College of Sports Medicine position stand. Progression models in resistance training for healthy adults. Med Sci Sports Exerc. 2009; 41:687-708. https://doi.org/10.1249/MSS.0b013e3181915670.

356. Toigo M, Boutellier U. New fundamental resistance exercise determinants of molecular and cellular muscle adaptations. Eur J Appl Physiol. 2006:97:64363. https://doi.org/10.1007/s00421-006-0238-1.

357. Montero D, Lundby C. Refuting the myth of non-response to exercise training: 'non-responders' do respond to higher dose of training. J Physiol. 2017;595:3377-87. https://doi.org/10.1113/JP273480.

358. Churchward-Venne TA, Tieland M, Verdijk LB, Leenders M, Dirks ML, de Groot LCPGM, van Loon LJC. There are no nonresponders to resistance-type exercise training in older men and women. J Am Med Dir Assoc. 2015;16: 400-11. https://doi.org/10.1016/j.jamda.2015.01.071.

359. Northey JM, Cherbuin N, Pumpa KL, Smee DJ, Rattray B. Exercise interventions for cognitive function in adults older than 50: a systematic review with meta-analysis. Br J Sports Med. 2017. https://doi.org/10.1136/ bjsports-2016-096587.

360. Engeroff T, Niederer D, Vogt L, Banzer W. Intensity and workload related dose-response effects of acute resistance exercise on domain-specific cognitive function and affective response - a four-armed randomized controlled crossover trial. Psychol Sport Exerc. 2019;43:55-63. https://doi. org/10.1016/j.psychsport.2018.12.009.

361. Hillman $\mathrm{CH}$, Kamijo K, Scudder M. A review of chronic and acute physical activity participation on neuroelectric measures of brain health and cognition during childhood. Prev Med. 2011;52(Suppl 1):S21-8. https://doi org/10.1016/j.ypmed.2011.01.024.

362. Hillman $\mathrm{CH}$, Pontifex $\mathrm{M}$, Themanson JR. Acute aerobic exercise effects on event-related brain potentials. In: McMorris T, Tomporowski PD, Audiffren M, editors. Exercise and cognitive function. Chichester: Wiley; 2009. p. 161-78. https://doi.org/10.1002/9780470740668.ch8.

363. Fortes LS, Costa MC, Perrier-Melo RJ, Brito-Gomes JL, Nascimento-Júnior JRA, de Lima-Júnior DRAA, Cyrino ES. Effect of volume in resistance training on inhibitory control in young adults: a randomized and crossover investigation. Front Psychol. 2018;9:2028. https://doi.org/10.33 89/fpsyg.2018.02028.

364. Tsukamoto H, Suga T, Takenaka S, Tanaka D, Takeuchi T, Hamaoka T, et al. Repeated high-intensity interval exercise shortens the positive effect on executive function during post-exercise recovery in healthy young males. Physiol Behav. 2016;160:26-34. https://doi.org/10.1016/j.physbeh.2 016.03.029.

365. Lee JKW, Koh ACH, Koh SXT, Liu GJX, Nio AQX, Fan PWP. Neck cooling and cognitive performance following exercise-induced hyperthermia. Eur J Appl Physiol. 2014;114:375-84. https://doi.org/10.1007/s00421-013-2774-9.

366. Hashimoto T, Tsukamoto H, Takenaka S, Olesen ND, Petersen LG, Sørensen $\mathrm{H}$, et al. Maintained exercise-enhanced brain executive function related to cerebral lactate metabolism in men. FASEB J. 2017. https://doi.org/10.1096/ fj.201700381RR.
367. Riske L, Thomas RK, Baker GB, Dursun SM. Lactate in the brain: an update on its relevance to brain energy, neurons, glia and panic disorder. Ther Adv Psychopharmacol. 2017;7:85-9. https://doi.org/10.1177/2045125316675579.

368. Taher M, Leen WG, Wevers RA, Willemsen MA. Lactate and its many faces. Eur J Paediatr Neurol. 2016;20:3-10. https://doi.org/10.1016/j.ejpn.2015.09.008.

369. van Hall G, Stromstad M, Rasmussen P, Jans O, Zaar M, Gam C, et al. Blood lactate is an important energy source for the human brain. J Cereb Blood Flow Metab. 2009;29:1121-9. https://doi.org/10.1038/jcbfm.2009.35.

370. Brooks GA. The science and translation of lactate shuttle theory. Cell Metab. 2018;27:757-85. https://doi.org/10.1016/j.cmet.2018.03.008.

371. Quistorff B, Secher NH, van Lieshout JJ. Lactate fuels the human brain during exercise. FASEB J. 2008;22:3443-9. https:/doi.org/10.1096/fj.08-106104.

372. Schiffer T, Schulte S, Hollmann W, Bloch W, Strüder H. Effects of strength and endurance training on brain-derived neurotrophic factor and insulinlike growth factor 1 in humans. Horm Metab Res. 2009;41:250-4. https://doi. org/10.1055/s-0028-1093322.

373. Gentil P, Oliveira E, Bottaro M. Time under tension and blood lactate response during four different resistance training methods. J Physiol Anthropol. 2006;25:339-44. https://doi.org/10.2114/jpa2.25.339.

374. Goto K, Ishii N, Kizuka T, Kraemer RR, Honda Y, Takamatsu K. Hormonal and metabolic responses to slow movement resistance exercise with different durations of concentric and eccentric actions. Eur J Appl Physiol. 2009;106: 731-9. https://doi.org/10.1007/s00421-009-1075-9.

375. Boroujerdi SS, Rahimi R. Acute GH and IGF-I responses to short vs. long rest period between sets during forced repetitions resistance training system. S Afr J Res Sport Phys Educ Recreat. 2008;30:31-8.

376. Dankel SJ, Jessee MB, Mattocks KT, Mouser JG, Counts BR, Buckner SL, Loenneke JP. Training to fatigue: the answer for standardization when assessing muscle hypertrophy? Sports Med. 2017;47:1021-7. https://doi. org/10.1007/s40279-016-0633-7.

377. Dankel SJ, Mattocks KT, Jessee MB, Buckner SL, Mouser JG, Counts BR, et al. Frequency: the overlooked resistance training variable for inducing muscle hypertrophy? Sports Med. 2017:47:799-805. https://doi.org/10.1007/s40279016-0640-8.

378. Figueiredo VC, de Salles BF, Trajano GS. Author's reply to Souza et al: comment on: "volume for muscle hypertrophy and health outcomes: the most effective variable in resistance training". Sports Med. 2018. https://doi. org/10.1007/s40279-018-0866-8.

379. Figueiredo VC, de Salles BF, Trajano GS. Volume for muscle hypertrophy and health outcomes: the Most effective variable in resistance training. Sports Med. 2018;48:499-505. https://doi.org/10.1007/s40279-017-0793-0.

380. Grgic J, Schoenfeld BJ, Davies TB, Lazinica B, Krieger JW, Pedisic Z. Effect of resistance training frequency on gains in muscular strength: a systematic review and meta-analysis. Sports Med. 2018;48:1207-20. https://doi.org/10.1 007/s40279-018-0872-x.

381. Ralston GW, Kilgore L, Wyatt FB, Baker JS. The effect of weekly set volume on strength gain: a meta-analysis. Sports Med. 2017. https://doi.org/10.1007/ s40279-017-0762-7.

382. de Salles BF, Simao R, Miranda F, Novaes JS, Lemos A, Willardson JM. Rest interval between sets in strength training. Sports Med. 2009;39:765-77. https://doi.org/10.2165/11315230-000000000-00000.

383. Schoenfeld BJ, Ogborn D, Krieger JW. Effects of resistance training frequency on measures of muscle hypertrophy: a systematic review and meta-analysis. Sports Med. 2016;46:1689-97. https:/doi.org/10.1007/s40279-016-0543-8.

384. Schoenfeld BJ, Ogborn DI, Krieger JW. Effect of repetition duration during resistance training on muscle hypertrophy: a systematic review and meta-analysis. Sports Med. 2015;45:577-85. https://doi.org/10.1007/ s40279-015-0304-0.

385. Souza DC, Viana RB, Coswig VS, Fisher JP, Steele J, Gentil P. Comment on: volume for muscle hypertrophy and health outcomes: the most effective variable in resistance training. Sports Med. 2018. https://doi.org/10.1007/s4 0279-018-0865-9.

386. Tan B. Manipulating resistance training program variables to optimize maximum strength in men: a review. J Strength Cond Res. 1999:13:289.

387. Grgic J, Schoenfeld BJ, Latella C. Resistance training frequency and skeletal muscle hypertrophy: a review of available evidence. J Sci Med Sport. 2018 https://doi.org/10.1016/j.jsams.2018.09.223.

388. Schoenfeld BJ, Ogborn DI, Vigotsky AD, Franchi MV, Krieger JW Hypertrophic effects of concentric vs. eccentric muscle actions: a systematic review and meta-analysis. J Strength Cond Res. 2017:31:2599-608. https:// doi.org/10.1519/JSC.0000000000001983. 
389. Schoenfeld B, Grgic J. Does training to failure maximize muscle hypertrophy? Strength Cond J. 2019;1. https://doi.org/10.1519/SSC. 0000000000000473.

390. Morton RW, Colenso-Semple L, Phillips SM. Training for strength and hypertrophy: an evidence-based approach. Curr Opin Physiol. 2019. https:// doi.org/10.1016/j.cophys.2019.04.006.

391. Borde R, Hortobagyi T, Granacher U. Dose-response relationships of resistance training in healthy old adults: a systematic review and meta-analysis. Sports Med. 2015;45:1693-720. https:/doi.org/10.1007/s40279-015-0385-9.

392. Carpinelli RN, Otto RM. Strength training: single versus multiple sets. Sports Med. 1999;27:409-16. https://doi.org/10.2165/00007256-199927060-00006.

393. Garber CE, Blissmer B, Deschenes MR, Franklin BA, Lamonte MJ, Lee I-M, et al. American College of Sports Medicine position stand. Quantity and quality of exercise for developing and maintaining cardiorespiratory, musculoskeletal, and neuromotor fitness in apparently healthy adults: guidance for prescribing exercise. Med Sci Sports Exerc. 2011;43:1334-59. https://doi.org/10.1249/MSS.0b013e318213fefb.

394. Chodzko-Zajko WJ, Proctor DN, Fiatarone Singh MA, Minson CT, Nigg CR, Salem GJ, Skinner JS. American College of Sports Medicine position stand. Exercise and physical activity for older adults. Med Sci Sports Exerc. 2009;41: 1510-30. https://doi.org/10.1249/MSs.0b013e3181a0c95c.

395. Liu Q, Zhou R, Chen S, Tan C. Effects of head-down bed rest on the executive functions and emotional response. PLoS One. 2012;7:e52160. https://doi.org/10.1371/journal.pone.0052160.

396. Lipnicki DM, Gunga H-C, Belavý DL, Felsenberg D. Bed rest and cognition: effects on executive functioning and reaction time. Aviat Space Environ Med. 2009;80:1018-24. https://doi.org/10.3357/ASEM.2581.2009.

397. Marusic U, Kavcic V, Pisot R, Goswami N. The role of enhanced cognition to counteract detrimental effects of prolonged bed rest: current evidence and perspectives. Front Physiol. 2018;9:1864. https:// doi.org/10.3389/fphys.2018.01864.

398. Li K, Guo X, Jin Z, Ouyang X, Zeng Y, Feng J, et al. Effect of simulated microgravity on human brain gray matter and white matter-evidence from MRI. PLoS One. 2015;10:e0135835. https://doi.org/10.1371/journal.pone.0135835.

399. Yuan P, Koppelmans V, Reuter-Lorenz P, de Dios Y, Gadd N, Wood S, et al. Vestibular brain changes within 70 days of head down bed rest. Hum Brain Mapp. 2018;39:2753-63. https://doi.org/10.1002/hbm.24037.

400. Alkner BA, Tesch PA. Knee extensor and plantar flexor muscle size and function following 90 days of bed rest with or without resistance exercise. Eur J Appl Physiol. 2004:93:294-305. https://doi.org/10.1007/s00421-004-1172-8.

401. Belavý DL, Miokovic T, Armbrecht G, Richardson CA, Rittweger J, Felsenberg D. Differential atrophy of the lower-limb musculature during prolonged bed-rest. Eur J Appl Physiol. 2009;107:489-99. https://doi.org/10.1007/ s00421-009-1136-0.

402. Berg HE, Eiken O, Miklavcic L, Mekjavic IB. Hip, thigh and calf muscle atrophy and bone loss after 5-week bedrest inactivity. Eur J Appl Physiol. 2007;99:283-9. https://doi.org/10.1007/s00421-006-0346-y.

403. Berg HE, Larsson L, Tesch PA. Lower limb skeletal muscle function after 6 wk of bed rest. J Appl Physiol. 1997;82:182-8. https://doi.org/10.1152/jappl.1997.82.1.182

404. de Boer MD, Seynnes OR, Di Prampero PE, Pisot R, Mekjavić IB, Biolo G, Narici MV. Effect of 5 weeks horizontal bed rest on human muscle thickness and architecture of weight bearing and non-weight bearing muscles. Eur J Appl Physiol. 2008;104:401-7. https://doi.org/10.1007/s00421-008-0703-0.

405. Germain P, Gell A, Marini J-F. Muscle strength during bedrest with and without muscle exercise as a countermeasure. Europ J Appl Physiol. 1995; 71:342-8. https://doi.org/10.1007/BF00240415.

406. Kortebein P, Ferrando A, Lombeida J, Wolfe R, Evans WJ. Effect of 10 days of bed rest on skeletal muscle in healthy older adults. JAMA. 2007;297:1772-4. https://doi.org/10.1001/jama.297.16.1772-b.

407. Kortebein P, Symons TB, Ferrando A, Paddon-Jones D, Ronsen O, Protas E, et al. Functional impact of 10 days of bed rest in healthy older adults. J Gerontol Ser A Biol Med Sci. 2008:63:1076-81.

408. Pišot R, Marusic U, Biolo G, Mazzucco S, Lazzer S, Grassi B, et al. Greater loss in muscle mass and function but smaller metabolic alterations in older compared with younger men following 2 wk of bed rest and recovery. J Appl Physiol. 2016:120:922-9. https://doi.org/10.1152/ japplphysiol.00858.2015.

409. Henriksson H, Henriksson P, Tynelius P, Ortega FB. Muscular weakness in adolescence is associated with disability 30 years later: a population-based cohort study of 1.2 million men. Br J Sports Med. 2018. https://doi.org/1 0.1136/bjsports-2017-098723.
410. Coelho HJ, Rodrigues B, de Oliveira Gonçalves I, Uchida MC. Effects of a short-term detraining period on muscle functionality and cognition of strength-trained older women: a preliminary report. J Exerc Rehabil. 2017;13: 559-67. https://doi.org/10.12965/jer.1735010.505.

\section{Publisher's Note}

Springer Nature remains neutral with regard to jurisdictional claims in published maps and institutional affiliations.
Ready to submit your research? Choose BMC and benefit from:

- fast, convenient online submission

- thorough peer review by experienced researchers in your field

- rapid publication on acceptance

- support for research data, including large and complex data types

- gold Open Access which fosters wider collaboration and increased citations

- maximum visibility for your research: over $100 \mathrm{M}$ website views per year

At $\mathrm{BMC}$, research is always in progress.

Learn more biomedcentral.com/submissions 